Version of Record: https://www.sciencedirect.com/science/article/pii/S0165188919301058

Manuscript_89fde8ae55755318314bf10d88c0e385

\title{
Episodes of War and Peace in an Estimated Open Economy Model*
}

\author{
Stéphane Auray ${ }^{\dagger} \quad$ Aurélien Eyquem ${ }^{\ddagger}$
}

June 13, 2019

\begin{abstract}
This paper proposes a straight model-based analysis of historical war episodes. We analyze the effects of world wars on the macroeconomic dynamics in the US, France, Germany, and the UK, by means of an estimated open-economy model where war episodes are modeled as an additional source of observed shocks. The model allows war episodes to affect the economy through lower capital depreciation, partial default on public debt, a military draft, changes in household preferences, and spillovers on other shocks (productivity, investment, trade, policy variables). In the US, the bulk of fluctuations during war episodes can be mainly explained by the rise in government spending, and the war shock plays a minor role. In other countries, the war shock is an essential driver of fluctuations. We also discuss the size and state-dependence of public spending multipliers, and produce a counterfactual exercise to quantify the welfare losses from war episodes.
\end{abstract}

Keywords: Fluctuations, War, Trade, Taxes, Public Debt, Bayesian estimations, Multipliers, Welfare.

JEL Classification: E31, E32, E62, F41, H56, H63.

${ }^{*}$ We thank the Editor and three referees for insightful comments that lead to an improved paper, as well as participants at various seminars and conferences for helpful comments. The authors acknowledge the nancial support of Projets Generique ANR 2015, Grant Number ANR-15-CE33-0001-01.

${ }^{\dagger}$ CREST-Ensai and Université du Littoral Côte d'Opale. ENSAI, Campus de Ker-Lann, Rue Blaise Pascal, BP 37203, 35172 BRUZ Cedex, France. stephane.auray@ensai.fr.

${ }^{\ddagger}$ Univ Lyon, Université Lumière Lyon 2, GATE UMR 5824, F-69130 Ecully, France, and Institut Universitaire de France. aurelien. eyquem@univ-lyon2.fr.

(C) 2019 published by Elsevier. This manuscript is made available under the CC BY NC user license https://creativecommons.org/licenses/by-nc/4.0/ 


\section{Introduction}

How can a dynamic general equilibrium model account for the macroeconomic effects of war episodes like world wars? This paper proposes an approach based on the estimation of a mediumscale model on a large set of historical macroeconomic time series for France, Germany, the UK and the US dating back to the $19^{\text {th }}$ century. The model features usual characteristics of DSGE models, and is augmented with a variety of assumptions that help the model to account for the macroeconomic effects of war episodes. The paper can be thought of as an ambitious extension of papers like McGrattan and Ohanian (2010), or Devereux and Smith (2007), as it makes use of a general equilibrium model to account for historical episodes for various countries. The chief difference between our paper and most papers that study historical episodes is that we estimate our model on a long historical dataset that comprises both World War I (WWI) and World War II (WWII) episodes, the hyperinflation period of the 20's in Germany, the Great Depression of the 30 's, and the post-war recovery.

The model is a significant open-economy extension of the Smets and Wouters (2005) model. It allows for trade in some components of demand (private consumption and investment), and consider incomplete international financial markets, to account for potential wealth transfers induced by war episodes. It also includes a more extensive set of policy instruments: the money growth rate, public spending, public investment, public debt and distorsionary taxes on labor and capital. We consider structural shocks that affect productivity, the efficiency of investment, labor and capital income tax rates, public consumption, the money growth rate, and foreign demand. ${ }^{1}$

War episodes are modeled as an additional source of shocks, that leads some parameters to switch to (estimated) specific values and trigger some (estimated) specific effects on other structural shocks. More precisely, we introduce an (observed) indicator variable $\Delta_{t}$ that takes two values, $\Delta_{t}=1$ during world war episodes, and $\Delta_{t}=0$ otherwise. When $\Delta_{t}=1$, the depreciation rate of capital rises to capture war-related capital destruction, the possibility of a military draft is introduced, a partial default on public debt may occur, and households' preferences towards the public good can be affected. In addition, when $\Delta_{t}=1$, a war-specific effect on exogenous variables such as productivity or foreign demand is considered, which provides an additional degree of flexibility to the model. Those may capture all the features that are not explicitly taken into account by our model, but might affect aggregate productivity, investment, trade, policy instruments during war episodes. ${ }^{2}$ Canova, Ferroni and Matthes (2019) show that allowing for

\footnotetext{
${ }^{1}$ We also introduce a measurement error shock on the measurement equation of GDP growth.

${ }^{2}$ The model does not take explicitly into account all the dimensions along which war episodes affect the economy: rationing, financial markets disruptions, changes in national borders, changes in the monetary standard - from fixed exchange rates before WWI, to suspension during WWI, to resumption afterward, to floating rates before WWII, to capital controls during WWII, Bretton Woods after WWII and its suspension after 1973 -, diseases, population displacement, to name just a few.
} 
time-varying nature of some parameters in DGSEs can affect substantially the decision rules and resulting IRFs, and that time-varying or state-dependent parameters can improve the quality of the fit of estimated models. From a methodological point of view, our approach is not a Markov-Switching Bayesian estimation because the state (the war indicator variable) is perfectly observed, but the idea is to capture some of the non-linearity of the data generating process due to war episodes.

We have four different datasets for France (1898-2006), Germany (1880-2008), UK (1870-2005) and the US (1871-2010). For each country, the dataset features a indicator variable $\Delta_{t}$ for world war episodes and a set of macroeconomic quantities or prices that mixes data mostly from Barro and Ursúa (2017) and from Piketty and Zucman (2014). Models are estimated using Bayesian methods. For each country, we obtain a set of point estimates for parameters and a set of smoothed structural shocks that fit the observed time series. Our main goal is to understand how the model accounts for the dynamics of the economy during war episodes. In particular, we are interested in the estimated relative contribution of war-specific channels compared to other sources of fluctuations. Along with McGrattan and Ohanian (2010), our historical decomposition finds that the contribution of war-specific channels is relatively minor for the US, and that the bulk of fluctuations during war episodes is mostly explained by large positive public spending shocks. For France and Germany, the contribution of shocks on the war indicator variable is much more important relative to other types of shocks. Historical decompositions for the UK are somewhere in between those two situations: shocks on the war indicator variable are important in explaining the investment ratio and net exports, but not so much GDP growth rate or the inflation rate. Hence, the "macroeconomic of war and peace" can not solely rely on government spending shocks and productivity shocks for countries other than the US. Capital destruction, negative productivity and investment spillovers from war episodes, foreign demand dynamics, war-specific tax dynamics all matter substantially, at least for countries like France or Germany.

Based on our estimations, we also investigate the effects of simulated war episodes on the dynamics of the four countries. In the US, we find that war episodes are mostly driven by the positive public spending spillover. Other channels (draft, capital depreciation, default) and other spillovers play only minor roles. To some extent, the dynamics for the UK is similar to that of the US since the government spending spillover plays a key role too. For the UK however, other important features have significant effects: war episodes reduce productivity, hurt investment efficiency, and produce a disruption in external trade, captured by a fall in foreign demand. France and Germany feature different responses. In these countries, our estimations find the public spending spillover to be statistically non-significant but productivity and invest- 
ment spillovers are negative and significant. ${ }^{3}$ As a consequence, a simulated war episode lowers GDP by $40 \%$, and consumption falls more than GDP. Channels like the depreciation rate of capital also matter more than in the US or in the UK. For France, the trade spillover is also negative and very large.

Our main conclusions thus complement Braun and McGrattan (1993) and McGrattan and Ohanian (2010). According to them, a neoclassical model fed with large public spending shocks explains most of the dynamics of the economy during world war episodes in the US or in the UK. ${ }^{4}$ We find similar results for the US and, to some extent, for the UK. However, for France and Germany, the macroeconomic effects of war episodes can not be reduced to the sole massive rise in public spending. We find that productivity, investment or trade spillovers, and the shock on the war indicator variable in general, are important for those countries.

Our paper echoes a series of work suggesting that these are important aspects of macroeconomic dynamics during war episodes. In particular, Auray, Eyquem and Jouneau-Sion (2014) show that capital depreciation shocks à la Ambler and Paquet (1994) crucially contribute to the macroeconomic dynamics induced by major war episodes. ${ }^{5}$ Another part of the literature also highlights the importance of external trade and finance to account for the dynamics of economies during wars. ${ }^{6}$ More generally, war episodes most often induce large disruptions in trade, that contribute to the dynamics of key domestic macroeconomic variables (see Anderton and Carter (2001) or more recently Glick and Taylor (2010)). These channels are potentially captured by our flexible model assumptions. ${ }^{7}$

Using our estimation results, we also investigate the question of state-dependent public spending multipliers. Indeed, many papers use war episodes to identify the effects of discretionary public spending shocks, the "narrative approach". ${ }^{8}$ It is therefore crucial to know whether the resulting multipliers are the same during war episodes and during normal times. We find that the impact and short-term output multipliers are not significantly different in the US and in the Germany. For France and the UK, we find that impact and short-run output spending multipliers are

\footnotetext{
${ }^{3}$ Of course public spending rises in the data in these countries, but the estimations capture this rise by means of positive innovations to public spending rather than by estimating a positive spillover from war episodes. This may come from large differences in the spending patterns during WWI and WWII, or from differences in the timing of spending increases.

${ }^{4}$ An additional contribution is Ohanian (1997), who shows the great importance of financing schemes in the effects of war episodes on output and welfare.

${ }^{5}$ See also Furlanetto and Seneca (2014) regarding the importance of capital depreciation shocks over the business cycle in normal times.

${ }^{6}$ For example, Devereux and Smith (2007) analyze the 1871 Franco-Prussian war indemnity through the lens of the transfer problem, invoking the 1929 Keynes-Ohlin controversy.

${ }^{7}$ Focusing on a different issue, Martin, Mayer and Thoenig (2008) identify the impact of international trade on the occurrence of conflicts. To sum up, data show that the sign and the magnitude of the relationship between trade openness and armed conflicts depend on the specific characteristics of trade flows and agreements but that major conflicts reduce international trade flows.

${ }^{8}$ See Ramey and Shapiro (1997), Ramey (2011b), Ramey (2011a), and more recently Ben Zeev and Pappa (2015) and Ramey (2019).
} 
significantly larger during war episodes than during normal times, but that long-run multipliers tend to converge. Our results point to the possibility that output spending multipliers differ during war episodes, at least for some countries. Finally, we also quantify the welfare losses from war episodes and contrast those to the welfare losses from fluctuations. Unsurprisingly, we find that war episodes generate large welfare losses relative to other shocks, especially for Germany and France.

The paper is organized as follows. Section 2 describes and justifies our original model assumptions. Section 3 presents our datasets. Section 4 presents the estimation strategy. Section 5 reports our estimates for the US, discusses the resulting historical decomposition and analyzes the state-dependence of public spending multipliers. Section 6 compares our results for the UK, France and Germany to those derived for the US. Section 7 presents an analysis of the welfare losses from business cycles, as well as a quantification of the specific welfare losses generated by war episodes. Section 8 concludes.

\section{Datasets}

We have four separate datasets respectively for France (1898-2006), Germany (1880-2008), UK (1870-2005) and the US (1871-2010). For each country, a first time series is an indicator variable for war periods $\Delta_{t}$ that takes two values: $\Delta_{t}=1$ during world war episodes, and $\Delta_{t}=0$ otherwise. In the model, this variable will be treated as an exogenous shock.

In addition to the war indicator variable, for each country, the dataset includes GDP and consumption per capita in $2006 \$$, investment as a percentage of GDP $\left(i_{t} / y_{t}\right)$, total consumption expenditure (public and private) as a percentage of GDP $\left(\left(c_{t}+g_{t}\right) / y_{t}\right)$, net exports as a percentage of GDP $\left(n x_{t} / y_{t}\right)$, the public debt-to-GDP ratio $\left(b_{t}^{r} / y_{t}\right)$, total tax receipts as a percentage of GDP and the PPI or CPI inflation rate $\left(\pi_{d, t}\right.$ or $\left.\pi_{t}\right)$. GDP and consumption per capita are taken from the dataset of Barro and Ursúa (2017). Other variables are taken mostly from Piketty and Zucman (2014). For the US, total tax receipts are taken from Mitchell (1998) before 1947 and the FRED database after 1947. For Germany, total tax receipts are taken from Flandreau and Zumer (2004) before 1913 and from Piketty and Zucman (2014) from 1950 onwards. The inflation rate is based on the CPI for France and Germany, and on the GDP deflator for the UK and the US, a distinction that our open-economy model handles easily. ${ }^{9}$

Our datasets are made stationary in the following way. Some variables are considered in growth rates and demeaned. We thus consider the demeaned log-difference of GDP $\left(d y_{t}^{o b s}=\Delta \log \left(y_{t}\right)-\right.$ $\left.\overline{\Delta \log \left(y_{t}\right)}\right)$, consumption $\left(d c_{t}^{o b s}=\Delta \log \left(c_{t}\right)-\overline{\Delta \log \left(c_{t}\right)}\right)$ and inflation $\left(\pi_{t}^{o b s}=\Delta \log \left(p_{t}\right)-\overline{\Delta \log \left(p_{t}\right)}\right.$ for France and Germany, and $\pi_{t}^{o b s}=\Delta \log \left(p_{d, t}\right)-\overline{\Delta \log \left(p_{d, t}\right)}$ for the US and the UK). We take

\footnotetext{
${ }^{9}$ Over the whole sample, it was not possible to obtain a GDP deflator for the four countries.
} 
public debt stocks and tax receipts in levels combining the ratios with the levels of GDP, and take the demeaned log-differences $\left(d b_{t}^{o b s}=\Delta \log \left(b_{t}^{r}\right)-\overline{\Delta \log \left(b_{t}^{r}\right)}\right.$ and $\left.d t_{t}^{o b s}=\Delta \log \left(T_{t}\right)-\overline{\Delta \log \left(T_{t}\right)}\right)$.

Other variables, total consumption expenditure $\left(c g y_{t}^{o b s}\right)$, net exports $\left(n x y_{t}^{o b s}\right)$ or investment $\left(i y_{t}^{o b s}\right)$ are expressed relative to GDP. Over the whole sample, those variables display trends, mostly because the share of public spending in GDP has risen substantially over time, lowering the share of private investment and consumption in GDP. We make these ratios stationary by removing a linear-quadratic trend. Whenever our datasets have missing points, they are handled as follows. ${ }^{10}$ Series are first interpolated with a spline before being transformed (taken in log-difference or having their trend removed). Then the interpolated missing observations are removed, to be properly handled as missing observations by the estimation algorithm (see Section 4). Appendix A reports the time series used to estimate the model.

For France and the UK, the reported time series show that war episodes significantly depressed the economy: the GDP growth rate and the consumption growth rate fell to historical lows, consumption growth fell as much as or more than the GDP growth, inflation was very high, the investment-to-GDP ratios reached historically low levels, the total consumption expenditure to GDP ratios were the highest in history, because public expenditure exploded. Net exports dropped dramatically and public debt jumped to very high levels. For these two countries, war periods represent the largest swing in the reported time series, by far.

During WWI, France and the UK went to war simultaneously in the summer of 1914. France and the UK faced Germany on the front in eastern France and in the seas, in northern France and in the North Sea. The UK decided to impose a maritime economic blockade on Germany. From 1915 to 1917 , the conflict was mostly a "Position war", where belligerents were completely immobile for months. In July 1918 occurred the major "Second Marne Battle", that saw the Allies and France in particular inflict great losses to Germany, thereby ending the war in November 1918. This quick summary suggests that France and the UK had relatively similar war experiences during WWI.

As for WWII, it was officially declared when Germany invaded Poland in 1939, an ally of France and the UK. However, they did not react during the first months. In May and June 1940, France was invaded by Germany, but the UK fought Germany in the air and seas. From September 1940 to May 1941, the UK suffered many bombings, leading to large destruction in London and Coventry. Germany and the UK also fought in the Mediterranean Sea, mobilizing a lot of UK military resources. After the US entered the war in 1942, they supplied the UK with military and civilian equipments and current consumption goods. The Allies finally broke the Atlantic

\footnotetext{
${ }^{10}$ For Germany, investment and consumption expenditure to GDP have missing points from 1914 to 1924 , and from 1939 to 1949. Net exports to GDP have missing points from 1919 to 1924 and from 1939 to 1949 . Inflation data in 1922 and 1923 are considered missing. Total tax receipts are missing from 1914 to 1949. For the US, tax receipts are missing from 1918 to 1924.
} 
Wall in June 1944, during the Normandie Landings, and freed France (among others). France and the UK therefore had quite different involvements in WWII, France was at war only for a few months, lost almost the entirety of its military equipments to Germany, and was occupied until late 1944. The UK was at war almost continuously from 1939 to 1945, and obtained substantial help from the Allies (the US in particular) starting in 1942.

The dataset for Germany shares some of the features highlighted for France and the UK. During world war episodes, GDP and consumption growth fell substantially, net exports were highly depressed (during WWI). Due to the abundance of missing data points, the picture remains difficult to square completely with the narratives for France and the UK. In addition, the postWWI reparation payments and the associated subsequent hyperinflation episode in the early 20 's is an additional major swing in the time series of Germany, in particular when looking at skyrocketing inflation and plunging public debt growth. Further, the Great Depression of the early 30's also plays a major role in the observed macroeconomic time series: this episode witnessed the lowest investment-to-GDP ratio and the highest total consumption to GDP ratio in the history of Germany, although it must be noted that data points are missing during war episodes for both variables.

During WWI, Germany had to fight the Soviet Union, France and the UK. They suffered an economic blockade after the UK controlled the North Sea, and eventually lost WWI. Historians believe that WWII is widely rooted in the severity of the Versailles Treaty that resulted from WWI, and in the 1929 crisis that led many countries to apply protectionist measures and, for Germany in particular, rearmament policies to restore economic growth. ${ }^{11}$ During WWII, Germany invaded many countries and seized a large quantity of military and civilian resources. However, given that Germany was on three fronts simultaneously, the economy had a hard time producing enough. In addition, the building of the Atlantic Wall was expensive in terms of labor and construction material. Late 1944 and 1945, Germany was severely destroyed by bombings, and invaded by the Soviet Union and Allied Forces. The amount of destruction (housing, facilities, infrastructure) undergone in 1945 was massive, as suggested by the large observed fall in GDP growth. During both world wars, Germany was fighting all along, on home and foreign soils, experienced and inflicted great amounts of human casualties and material destruction.

The dataset for the US shows a different pattern, as war episodes depressed consumption growth but saw a rise in GDP growth. The investment ratio fell during world wars while the total expenditure ratio rose. However, historical lows/highs for these variables are reached during the Great Depression of the 30's. Similarly, the lowest GDP and consumption growth rates are observed during the Great Depression. The pattern of net exports is also quite different: net exports went up dramatically during WWI and after 1942 during WWII. Public debt growth

\footnotetext{
${ }^{11}$ To a certain extent, the involvement of Germany in the 1936 Spanish Civil War, the Anschluss and the Sudeten conflict in 1938 all suggest that Germany was already at war prior 1939.
} 
jumped quite significantly during both world wars, in line with the fact that public expenditure rose to historical highs during both war episodes. Notice also that inflation rose to high levels during war episodes, especially during WWI. One of the reasons the US had different economic dynamics during world wars is most certainly due to the late involvement in both world wars, and the relative preservation of the US soil with respect to combats and destruction.

Indeed, the US remained neutral for a long time before entering WWI in June 1917. They offered a massive support in terms of military divisions (representing up to $31 \%$ of Allied human forces), as well as marine forces. Their support was key to win the war, and in particular the Battle of the Atlantic, during which Germany tried to destroy commercial ships headed to the UK, as a retaliation against the economic blockade. The US also entered WWII quite late, in 1942, and initially focused their military resources on the Pacific front. Later in 1942 and in 1943, the US started supplying the UK in goods and equipments, and ended-up engaging great amounts of resources until 1945 to help win the war. Overall, the US experienced little destruction on US soil during both wars, but consumed a lot of resources in terms of military equipments, and providing numerous armed forces through massive military drafts.

\section{The model}

We consider a small open economy model with a government in charge of fiscal and monetary policy. The model is based on a standard DSGE such as Smets and Wouters (2003) with sticky prices and wages, but is extended along many dimensions. First, it considers an open economy with trade in consumption and investment goods, home bias, and an incomplete international financial market. These assumptions are introduced to account for trade balance dynamics and potential wealth transfers. Second, it introduces money in the utility function and monetary policy is not conducted through a Taylor-type rule, but is affected by exogenous money growth rate shocks. In addition, seigniorage revenues are transferred to the government. ${ }^{12}$ Both assumptions are consistent with a non-trivial role for monetary policy and for a potential financing of public spending through seigniorage revenues, a feature that is likely to happen during or after war episodes. Third, the government levies distortionary taxes on labor and capital income. Both tax rates are assumed to follow exogenous processes reflecting discretionary decisions made by the government. The government spends on domestic consumption goods, invests in domestic public capital goods, issues government bonds, levies taxes and has access to seigniorage revenues by issuing money. These features allow us to consider a set of shocks that is quite different from

\footnotetext{
${ }^{12}$ Several contributions, starting with Friedman and Schwartz (1963), highlight the consistency of exogenous money growth rules with monetary facts (see also Monnet and Weber (2001)). Further, observational equivalence under a variety of assumptions has been extensively proven in the literature on monetary policy. Finally, a substantial amount of Central Banks' actions in the early $20^{\text {th }}$ century can be understood by examining their international role in defending the Gold Standard (see Fishback (2010)). This is particularly the case for the Fed during the 30's, and motivates our modeling of monetary policy decisions as exogenous innovations to the money growth rate.
} 
those considered by Smets and Wouters (2003), as we consider tax shocks and leave preference or mark-up shocks aside. Finally, we introduce an indicator variable that is $\Delta_{t}=1$ during war episodes and $\Delta_{t}=0$ otherwise. When $\Delta_{t}=1$, the depreciation rate of public and private capital stocks is larger, the possibility of a military draft is opened, a partial default on public debt can arise, and the elasticity of substitution between public and private goods in households' preferences can take a different value. The next paragraphs discuss the key departures from usual open-economy DSGE models while the details of the model are given in Appendix B.

We consider a unit continuum of households indexed in $j$ that maximize their lifetime welfare

$$
\mathcal{W}_{t}=E_{t}\left\{\sum_{s=t}^{\infty} \beta^{s-t}\left(\frac{\widetilde{c}_{s}(j)^{1-\sigma_{c}}}{1-\sigma_{c}}+\chi_{m} \frac{\left(m_{s}(j) / p_{s}\right)^{1-\sigma_{m}}}{1-\sigma_{m}}-\chi_{n} \frac{n_{s}(j)^{1+\psi}}{1+\psi}\right)\right\}
$$

In the welfare index, total consumption $\widetilde{c}_{s}(j)$ is a bundle of individual consumption of the private good $c_{t}(j)$ and the total consumption of public good $g_{t}$

$$
\widetilde{c}_{t}(j)=\left(\varphi c_{t}(j)^{\frac{\nu_{t}-1}{\nu_{t}}}+(1-\varphi) g_{t}^{\frac{\nu_{t}-1}{\nu_{t}}}\right)^{\frac{\nu_{t}-1}{\nu_{t}}}, \nu_{t}>0
$$

When $\nu_{t}>1$, private and public goods are substitutes while $\nu_{t}<1$ implies complementarity. ${ }^{13}$ We introduce the possibility that this parameter takes different values whether countries experience a war episode or not, that is

$$
\nu_{t}=\left(1-\Delta_{t}\right) \nu_{n o r m}+\Delta_{t} \nu_{w a r}
$$

where $\Delta_{t}=\{0,1\}$ is an indicator variable that equals one during war episodes and zero in normal times. Endogenous labor supply and money in the utility function are introduced to account respectively for labor market and money market dynamics over the business cycle in normal times and during war episodes.

The budget constraint of agent $j$ is relatively standard. She has access to four assets: money, private capital, public debt and foreign assets. The originality of our model is to allow for a war-specific partial default on public debt, and for a war-specific depreciation rate of private and public capital. Formally, these war-specific features are triggered by the war indicator variable $\Delta_{t}$. The first assumption intends to capture the potential malfunctioning of public bond markets during war episodes, or some kind of fiscal repression. According to the second one, capital depreciation is higher during war episodes:

$$
\delta_{t}=\delta\left(1+\Delta_{t} p^{\delta}\right), p^{\delta}>0
$$

\footnotetext{
${ }^{13}$ See Bouakez and Rebei (2007) and references therein for a discussion of the empirical relevance of this assumption.
} 
As in Auray et al. (2014), this specification captures some of the capital destruction through higher capital depreciation, where $p^{\delta}$ governs the size of war-related destruction. Notice that the time-varying depreciation rate of capital applies to both private and public capital.

In addition, capital accumulation is subject to investment adjustment costs and to investment shocks $\zeta_{t}$. These shocks evolve according to an autoregressive process, augmented with a specific effect during war episodes. As in Justiniano, Primiceri and Tambalotti (2011), they may capture all the potential sources of frictions that affect the transformation of savings into future capital input.

$$
\zeta_{t}=\left(1-\rho_{\zeta}\right)+\rho_{\zeta} \zeta_{t-1}+\phi_{\zeta} \Delta_{t}+\varepsilon_{t}^{\zeta}
$$

The idea of the war-specific spillover $\phi_{\zeta}$ is to account for the potential extra kick in private capital accumulation that war episodes might generate through expropriation, changes in the purpose of production facilities, disruption in aggregate private demand, banking or financial frictions, or rising uncertainty in general.

The derivation of the first-order conditions is standard and thus reported in Appendix B. It is useful however to point that we allow for trade in consumption and capital goods, as those goods are made of domestic $(d)$ and foreign $(f)$ goods. The bundle has a CES specification allowing for home bias and a non-unitary elasticity of substitution. Further, our open-economy framework allows for incomplete international asset markets, to account for potential wealth transfers that might occur during war episodes, or even during normal times.

There is a continuum of final good producers indexed in $\omega$, with the following production function

$$
y_{t}(\omega)=a_{t} k_{t}^{s}(\omega)^{\iota}\left(\left(1-\Delta_{t} p^{\ell}\right) \ell_{t}(\omega)\right)^{1-\iota}, p^{\ell}>0
$$

where $k_{t}^{s}$ is a measure of capital services used in production - we allow for a variable utilization rate in the optimization program of households - and $\left(1-\Delta_{t} p^{\ell}\right) \ell_{t}$ is the amount of labor that firms use to produce. Total labor $\ell_{t}$ is affected by a potential military draft that lowers the amount of labor used by private firms during war episodes by $p^{\ell}$. Finally, $a_{t}$ is a productivity measure following an autoregressive process. Again, we introduce the possibility that war episodes have extra effects on productivity through channels that are not explicitly specified in the model through a war spillover $\phi_{a}$ :

$$
a_{t}=\left(1-\rho_{a}\right)+\rho_{a} a_{t-1}+\phi_{a} \Delta_{t}+\varepsilon_{t}^{a}
$$

Those factors might relate to shift in the type of products that firms produce (from regular industrial goods to weapons or military equipments), capital and labor reallocation among firms, changes in the composition of the labor force, congestion in transport/public infrastructure, bad communication between headquarters and other establishments of the same firm, among other 
things.

The government is in charge of both monetary policy, public spending and fiscal policy. Its budget constraint is

$$
b_{t}+m_{t}+T_{t}=r_{t-1}\left(1-\Delta_{t} p^{b}\right) b_{t-1}+m_{t-1}+\Delta_{t} p^{\ell} w_{t} \ell_{t}+p_{d, t}\left(g_{t}+i_{t}^{g}\right)
$$

where

$$
T_{t}=\tau_{t}^{n} w_{t} n_{t}+\tau_{t}^{k}\left(r_{t}^{k} z_{t}-p_{t} \delta_{t}\right) k_{t-1}+\operatorname{tax}_{t}
$$

stands for total tax receipts. The left-hand side of Equation (8) shows government revenues and the right-hand side features government expenditure. In particular, the government has to pay drafted people. ${ }^{14}$ Following Leeper (1991), we model fiscal policy as a set of feedback rules for taxes and government spending, which ensures that the intertemporal government budget constraint holds and that the equilibrium is determinate. These rules imply that policy instruments react to the lagged deviations of real public debt $b r_{t}$ to its steady-state value. In addition, we consider war-specific spillovers on taxes and spending through $\phi_{g}, \phi_{\tau^{n}}$ and $\phi_{\tau^{k}}$. Those are intended to capture war-specific decisions made by governments in terms of public spending, tax policies, and more broadly war-specific government financing schemes. Further, policy instruments are also affected by autoregressive exogenous shocks:

$$
\begin{aligned}
g_{t} & =g+d_{\tau_{n}}\left(b r_{t-1}-b r\right)+\phi_{g} \Delta_{t}+s_{t}^{g} \\
\tau_{t}^{n} & =\tau^{n}+d_{\tau^{n}}\left(b r_{t-1}-b r\right)+\phi_{\tau^{n}} \Delta_{t}+s_{t}^{\tau^{n}} \\
\tau_{t}^{k} & =\tau^{k}+d_{\tau^{k}}\left(b r_{t-1}-b r\right)+\phi_{\tau^{k}} \Delta_{t}+s_{t}^{\tau^{k}}
\end{aligned}
$$

where

$$
\begin{aligned}
s_{t}^{g} & =\rho_{g} s_{t-1}^{g}+\varepsilon_{t}^{g} \\
s_{t}^{\tau_{n}} & =\rho_{\tau_{n}} s_{t-1}^{\tau_{n}}+\varepsilon_{t}^{\tau_{n}} \\
s_{t}^{\tau_{k}} & =\rho_{\tau_{k}} s_{t-1}^{\tau_{k}}+\varepsilon_{t}^{\tau_{k}}
\end{aligned}
$$

We consider that money supply grows at a rate $\mu_{t}^{m}=m_{t} / m_{t-1}$ that also follows an autoregressive process augmented with a war-specific spillover $\phi_{\mu}$ :

$$
\mu_{t}^{m}=\left(1-\rho_{m}\right)+\rho_{m} \mu_{t-1}^{m}+\phi_{\mu} \Delta_{t}+\varepsilon_{t}^{m}
$$

The latter is introduced to account for potential war-specific seigniorage to monetize public debt.

Further, as in Auray et al. (2014), the government adjusts the amount of public investment to

\footnotetext{
${ }^{14}$ Here we follow the assumption made by Siu (2008) in its baseline model according to which wages paid to the military equal market wages.
} 
secure a given and constant level of public capital $k^{g}$ :

$$
i_{t}^{g}=\delta_{t} k^{g}
$$

which will trigger a rise in public investment during war episodes, capturing the need to rebuild destroyed military equipment, facilities, buildings, or public infrastructure (roads, bridges, etc...).

A final source of fluctuations in the model is foreign demand. The latter enters the goods market clearing condition and raises or lowers the demand for domestic goods that are exported to the rest of the world (See Equation (B.40) in Appendix B). Foreign demand is considered exogenous to the economic conditions of domestic economy, and is affected by an autoregressive shock, augmented with a war-specific component. The latter intends to capture the potential disruptions in trade and/or wealth transfers the war episode might produce through global demand slowdown, a restriction of the use of transportation infrastructure for the purpose of private trade, among other things. The war spillover could as well boost trade, for instance if the country is invaded and the occupant massively shifts local resources to its own country, or if the occupied country produces goods or equipment for the occupant.

Overall, the model features the following structural shocks: the productivity shock $\varepsilon_{t}^{a}$, the investment shock $\varepsilon_{t}^{\zeta}$, the foreign demand shock $\varepsilon_{t}^{y_{*}}$, the tax shocks $\varepsilon_{t}^{\tau_{n}}$ and $\varepsilon_{t}^{\tau_{k}}$, the public spending shock $\varepsilon_{t}^{g}$, the money growth shock $\varepsilon_{t}^{\mu}$ and the shock on the war indicator variable $\Delta_{t}$. The latter is particular in that it introduces a war-specific regime in which capital depreciates more quickly by $p^{\delta}$, public debt is partly defaulted on by a fraction $\left(1-p^{b}\right)$, a fraction $p^{\ell}$ of the labor force is being drafted, and the degree of substitutability between the private good and the public good $\nu_{t}$ in the utility of households is affected. Finally, the shock on the war indicator variable potentially triggers spillovers on all the other driving forces of the model.

We believe that the introduction of the war indicator variable is able to capture some of the disruptions in economic activity that occur during war episodes: destruction of human lives, private and public facilities and military equipment, changes in consumption dynamics through public restrictions on consumption goods, higher public spending in consumption or capital goods, lower aggregate productivity, brutal changes in tax rates or tax receipts, seigniorage, partial default, large trade/global demand disruptions, wealth transfers through expropriation and spoliation of national goods when a country is invaded, etc... In addition, note that the effects of war episodes, triggered by a shock on $\Delta_{t}$, on other shocks through spillover terms can be persistent, thereby affecting the dynamics of exogenous variables long after war episodes are over.

Nevertheless, the war indicator variable and the spillover terms do not necessarily accurately account for all the effects of world war episodes, and other shocks might be important. For 
instance, if seigniorage was used after WWII but not after WWI in a given country, the spillover coefficient might not be significantly different from zero in the estimation, and the innovations on money growth will play a major role. As such, the war indicator variable can not integrally account for the economic dynamics during war periods. All shocks, including the war indicator variable, might be of importance. We argue however that our shocks and model assumptions are flexible ways of taking into account the complex dynamics and interactions that may arise during war episodes as well as during normal times. Our approach here can therefore be brought in relation with the proposal of Chari, Kehoe and McGrattan (2007), who argue that models can be used to uncover the dynamics of wedges: exogenous shocks may capture some of the dynamics from the data that are not modeled explicitly.

\section{Estimation}

We estimate our model using Bayesian methods, adopting the standard approach of An and Schorfheide (2007). This implies obtaining the posterior distribution of our estimated parameters based on the linear approximation of the model's solution around the steady state using the Kalman filter. A major advantage of the approach is that it allows for the extraction of the dynamics of shocks, as well as the historical paths of endogenous variables. We will therefore have a complete quantitative evaluation of the model with respect to the data. In the model section, we introduced an indicator variable $\Delta_{t}$ for war episodes. This variable is treated as an exogenous shock, and the war indicator variable is included in the set of observed variables. More precisely, for each country, let $\Delta_{t}^{o b s}$ denote an indicator variable that is $\Delta_{t}^{o b s}=1$ during war episodes and $\Delta_{t}^{o b s}=0$ otherwise, and impose $\Delta_{t}=\Delta_{t}^{o b s}$ as one of the measurement equations.

Steady state. We analyze the linearized dynamics of the model around a symmetric steady-state without inflation, implying zero net foreign assets. ${ }^{15}$ We consider that the steady state of the economy corresponds to normal times, and we thus impose $\Delta=0$. Our goal is to identify the sources of macroeconomic fluctuations with a specific interest in war episodes, focusing on France, Germany, the UK and the US. The model is flexible enough to allow for cross-country differences and remains relatively agnostic on the behavior of the government. Aside from the fiscal rules, policy instruments are allowed to feature a war-specific reaction, with no sign restrictions imposed on those spillovers from war episodes when estimating them. ${ }^{16}$

Data vs. model mapping. For each country, a version of the model is estimated using the countryspecific dataset described in Section 2. Given that measurement error in the data is very likely, we add a measurement error shock on the GDP measurement equation, that is specified as an

\footnotetext{
${ }^{15}$ Details about the steady state are given in Appendix B.

${ }^{16}$ More precisely the prior distributions considered for spillovers are Normals with a prior mean of zero, allowing the algorithm to visit positive and negative values when computing the mode and running $\mathrm{MH}$ replications.
} 
autoregressive process with zero mean and iid innovations:

$$
\begin{aligned}
d y^{o b s_{t}} & =\log \left(y_{t}\right)-\log \left(y_{t-1}\right)+y_{t}^{e r r} \\
y_{t}^{e r r} & =\rho_{e r r} y_{t-1}^{e r r}+\varepsilon_{t}^{e r r}
\end{aligned}
$$

where $d y^{o b s_{t}}$ is the observed GDP growth rate and $y_{t}$ is the model-based measure of GDP. Overall, including the measurement error shock, the model features 9 shocks. To avoid stochastic singularity, an estimation of the model requires at least 9 time series. For each country, the dataset includes 8 macroeconomic time series (see Section 2) and the observed war indicator variable, providing a total of 9 observed variables. Let $\Theta^{s}$ denote the vector of structural parameters to be estimated, $\Theta^{c}$ the vector of calibrated parameters, and $X_{t}$ a vector of endogenous variables. The state-space form of the model writes

$$
X_{t}=A\left(\Theta^{s}, \Theta^{c}\right) X_{t-1}+B\left(\Theta^{s}, \Theta^{c}\right) \varepsilon_{t}, \text { where } \varepsilon_{t} \sim N(0, \Sigma)
$$

where

$$
\varepsilon_{t}=\left[\varepsilon_{t}^{a}, \varepsilon_{t}^{\zeta}, \varepsilon_{t}^{g}, \varepsilon_{t}^{\tau^{n}}, \varepsilon_{t}^{\tau^{k}}, \varepsilon_{t}^{\mu}, \varepsilon_{t}^{y^{*}}, \Delta_{t}, \varepsilon_{t}^{e r r}\right]
$$

is the vector of innovations to the 7 structural shocks, the war indicator variable and the measurement error shock. The measurement equation is given by ${ }^{17}$

$$
M_{t}=C\left(\Theta^{s}, \Theta^{c}\right)+D\left(\Theta^{s}, \Theta^{c}\right) X_{t}
$$

where

$$
M_{T}=\left\{d y_{t}^{o b s}, d c_{t}^{o b s}, \pi_{t}^{o b s}, d b_{t}^{o b s}, d t_{t}^{o b s}, c g y_{t}^{o b s}, n x y_{t}^{o b s}, i y_{t}^{o b s}, \Delta_{t}^{o b s}\right\}_{t=1}^{T}
$$

is the vector of observed variables. The estimation procedure consists in finding the posterior distribution $\mathcal{P}\left(\Theta^{s} \mid M_{T}\right)$ of the parameters conditional on the data sample $M_{T}$ exploiting the DSGE model likelihood function $\mathcal{L}\left(M_{T} \mid \Theta^{s}\right)$ and the prior distribution of parameters $\mathcal{P}\left(\Theta^{s}\right)$

$$
\mathcal{P}\left(\Theta^{s} \mid M_{T}\right) \propto \mathcal{L}\left(M_{T} \mid \Theta^{s}\right) \mathcal{P}\left(\Theta^{s}\right)
$$

The likelihood function $\mathcal{L}\left(M_{T} \mid \Theta^{s}\right)$ is computed using the Kalman filter using

$$
\mathcal{L}\left(M_{T} \mid \Theta^{s}\right)=\prod_{t=1}^{T} \mathcal{L}\left(M_{t} \mid M_{t-1}, \Theta^{s}\right)
$$

where $M_{t}$ is the set of observed variables at time $t$ and $M_{t-1}$ stands for the information set from period 1 to $t-1$.

\footnotetext{
${ }^{17}$ The set of estimated equations, including the measurement equations, is given at the end of Appendix B.
} 
We use the Dynare built-in estimation routine. The latter copes with missing observations treating them as unobserved states and using the Kalman filter to infer their values during estimation. Our goal is to use the estimated model to fill in the gaps in time series rather than using the interpolated data, because we believe that our model does a better job in filling these gaps than simple splines. This is important since missing data, especially for Germany, mostly pertain to periods of war episodes.

Calibrated parameters. Before estimating the model, we fix the values of some of the parameters, either to preserve the model's steady state or because of weak identification from the data. ${ }^{18}$ The vector of calibrated parameters that are common to all countries is:

$$
\Theta^{c 1}=\left[\beta, \psi, \sigma_{c}, \sigma_{m}, \delta, \phi_{z}, \iota, \alpha, \phi_{f}, \chi_{m}, \chi_{n}, \theta^{w}\right]
$$

The time unit is the year. The steady-state discount factor is $\beta=0.96$, producing an average $4.17 \%$ real interest rate. The risk-aversion parameters on (total) consumption and real money balances are respectively $\sigma_{c}=1.5$ and $\sigma_{m}=1.5$. The steady-state capital depreciation rate is $\delta=10 \%$, the adjustment cost on utilization is $\phi_{z}=0.15$ and the capital share is $\iota=0.36$. The import share is $\alpha=0.15$ and the adjustment cost on foreign assets is $\phi_{f}=0.025$, as in Ghironi and Melitz (2005). The value of the labor disutility parameter $\chi_{n}$ is adjusted to normalize hours of work to one, which makes our choice for the calibrated value of the wage mark-up $\left(1 /\left(\theta^{w}-1\right)=20 \%\right)$ basically inessential (see Appendix B for details). The Frisch labor supply elasticity $1 / \psi$ is calibrated to $2 / 3$, a rather consensual value. Finally, the real balances utility parameter is set to $\chi_{m}=0.05$, to produce steady-state real balances to GDP between 0.2 and 0.25 , in accordance with (unreported) evidence from our dataset. Those parameters remain fixed across countries and their values are summarized in Table 1 below.

Table 1: Calibrated common parameter values $\left(\Theta^{c 1}\right)$

\begin{tabular}{lr}
\hline \hline Discount factor & $\beta=0.96$ \\
Frisch elasticity on labor supply & $1 / \psi=2 / 3$ \\
Risk-aversion (consumption) & $\sigma_{c}=1.5$ \\
Risk-aversion (real money balances) & $\sigma_{m}=1.5$ \\
Capital depreciation & $\delta=0.10$ \\
Utilization adjustment cost & $\phi_{z}=0.15$ \\
Capital share & $\iota=0.36$ \\
Import share & $\alpha=0.15$ \\
Adjustment cost on foreign assets & $\phi_{f}=0.0025$ \\
Real money utility parameter & $\chi_{m}=0.05$ \\
Wage mark-up & $1 /\left(\theta^{w}-1\right)=0.2$ \\
Labor disutility parameter & $\chi_{n}$ adjusted to get $n=1$ \\
\hline \hline
\end{tabular}

Country-specific calibrated parameters. Remaining calibrated parameters are country-specific, to

\footnotetext{
${ }^{18}$ We did run some pre-sample identification tests before estimation and those revealed that parameters such as the inverse of the Frisch elasticity were potentially weakly identified.
} 
account for the observed differences in the tax systems, the levels of public consumption to GDP $(\kappa)$ or public debt to GDP. The vector of country-specific calibrated parameters is

$$
\Theta^{c 2}=\left[\kappa, \kappa^{i}, \tau^{n}, \tau^{k}, \theta^{p}\right]
$$

Our calibrated values are consistent with the raw datasets, that contain useful information about key ratios. We also use some of Piketty and Zucman's data that are not used to estimate the model, such as the average capital or labor income tax rates when those are available. Using average values of tax rates in France, we set the steady-state tax rates to $\tau^{n}=0.3$ and $\tau^{k}=0.22$. The average government investment rate, taken from French data is $\kappa^{i}=0.0253$. We adjust public consumption to GDP $\kappa=0.1346$ to match exactly the average level of debt to GDP $(75 \%)$ over the sample. Last, we set $\theta^{p}=6$ to match average net profits $(20 \%)$. In the absence of empirical evidence for profits in Germany, we set $\theta^{p}=6$. Data for Germany suggest $\kappa^{i}=0.0164$ and $\kappa=0.1490$. The average level of capital income taxation is $\tau^{k}=0.2$. We adjust $\tau^{n}=0.2926$ to match the average level of debt to GDP $(45 \%)$ over the sample. Concerning the UK, (unreported) evidence suggest an average profit rate of $25 \%$, implying $\theta^{p}=5$, and the average government investment-to-GDP ratio is $\kappa^{i}=0.0263$. We assume $\tau^{k}=0.2$ and $\tau^{n}=0.3$, and adjust $\kappa=0.1138$ to hit the $97 \%$ average debt-to-GDP ratio featured in the raw dataset. Finally, for the US, based on the raw dataset, we set $\kappa^{i}=0.0190$, impose $\kappa=0.10$ with $\tau^{k}=0.35$ and adjust $\tau^{n}=0.1678$ to hit the average debt-to-GDP ratio featured in the raw dataset (55\%). Those parameter values are summarized in Table 2 below.

Table 2: Calibrated country-specific parameter values $\left(\Theta^{c 2}\right)$

\begin{tabular}{lcccc}
\hline \hline & France & Germany & UK & US \\
Share of public investment in GDP $\left(\kappa^{i}\right)$ & 0.0253 & 0.0164 & 0.0263 & 0.0190 \\
Share of public consumption in GDP $(\kappa)$ & 0.1346 & 0.1490 & 0.1138 & 0.1000 \\
Labor income tax rate $\left(\tau^{n}\right)$ & 0.3000 & 0.2926 & 0.3000 & 0.1678 \\
Capital income tax rate $\left(\tau^{k}\right)$ & 0.2200 & 0.2000 & 0.2000 & 0.3500 \\
Steady-state price mark-up $\left(1 /\left(\theta^{p}-1\right)\right)$ & 0.2000 & 0.2000 & 0.2500 & 0.2000 \\
\hline \hline
\end{tabular}

Estimated parameters. Remaining parameters of the model are estimated. Our prior distributions are as follows. The Calvo parameters on prices $\eta^{p}$ and on wages $\eta^{w}$ are Betas, with prior means 0.25 and standard deviations 0.1 . The Edgeworth complementarity parameters $\left(\nu_{\text {norm }}, \nu_{\text {war }}\right)$ are estimated separately but with the same priors. They are Inverse Gammas with prior means 0.5 and standard deviations 0.25 . The war-specific partial default parameter $p^{b}$, the war-specific draft parameter $p^{\ell}$ and the increase in the depreciation rate of capital induced by war episodes $p^{\delta}$ are all assumed to be Betas with prior means 0.1 and standard deviations 0.05. Following Smets and Wouters (2003), the investment adjustment cost parameter $\phi_{i}$ is a Normal with prior mean 5 and standard deviation 0.5. As in the standard international RBC literature (see Backus, Kehoe and Kydland (1993) or more recently Auray, Eyquem and Gomme (2016)), the trade elasticity is a Normal with prior mean 1.5 and a 0.25 standard deviation. Parameters of the government 
spending and tax rules $\left(d_{g}, d_{\tau_{n}}, d_{\tau_{k}}\right)$ have positive supports to avoid indeterminacy as much as possible. We assume they are Inverse Gammas with prior means 0.25 with a 0.25 standard deviation. We are completely agnostic about the sign of war spillovers on exogenous processes, and assume that $\left(\phi_{a}, \phi_{g}, \phi_{\varsigma}, \phi_{y^{*}}, \phi_{\tau_{n}}, \phi_{\tau_{k}}, \phi_{\mu}\right)$ are Normals with prior means 0 and standard deviations 2. Finally, the persistence of forcing processes (including the measurement error shock on GDP) are Betas with prior means 0.7 and standard deviations 0.2 and the standard deviations of innovations are Inverse Gammas, with prior means 0.1 and infinite standard deviations.

Estimation results. Tables 5 to 8 in Appendix C summarize the prior distributions and report the means of posterior parameter distributions along with $90 \%$ confidence intervals for each of the four countries, based on 250000 replications of the $\mathrm{MH}$ algorithm where the first $20 \%$ were discarded and where the scale parameter was adjusted to get a $30 \%$ acceptance rate. The estimated parameter values will be discussed in the next Section, starting with the case of the US and then contrasting the results for other countries. The Tables report the estimates for the baseline model with all channels through which war episodes might affect the economy, and a for a restricted model where all these channels are shut down: war spillovers and war specific parameter $\left(p^{\delta}, p^{\ell}\right.$, and $\left.p^{b}\right)$ are restricted to zero, and the Edgeworth parameter is assumed not to switch during war episodes, $\nu_{\text {war }}=\nu_{\text {norm }}$. By contrast with the baseline model, the restricted model provides information about the extent to which the war indicator variable $\Delta_{t}$ helps fit the data for the different countries.

\section{United States: estimation results and implications}

\subsection{Estimation results}

Prior and posterior distributions are reported in Appendix D and show that the estimation procedure provides enough information to update prior distributions. Further, Table 8 in Appendix C shows that most parameters found in other estimated models have comparable point estimates. For example Calvo parameters for the US are 0.4 for prices and 0.2 for wages, suggesting an adjustment frequency of prices and wages between 5 and 7 quarters, numbers that are consistent with estimates based on quarterly datasets and models. Similar comments are in order for parameters such as the investment adjustment cost, the trade elasticity or tax and spending rule parameters.

We rather focus on the Edgeworth complementarity parameter $\nu$, and war-specific parameters like spillovers on shocks, the size of war-related capital depreciation, draft or default on public debt, because they have critical impact on the dynamics of the economy during war episodes.

The Edgeworth parameter has been shown to be crucial for the size of government spending multipliers (see Bouakez and Rebei (2007) or more recently Leeper, Traum and Walker (2017)). 
Our estimation for the US favors a mild complementarity between public and private goods in households' utility function. The estimated values $\nu_{n o r m}$ and $\nu_{\text {war }}$ are close, and roughly equal to 0.5 - recall, substitutability is observed when $\nu>1 .{ }^{19}$ For the US, we can not conclude that these estimates are statistically different, as confidence intervals overlap. Based on post-war Canadian data and using ML methods, Bouakez and Rebei (2007) estimate a value of 0.3320 for this parameter. Larger values found by our empirical work reflect a lower complementarity between private and public goods in the US over our sample, resulting in lower estimates for spending multipliers.

For the US, the estimated value of $p_{\ell}$, the size of the war draft, is $6 \%$. It has to be compared with the numbers reported by Siu (2008): a $6.8 \%$ conscription in the US during WWI and a $15.6 \%$ conscription during WWII. Alternative sources point to a $11 \%$ draft during WWII. Our estimate is therefore in the range of empirically realistic values.

The estimated value of $p^{\delta}$, the size of war related capital destruction, is 9\%. According to Young and Musgrave (1980) the net private capital stock fell by $2.2 \%$ between 1940 and 1945 in the US (see their Table 1.A.1), less than our estimated number. However, the observed $2.2 \%$ number is over a 5-years period: in our model a $9 \%$ increase in capital depreciation lowers the capital stock by $9 \%$ on impact but produces a subsequent rise in investment. Over a 5-years period, the capital stock should therefore not fall as much as $9 \%$. In addition, our specification of the capital destruction parameter also accounts for the destruction of public capital. Overall, our point estimate is thus broadly consistent with the numbers reported by Young and Musgrave (1980).

Concerning the partial default parameter $p^{b}$, our model finds an average $12 \%$ depreciation of public financial assets during war episodes. We believe that this feature captures the rise of default risk or uncertainty perceived by the households. ${ }^{20}$

Let us now examine the sign and size of war-specific spillovers. Our estimation for the US shows that neither the spillover on productivity or investment are significantly different from zero at the $90 \%$ confidence level. However, the trade spillover is different from zero and positive: a "typical" war episode would raise foreign demand for US goods, that should result in an improvement of the trade balance. Our estimation finds that public spending respond positively and significantly, that the labor income tax responds positively while the capital income tax responds negatively.

\footnotetext{
${ }^{19}$ The assumption of Edgeworth complementarity/substitutability does not necessarily capture deeply microfounded features of households' preferences but we do think that it captures quite accurately the transmission mechanism of public spending shocks to private consumption. The latter may proceed through financial constraints, subsistence points, goods rationing or precautionary motives, but including each of these effects would require substantial additional modeling efforts and result in an even larger model to estimate.

${ }^{20}$ Evidence about the trading of government bonds from Germany in Zurich and Stockholm during the war period is reported by Frey and Waldenström (2004), and shows that war events play a major role in volumes traded. We take this as indirect evidence of our partial default channel.
} 
The money growth spillover is not significantly different from zero. While inflation spikes during war episodes in the data, our estimated model copes with this feature of the data by imposing positive money growth innovations, especially at the end of war periods or in the immediate post-war, rather than by producing a significantly positive money growth spillover.

Finally, comparing the baseline model with the restricted model (Table 8 in Appendix C) shows that the baseline model produces a much larger marginal density on the US dataset. This suggests that the baseline model is more strongly supported by the data. The Bayes factor is $e^{54.4}$, a number showing strong evidence in favor of our baseline model. We conclude that the shock on the war indicator variable and the associated transmission mechanisms help fit the data. In addition, point estimates for the parameters that are estimated in both versions of the model are in the same ballpark, showing that our baseline estimation is relatively robust.

\subsection{Historical decompositions}

We now analyze the contribution of the different shocks to the evolution of a subset of the observed variables between 1901 and 1950, with a focus on war episodes. We simulate the model only with the innovations of the shock considered and trace the evolution of the implied variables of interest. Since the estimated model is linear, the observed time series are thus the sum of the dynamics implied by each shock. ${ }^{21}$ We consider the contribution of the shock on the war indicator variable $\Delta_{t}$, "supply shocks" (considering productivity and investment specific shocks together), tax shocks (capital and labor income tax shocks together), the money growth, the public spending shock and the foreign demand shock. Our variables of interest are the observed growth rate of GDP, the observed inflation rate, the observed investment-to-GDP ratio and the observed net-exports-to-GDP ratio. Figure 1 reports the historical decompositions that results from the estimated smoothed structural innovations to the shocks (reported in Figure 17 in Appendix E).

Starting with the observed dynamics of GDP growth, Figure 1 shows that the contribution of the shock on the war indicator variable, that triggers the war specific regime for some parameters and shocks spillovers, is relatively limited. It raises GDP growth on impact, mostly through the spending spillover, but then produces a small contraction in GDP growth. It also contracts GDP growth substantially the first year after the war period, again mostly because the positive government spending spillover vanishes. Other shocks are crucial to actually match the dynamics of GDP growth during war episodes. Most striking is the contribution of government spending innovations, both during WWI and WWII, at the end of the conflicts, consistently with the narratives of Section 2. These innovations come in addition to the spending spillover, that can not account for GDP growth dynamics alone. Negative government spending innovations also

\footnotetext{
${ }^{21} \mathrm{Up}$ to the initial conditions and measurement error shock, that are disregarded to preserve the clarity of the Figures.
} 


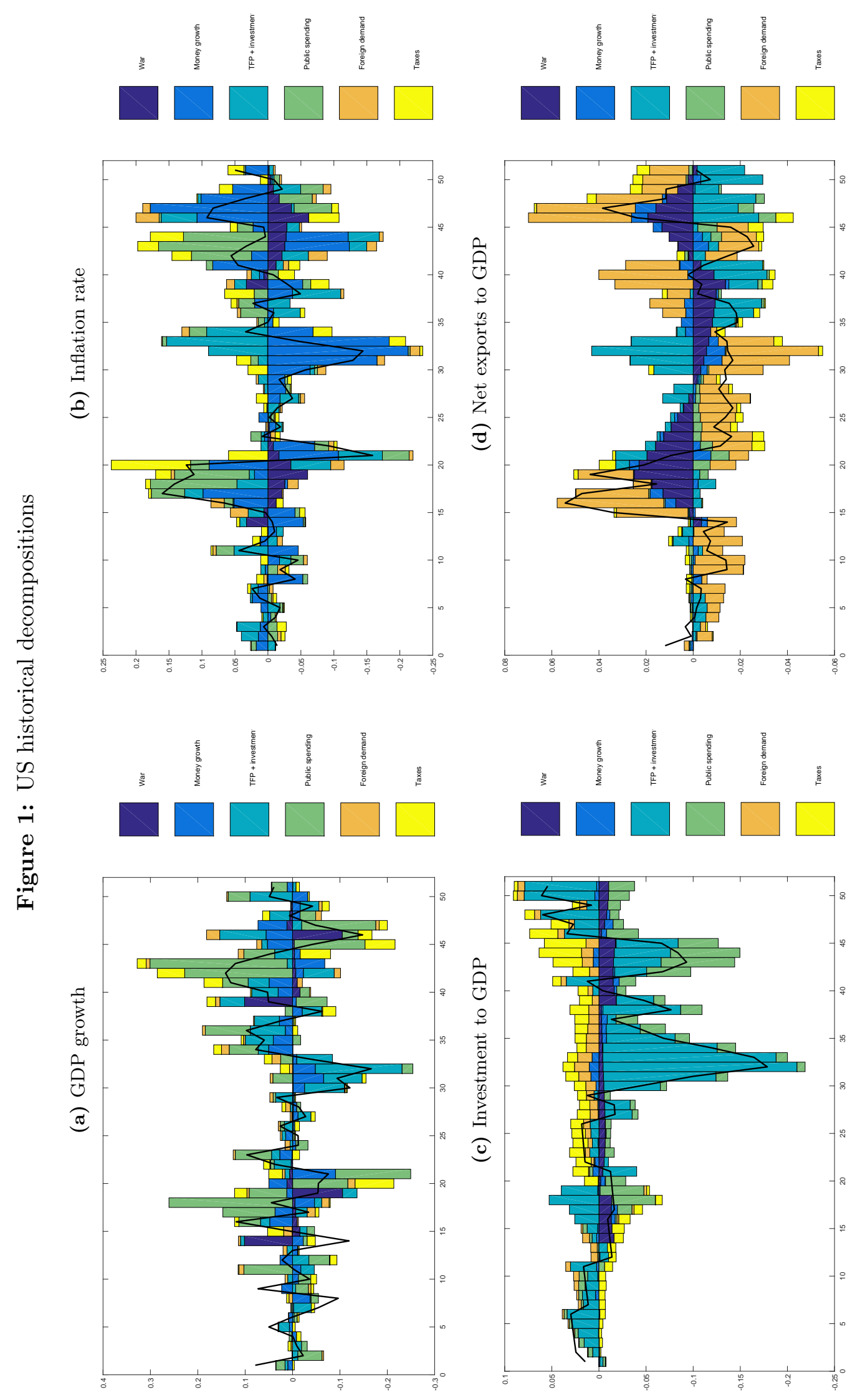


contribute to the post-war slump by a substantial amount. Supply shock innovations contribute only marginally to the dynamics of GDP growth during WWI but more substantially and positively during WWII. These effects are clearly consistent with the findings of McGrattan and Ohanian (2010), who find that a large positive government spending and productivity shocks account quite well for the dynamics of US GDP growth during WWII. Finally, our estimation finds an important role for positive money growth innovation after WWII, to inflate some of the war-related debt away. Overall, innovations to tax and foreign demand shocks play little role in the dynamics of US GDP growth during war episodes. ${ }^{22}$

Other panels of Figure 1 suggest that the shock on the war indicator variable lowers inflation in the US, lower the investment-to-GDP ratio and boosts net exports, mostly through the positive trade spillover. Unless for net exports, however, this shock is not the most important historical driver of these remaining variables during war episodes: inflation is more clearly driven by innovations to the money growth rate and government spending shocks, the investment-to-GDP ratio by innovations to the supply, government spending and tax shocks. Innovations to the foreign demand shock also contribute quite substantially to the dynamics of net exports to GDP.

Overall, this historical decomposition sheds light on the contribution of the on the war indicator variable to the US economy. It certainly drives some of the dynamics of macroeconomic aggregates over these periods, but it is clearly not enough to fully account for those. In particular, additional innovations to government spending shocks, productivity shocks and money growth shocks matter at least as much.

\subsection{Public spending multipliers}

Our previous analysis makes clear that the rise in government spending during war episodes is a robust feature of war periods in the US. On top of the spillover implied by the shock on the war indicator variable, our historical decomposition suggests that a large fraction of macroeconomic fluctuations during war episodes results from the rise of government spending. An interesting question is thus: how do war episodes affect the value of public spending multipliers? As explained in Appendix E, a shock to the war indicator variable already produces a very large rise in public investment and consumption, that boosts output. Does an additional public spending shock produce a larger or a lower spending multipliers in this case, compared to a shock that would hit at the steady state? To answer this question, we draw values of our estimated parameters from the posterior distributions and for each draw, compute the present-value public consumption output multiplier when the shock hits in the first year of a war episode - imposing that our war indicator variable is one during 5 years - and when the shock hits at the steady state - when the war indicator variable is always zero. We conduct non-linear simulations under

\footnotetext{
${ }^{22}$ As a by product of our analysis, our model finds that the Great Depression of the 30's is mostly explained by negative supply and money growth shocks, in line with most contributions on the subject (see Appendix H).
} 
perfect foresight and disregard any kind of other source of uncertainty. ${ }^{23}$ The main purpose of non-linear perfect foresight simulations is to account for the non-linearities implied by the shock on the war indicator variable. The latter triggers a switch in parameters that crucially affect the size of spending multipliers, such as the Edgeworth complementarity parameter or the capital depreciation rate, with an effect on the dynamics of the real interest rate. The shock on the war indicator variable also activates spillovers with persistent effects. ${ }^{24}$

Figure 2 below reports the value of the present-value multipliers, representing the discounted dollar increase in output, consumption or investment that results from a dollar increase in public consumption $g_{t}$. It also reports multipliers confidence intervals. When the shock hits at the steady state, the reference path of variable $x$ against which deviations are computed is the steady state. When the shock hits conditional on a 5-years war episode, the reference path of variable $x$ is the path implied by a shock on the war indicator variable only. ${ }^{25}$

Our results suggest that output present-value multipliers (PVMs hereafter) are rather large on impact (larger than 1) and then fall under the combined effects of public spending and tax rules that ensure debt sustainability in the long run. Long-run median present-value output multipliers remain slightly above one. In addition, they are a little higher during war episodes than during normal times. This difference essentially reflects the difference in the responses of consumption and investment. During normal times, private consumption is crowded-in - due to the Edgeworth complementarity between public and private goods in the utility function of households - and investment increases slightly. During a war episode, private consumption is crowded-out, and investment increases more substantially, producing overall larger median estimates of the spending output multiplier. Yet, according to our estimates and confidence intervals, this difference is not statistically significant. The key difference between war times and normal times is that war episodes are characterized by a positive labor income tax spillover and a negative capital income tax spillover: the latter alters the intertemporal price of consumption and provides incentives for households to skew their current expenditure towards capital accumulation against consumption. Hence, war episodes favor a larger positive response of investment and a

\footnotetext{
${ }^{23}$ All the remaining innovations to shocks are assumed to be zero.

${ }^{24}$ When estimated spillover parameters are not statistically different from zero, that is, when their $90 \%$ confidence interval is wide and comprises positive and negative values, we simply impose the spillover parameter to be zero in the simulations. This avoids "polluting" the simulations with spillover effects that are not informative according to the estimation.

${ }^{25}$ Let

$$
P V M_{x, T}^{s s}=\frac{\sum_{j=1}^{T} \beta^{j}\left(x_{t+j}^{g}-x\right)}{\sum_{j=1}^{T} \beta^{j}\left(g_{t+j}^{g}-g\right)}, \text { for } x=y, c, i
$$

denote the multiplier in normal times and

$$
P V M_{x, T}^{\text {war }}=\frac{\sum_{j=1}^{T} \beta^{j}\left(x_{t+j}^{\text {war }+g}-x_{t+j}^{\text {war }}\right)}{\sum_{j=1}^{T} \beta^{j}\left(g_{t+j}^{\text {war }+g}-g_{t+j}^{\text {war }}\right)}, \text { for } x=y, c, i
$$

denote the multiplier conditional on a 5 -years war episode.
} 
Figure 2: Present-value multipliers at different horizons
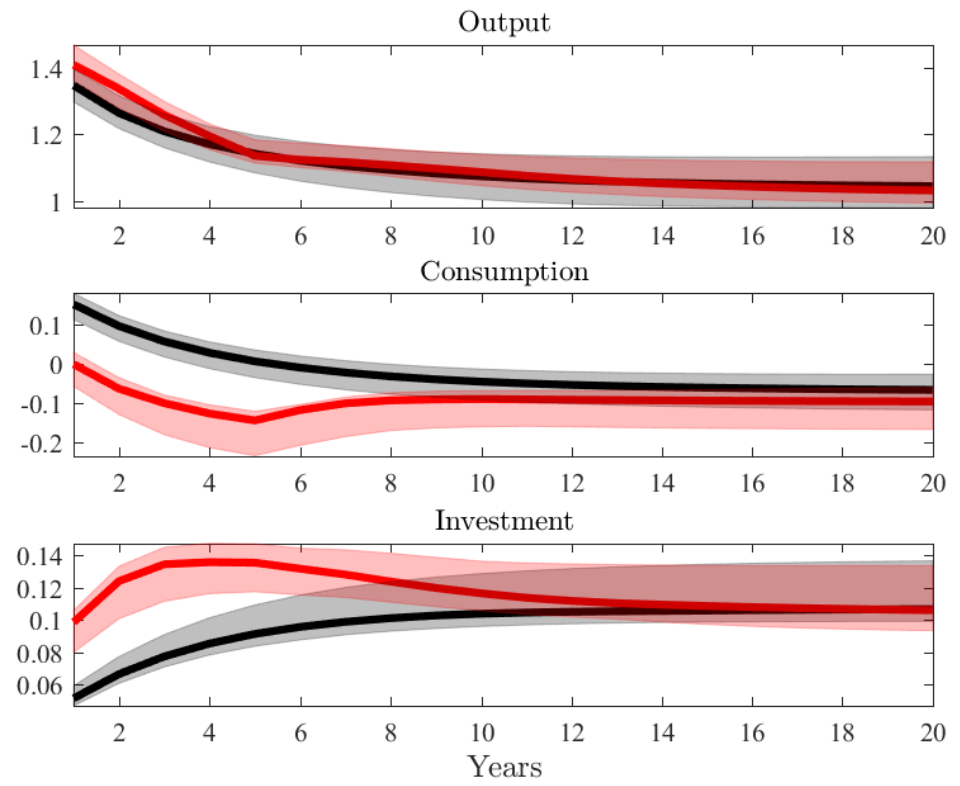

Black: normal times. Red: war episodes. Shaded areas correspond to one standard deviation confidence intervals $\left(16^{\text {th }}\right.$ and $84^{\text {th }}$ percentiles) based on 120 replications of our non-linear perfect foresight simulations. Each replication draws a vector of the estimated parameters from the posterior distributions and computes the multipliers.

crowding-out of private consumption.

Our estimates of multipliers based on US data belong to the upper range of estimated spending output multipliers reported by Ramey (2019). In addition, the question of state-dependent multipliers has recently been addressed with two different set of conclusions. Auerbach and Gorodnichenko (2012) find that multipliers are larger during periods of economic slack while Owyang, Ramey and Zubairy (2013) find no particular difference for the US but a significant one for Canada. In our model, multipliers differ during war episodes because when the war indicator variable is one, Edgeworth parameters may differ and some war-specific effects are triggered (spillovers, draft, default and capital depreciation), which can result in different transmission mechanisms for public spending shocks. While this non-linearity seems to matter for the impact response of consumption and investment, it does not produce significantly different output PVMs at medium or long horizons. Our results thus seem to back those of Owyang et al. (2013) more than those of Auerbach and Gorodnichenko (2012), based on our estimation on US data. 


\section{Results for UK, France and Germany}

\subsection{Estimation results}

As in the case of the US, prior and posterior distributions are reported in Appendix D and show that the estimation procedure provides enough information to update prior distributions. Table 3 below is an extraction of the posterior means and $90 \%$ confidence intervals of some key parameters for all countries, including the US for comparison purposes.

Table 3: Key parameter mean estimates, with $90 \%$ confidence intervals

\begin{tabular}{|c|c|c|c|c|}
\hline Structural parameters & France & Germany & 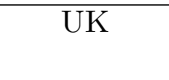 & US \\
\hline Calvo prices $\left(\eta^{p}\right)$ & $\begin{array}{c}0.20 \\
{[0.15,0.25]}\end{array}$ & $\begin{array}{c}0.22 \\
{[0.16,0.27]}\end{array}$ & $\begin{array}{c}0.25 \\
{[0.20,0.31]}\end{array}$ & $\begin{array}{c}0.40 \\
{[0.36,0.44]}\end{array}$ \\
\hline Calvo wages $\left(\eta^{w}\right)$ & $\begin{array}{c}0.27 \\
{[0.14,0.39]}\end{array}$ & $\begin{array}{c}0.40 \\
{[0.33,0.47]}\end{array}$ & $\begin{array}{c}0.14 \\
{[0.05,0.22]}\end{array}$ & $\begin{array}{c}0.20 \\
{[0.11,0.30]}\end{array}$ \\
\hline Edgeworth comp. $\left(\nu_{\text {norm }}\right)$ & $\begin{array}{c}0.50 \\
{[0.47,0.53]}\end{array}$ & $\begin{array}{c}0.56 \\
{[0.52,0.60]}\end{array}$ & $\begin{array}{c}0.60 \\
{[0.59,0.62]}\end{array}$ & $\begin{array}{c}0.55 \\
{[0.53,0.57]}\end{array}$ \\
\hline Edgeworth comp. $\left(\nu_{w a r}\right)$ & $\begin{array}{c}0.35 \\
{[0.30,0.40]}\end{array}$ & $\begin{array}{c}0.48 \\
{[0.40,0.55]}\end{array}$ & $\begin{array}{c}0.46 \\
{[0.42,0.51]}\end{array}$ & $\begin{array}{c}0.51 \\
{[0.47,0.55]}\end{array}$ \\
\hline War draft $\left(p^{\ell}\right)$ & $\begin{array}{c}0.08 \\
{[0.02,0.14]}\end{array}$ & $\begin{array}{c}0.08 \\
{[0.02,0.15]}\end{array}$ & $\begin{array}{c}0.11 \\
{[0.03,0.18]}\end{array}$ & $\begin{array}{c}0.06 \\
{[0.02,0.11]}\end{array}$ \\
\hline War default $\left(p^{b}\right)$ & $\begin{array}{c}0.08 \\
{[0.03,0.13]}\end{array}$ & $\begin{array}{c}0.10 \\
{[0.02,0.16]}\end{array}$ & $\begin{array}{c}0.06 \\
{[0.02,0.10]}\end{array}$ & $\begin{array}{c}0.12 \\
{[0.06,0.18]}\end{array}$ \\
\hline War capital depreciation $\left(p^{\delta}\right)$ & $\begin{array}{c}0.09 \\
{[0.02,0.15]}\end{array}$ & $\begin{array}{c}0.10 \\
{[0.02,0.17]}\end{array}$ & $\begin{array}{c}0.09 \\
{[0.02,0.15]}\end{array}$ & $\begin{array}{c}0.09 \\
{[0.02,0.16]}\end{array}$ \\
\hline Investment adj. cost $\left(\phi_{i}\right)$ & $\begin{array}{l}4.04 \\
{[3.21,4.89]}\end{array}$ & $\begin{array}{l}4.68 \\
{[3.85,5.52]}\end{array}$ & $\begin{array}{l}3.74 \\
{[2.92,4.53]}\end{array}$ & $\begin{array}{l}4.27 \\
{[3.49,4.05]}\end{array}$ \\
\hline Trade elasticity $(\mu)$ & $\begin{array}{l}1.48 \\
{[1.31,1.65]}\end{array}$ & $\begin{array}{c}1.24 \\
{[1.08,1.40]}\end{array}$ & $\begin{array}{c}1.17 \\
{[1.08,1.26]}\end{array}$ & $\begin{array}{l}1.26 \\
{[1.17,1.35]}\end{array}$ \\
\hline Labor tax rule $\left(d_{\tau^{n}}\right)$ & $\begin{array}{c}0.09 \\
{[0.07,0.12]}\end{array}$ & $\begin{array}{c}0.32 \\
{[0.18,0.44]}\end{array}$ & $\begin{array}{c}0.07 \\
{[0.06,0.09]}\end{array}$ & $\begin{array}{c}0.13 \\
{[0.08,0.17]}\end{array}$ \\
\hline Capital tax rule $\left(d_{\tau^{n}}\right)$ & $\begin{array}{c}0.13 \\
{[0.08,0.18]}\end{array}$ & $\begin{array}{c}0.15 \\
{[0.08,0.22]}\end{array}$ & $\begin{array}{c}0.11 \\
{[0.08,0.15]}\end{array}$ & $\begin{array}{c}0.17 \\
{[0.08,0.25]}\end{array}$ \\
\hline Spending rule $\left(d_{g}\right)$ & $\begin{array}{c}0.15 \\
{[0.09,0.21]}\end{array}$ & $\begin{array}{c}0.10 \\
{[0.07,0.13]}\end{array}$ & $\begin{array}{c}0.11 \\
{[0.07,0.15]}\end{array}$ & $\begin{array}{c}0.10 \\
{[0.07,0.13]}\end{array}$ \\
\hline \multicolumn{5}{|l|}{ War spillovers } \\
\hline Productivity $\left(\phi_{a}\right)$ & $\begin{array}{c}-0.05 \\
{[-0.08,-0.02]}\end{array}$ & $\begin{array}{c}-0.06 \\
{[-0.09,-0.03]}\end{array}$ & $\begin{array}{c}-0.02 \\
{[-0.04,-0.01]}\end{array}$ & $\begin{array}{c}0.01 \\
{[-0.01,0.02]}\end{array}$ \\
\hline Spending $\left(\phi_{g}\right)$ & $\begin{array}{c}0.01 \\
{[-0.09,0.11]}\end{array}$ & $\begin{array}{c}0.03 \\
{[-0.10,0.17]}\end{array}$ & $\begin{array}{c}0.34 \\
{[0.22,0.47]}\end{array}$ & $\begin{array}{c}0.14 \\
{[0.07,0.21]}\end{array}$ \\
\hline Investment $\left(\phi_{\varsigma}\right)$ & $\begin{array}{c}-0.62 \\
{[-1.08,-0.17]}\end{array}$ & $\begin{array}{c}-0.46 \\
{[-0.91,-0.02]}\end{array}$ & $\begin{array}{c}-0.34 \\
{[-0.64,-0.05]}\end{array}$ & $\begin{array}{c}0.06 \\
{[-0.31,0.41]}\end{array}$ \\
\hline Trade $\left(\phi_{y^{*}}\right)$ & $\begin{array}{c}-0.70 \\
{[-0.94,-0.45]}\end{array}$ & $\begin{array}{c}-0.08 \\
{[-0.29,-0.12]}\end{array}$ & $\begin{array}{c}-0.38 \\
{[-0.52,-0.24]}\end{array}$ & $\begin{array}{c}0.16 \\
{[0.06,0.26]}\end{array}$ \\
\hline Labor tax $\left(\phi_{\tau^{n}}\right)$ & $\begin{array}{c}-0.18 \\
{[-0.25,-0.10]}\end{array}$ & $\begin{array}{c}0.44 \\
{[0.24,0.63]}\end{array}$ & $\begin{array}{c}-0.14 \\
{[-0.20,-0.09]}\end{array}$ & $\begin{array}{c}0.13 \\
{[0.06,0.20]}\end{array}$ \\
\hline Capital tax $\left(\phi_{\tau^{n}}\right)$ & $\begin{array}{c}0.38 \\
{[0.18,0.59]}\end{array}$ & $\begin{array}{c}-1.75 \\
{[-2.49,-1.00]}\end{array}$ & $\begin{array}{c}0.22 \\
{[0.08,0.36]}\end{array}$ & $\begin{array}{c}-0.34 \\
{[-0.54,-0.14]}\end{array}$ \\
\hline Money growth $\left(\phi_{\mu}\right)$ & $\begin{array}{c}0.03 \\
{[-0.03,0.10]}\end{array}$ & $\begin{array}{c}-0.01 \\
{[-0.07,0.05]}\end{array}$ & $\begin{array}{c}0.02 \\
{[-0.00,0.05]}\end{array}$ & $\begin{array}{c}-0.02 \\
{[-0.04,0.01]}\end{array}$ \\
\hline
\end{tabular}

Notes: Results are extracted from Tables 5 to 8 in Appendix C.

Table 3 shows that countries other than the US have rather less sticky prices and more sticky wages. According to our estimates, Germany features more overall stickiness than France or the UK. In addition, France, Germany and the UK all feature significantly different estimates for the Edgeworth parameter $\nu$ during normal times and during war times, public and private goods being more strongly complementary during war episodes. This could result in different presentvalue multipliers compared to the US. The point estimates for the war draft parameters are all 
larger than in the US, the war partial default parameters are somehow smaller, and the war capital depreciation parameters are roughly the same than in the US. The largest war-specific depreciation factor is estimated at $10 \%$ for Germany, the country of our sample that arguably suffered the largest war-related capital destruction, especially at the end of WWII.

Another interesting difference is the sign and size of war spillovers. As opposed to the US, European countries of our sample feature negative productivity and investment war spillovers. We find that these spillover parameters are not significantly different from zero for the US. Similarly, a key difference is that the foreign demand spillover is found to be significant and negative for European countries, and significant but positive for the US. Only the UK features a positive public spending spillover while this parameter is muted for France and Germany. Finally, France and the UK are characterized by a financing of war efforts through the capital income tax along with a lower labor income tax, while Germany exhibits a financing pattern that is more similar to the US: an increase in the labor income tax and a lower capital income tax. For all countries, the spillover on money growth is muted.

Overall, our estimations find that many war-specific parameters are statistically different from zero. This tends to comfort our theoretical assumptions. However, those war-related assumptions, triggered by the shock on the war indicator variable, do not capture completely the macroeconomic dynamics observed during war episodes, and the estimation has to resort to additional innovations to structural shocks. For example, money spillovers are statistically non-significant while we know that governments have used money growth to partly inflate the debt away. In this respect, our model is able to capture this through two channels: the money growth spillover or innovations to the money growth rule. If the behavior of the government is different during WWI and WWII, or if positive money growth came only at the end of the conflicts and after, our model may not capture a significant spillover and rather capture seigniorage through money growth innovations. The same reasoning may apply for other spillovers, such as the public spending spillover in France and Germany, or the productivity spillover in the US. The former is found to be non-significant while data suggest that public spending increased during both WWI and WWII in France and Germany. The latter is muted while productivity shocks have been shown to be important during WWII (see McGrattan and Ohanian (2010)). Our estimations find these spillovers to be statistically non-significant but need positive innovations to the related structural shocks (public spending or productivity) to fit the data.

As a final piece of evidence in favor of our assumptions concerning the way war episodes affect the economy, Tables 5 to 7 in Appendix $\mathrm{C}$ all show that the marginal densities associated to estimations of the baseline model are larger than those associated with the estimations of the restricted model. Bayes factors are respectively $e^{11.02}$ for France, $e^{9.35}$ for Germany and $e^{34.96}$ for the UK, showing stronger support in favor of the baseline model. For European countries, as for the US, the estimated values of parameters estimated in both models are also roughly similar. 


\subsection{Historical decompositions}

We now proceed to the analysis of historical decompositions of key macroeconomic variables for European countries. Figures 22 to 24 in Appendix G report those decompositions.

Starting with France, Figure 22 shows that the shock on the war indicator variable plays a much bigger role in output dynamics than it does for the US. It explains the bulk of GDP growth fluctuations, along with public positive spending and negative innovations to productivity and investment shocks. A large part of the positive inflation dynamics during world wars is also explained by this shock, especially during WWI. The early dynamics of inflation during WWII are also well captured by the shock on the war indicator variable, but the late dynamics rely on large positive money growth innovations to fit the data. The shock on $\Delta_{t}$ lowers the investmentto-GDP ratio and the net exports-to-GDP ratio and contributes to explain a large fraction of those variables, especially during WWI. During the interwar period, the investment ratio is almost exclusively driven by negative productivity and investment shocks, and the dynamics of net exports is also driven by large foreign demand innovations. Figure 22 thus suggests that the shock on the war indicator variable and the associated transmission mechanisms are more important in explaining macroeconomic time series in France during world wars than it is for the US.

Now looking at the historical decomposition for Germany, Figure 23 also shows that the shock on the war indicator variable explains a substantial part of the observed GDP growth, the investment ratio and, to a lesser extent, net exports during war episodes. The shock depresses GDP growth, raises inflation, lowers the investment ratio and drives net exports in negative territories. During world wars, the public spending shock and the productivity/investment shocks also contribute to explain the dynamics of GDP growth and the investment ratio. The money growth shock is crucial in accounting for the dynamics of inflation (especially during WWI), and the foreign demand shock is key to the dynamics of net exports. ${ }^{26}$ In the case of Germany as well, the shock on the war indicator variable plays a crucial role in explaining the dynamics of the economy during world war episodes.

Let us finally look at the historical decomposition for the UK, in Figure 24. The results are more contrasted, somewhere in between the US and France/Germany. On the one hand, the shock on the war indicator variable contributes moderately and negatively to GDP growth dynamics, and little to inflation during WWI but more during WWII. On the other hand, it contributes quite significantly to the dynamics of the investment ratio and net exports, both during WWI and WWII. Government spending shocks contribute massively to the dynamics of GDP growth, of inflation during WWI and of the investment ratio during both world war episodes, and the

\footnotetext{
${ }^{26}$ Notice that the hyperinflation of the early 20 's is captured by a sequence of large and positive money growth shocks, that raise inflation, the investment ratio and net exports to GDP (see also Appendix H). The depression of the 30's appears in the form of negative investment and productivity shocks, as in the US.
} 
foreign demand shock accounts for a substantial fraction of the dynamics of net exports during WWII.

Our main conclusion from this exercise is that the shock on the war indicator variable accounts for a relatively marginal fraction of observed variables for the US, helps fit some of the data for the UK, and plays a critical role for France and Germany. We see this set of results as a useful complement to the literature: while the effects of war episodes can be accounted for by large spending and productivity shocks in the US and to a lesser extent in the UK, it is not the case for other countries such as France or Germany. The "macroeconomics of war and peace" should therefore allow for shocks such as our shock on the war indicator variable, that destroy part of the stock of capital, affect the labor force, alter the dynamics of public debt, disrupt trade, among other things, at least for countries such as France and Germany.

\subsection{The macroeconomic effects of a simulated war episode}

What are the effects of an artificial shock on the war indicator variable, i.e. a shock on $\Delta_{t}$, according to our estimated model? We consider the economy to be initially in the steadystate and abstract from all other sources of uncertainty. We feed in a 5-year shock on $\Delta_{t}$ and solve the model using non-linear perfect foresight simulations. ${ }^{27}$ Figures 3 and 4 depict the resulting macroeconomic effects in the three countries France, Germany and the UK, as well as the dynamics for the US, for a comparison. While the historical decompositions made it clear that the shock on the war indicator variable was not the sole (and for some countries like the US even not the main) driver of the economy, this exercise reveals key differences implied by our estimation concerning the conditional effects of a war episode.

According to Figures 3 and 4, a war episode in the UK has remarkably similar effects compared to the US. GDP rises on impact, consumption and investment fall, driven by the crowding-out effect of the massive rise in public spending. Because the latter is larger in the UK than in the US, public debt rises much above the levels reached by the US, but the global pattern is the same. One difference comes from the pattern of tax spillovers in the UK and in the US. In the UK, tax spillovers imply a fall in the labor income tax and a rise in the capital income tax. The pattern is the opposite for the US. These differences mainly alter the responses of hours worked and real wages but do not feed back much to other key macroeconomic variables. An additional difference is the large trade deficit observed in the UK, driven by the negative trade spillover. The US show a reduced trade deficit because the trade spillover is positive, mitigating the trade deficit generated by the rise in public spending.

Figures 3 and 4 show that a simulated war episode produces very different adjustments for France and Germany, compared to the US and the UK. Both countries show similar dynamics, although

\footnotetext{
${ }^{27}$ In other words, we consider an "MIT" shock on $\Delta_{t}$.
} 
Figure 3: Impulse Response Functions to a 5-year MIT shock on $\Delta_{t}$ - Macro variables
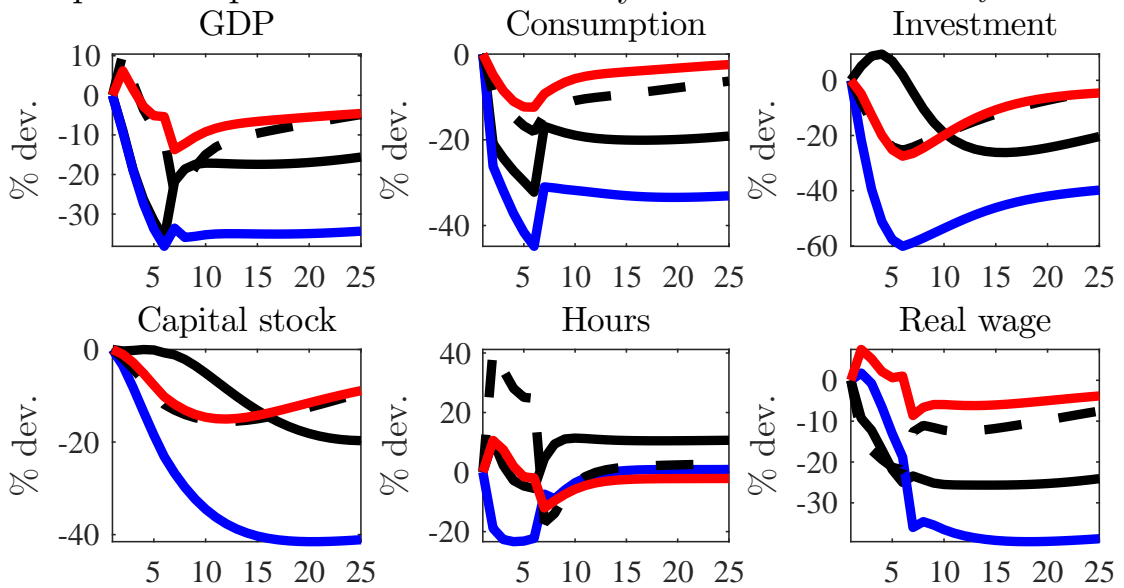

Hours
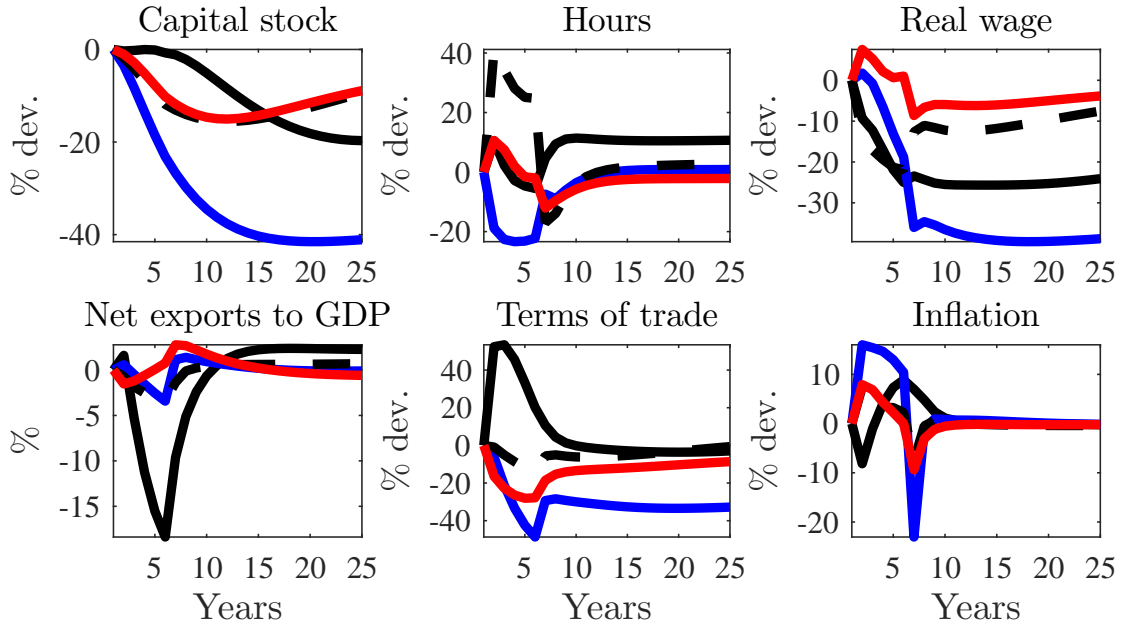

Black: France, Blue: Germany, Red: US, Dashed: UK

Figure 4: Impulse Response Functions to a 5-year MIT shock on $\Delta_{t}$ - Policy variables
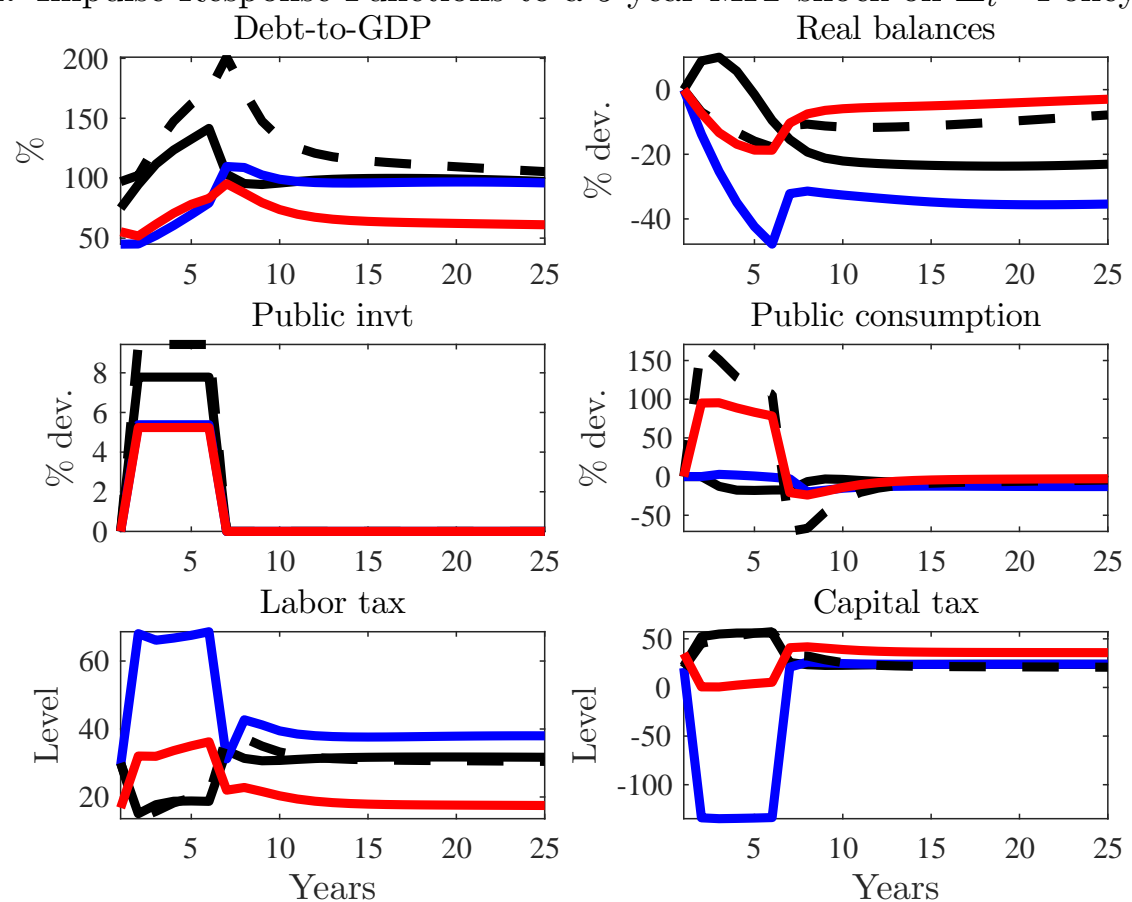

Black: France, Blue: Germany, Red: US, Dashed: UK 
the magnitude of adjustments is larger for Germany. In those countries, a war episode massively lowers GDP - by almost $40 \%$ in France and more than $40 \%$ in Germany. Consumption falls more than GDP, although public spending does not rise, suggesting that the depreciation of physical capital and the draft play much more prominent roles than in the UK or the US. France displays a massive trade deficit that reaches almost 20\% of GDP, while Germany experiences a moderate trade deficit. Because nominal rigidities are estimated to be larger in Germany, inflation rises massively, by more than $20 \%$, after reversing when the shock disappears. France and Germany are characterized by opposite patterns regarding taxes spillovers: France sees a rise in the capital tax and a fall in the labor tax (as the UK) and Germany sees a rise in the labor tax and a fall in the capital tax (as the US).

This exercise reveals that a shock on the war indicator variable, such as estimated by our model, has very different implications for the dynamics of the economy whether looking at the US or the UK, and countries such as France or Germany. For the latter, unsurprisingly, the dynamics is extremely negative for GDP growth, consumption, investment, inflation and net exports. We certainly do not claim that war episodes benefited to countries like the US or the UK, war obviously had negative consequences for all belligerents. Our main point is that the consequences of war episodes are quite different when those are not modeled as large spending and/or productivity shocks, as it is usually done in a literature that focuses on the US and the UK.

\subsection{Public spending output multipliers}

We perform the same computation of public spending multipliers for France, Germany and the UK. We proceed as in Section 4.3 and consider the effects of a shock on public consumption during normal times and conditional on a 5-years war episode. Figure 5 reports the public spending multipliers for the three countries, plus the US for a comparison, along with confidence bands.

First, the levels of multipliers differ across countries. France has the largest multipliers, between 1.4 and 1.7 on impact, and the long-term multipliers are above one. Then, the US also feature large impact multipliers, between 1 and 1.3, and the long-term multipliers are above one. Germany and the UK have lower impact multipliers, around 1, and much lower multipliers in the long run (around 0.5 for the UK and 0 for Germany). For Germany, these lower long-run multipliers are due to the very large estimated coefficient of the labor income tax feedback rule. For the UK, the larger estimated Edgeworth parameter - signalling less complementarity - is responsible, especially for normal-times multipliers.

Second, while Germany and the US have broadly similar impact and short-run output multipliers during war episodes and during normal times, France and the UK feature larger multipliers during war episodes. These differences are statistically significant, and suggest that, for those countries, 
Figure 5: Present-value multipliers at different horizons

(a) France
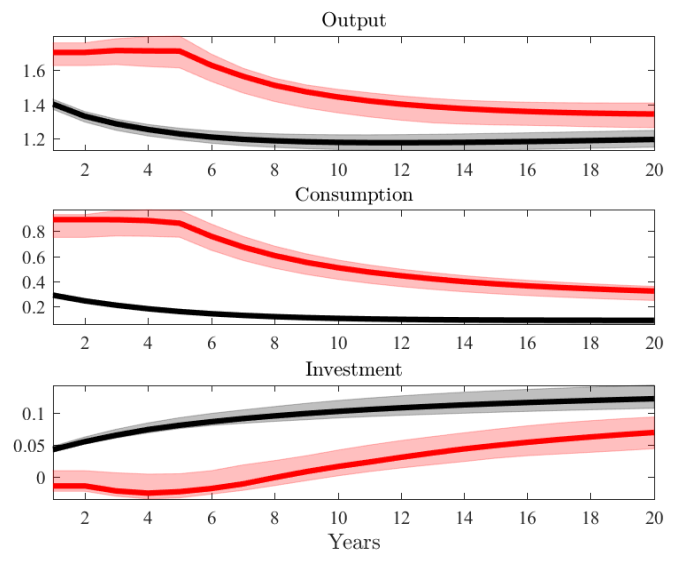

(c) UK
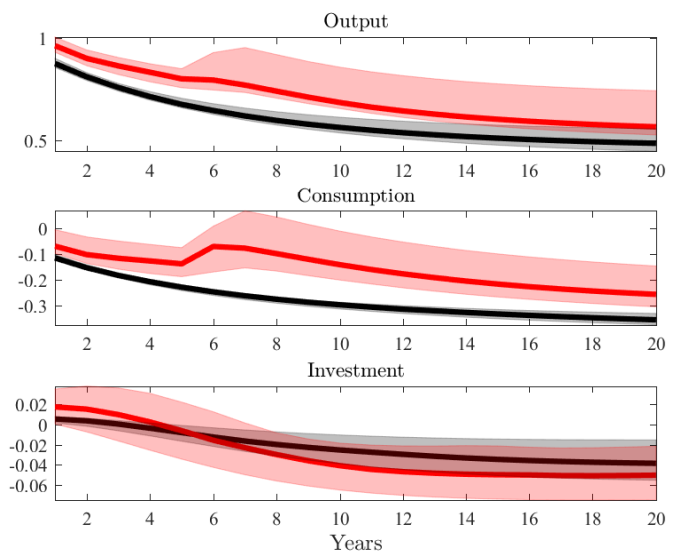

(b) Germany
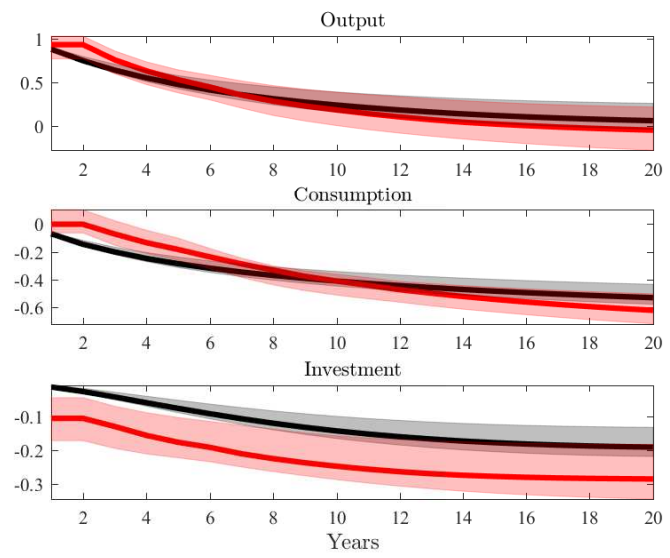

(d) US
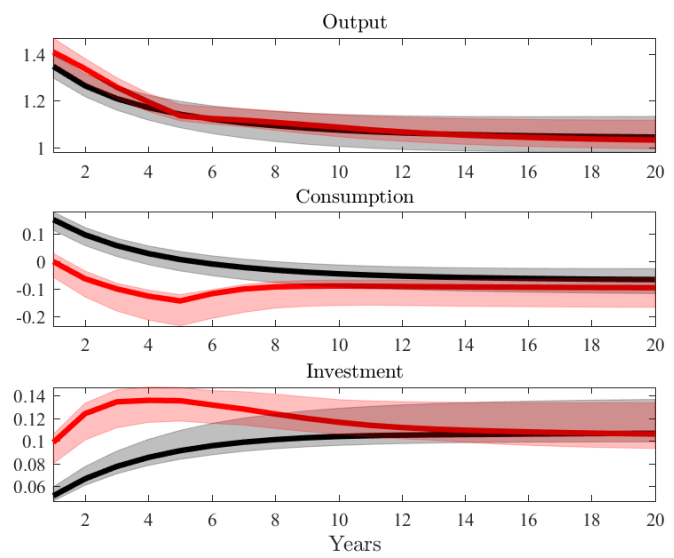

Black: normal times. Red: War episodes. Shaded areas correspond to one standard deviation confidence intervals $\left(16^{\text {th }}\right.$ and $84^{\text {th }}$ percentiles) based on 120 replications of our non-linear simulations. Each replication draws a vector of the estimated parameters from the posterior distributions reported in Appendix D and computes PVMs. 
the values of spending multipliers identified with war episodes might not be informative about the value of multipliers during normal times. The most obvious driver of this result for the UK and France is the larger difference in estimated Edgeworth parameters during normal times and during war episodes: in both countries the Edgeworth parameter is significantly lower during war episodes, making private consumption rise more after a spending shock than during normal times, leading to larger output multipliers.

Overall, our conclusion is that war episodes are indeed periods during which government spending rise massively. While interesting from the perspective of the identification of exogenous spending shocks, the resulting output multipliers may not necessarily be interpreted as informative about the size of multipliers during normal times because the structure of the economy may differ. Our results suggest that war episodes are associated with large disruptions in the functioning of the economy, with changes in the macroeconomic environment (households' behavior, taxes, capital efficiency) and hence with changes in transmission mechanisms, that might affect the size of spending multipliers. The above exercise indicates that it would be more likely the case for France and the UK, and less for Germany or the US.

\section{Welfare losses from war episodes}

Finally, we proceed to a welfare analysis. Using the series of smoothed structural shocks, i.e. the series of shocks that best replicate our datasets, we simulate the model for each country using estimated parameters. ${ }^{28}$ First, we feed the model with all smoothed structural shocks. Then, we run a counterfactual exercise and feed the model with all the smoothed structural shocks without the shock on the war indicator variable. Then we compute the welfare losses induced by war episodes, measured as the Hicksian consumption equivalent, i.e. the consumption compensation that makes households indifferent between living in a world with war episodes and in a world without them. This approach is also used to measure the welfare costs of other sources of macroeconomic fluctuations. Finally, we report the total welfare losses from fluctuations, measured as the Hicksian equivalent that makes households indifferent between an economy with fluctuations and an economy that remains in the "peaceful" steady state. ${ }^{29}$ The results are reported in Table 4 .

Table 4 suggests that war episodes have large negative welfare effects for France and Germany, moderately negative effects for the UK and positive effects in the US. These results can be understood through the behavior of key macroeconomic variables during war episodes. France and Germany experience large drops in private consumption that are not compensated by a rise in public spending - remember, the spending spillover is muted for those countries. They also experience large hikes in hours worked. Both lower consumption paths and higher paths

\footnotetext{
${ }^{28}$ We only abstract from innovations in the measurement error shock.

${ }^{29}$ As usual when introducing money in the utility function, the welfare effects of real balances are simply ignored.
} 
Table 4: Welfare costs, in percents

\begin{tabular}{lrrrr}
\hline \hline Welfare cost of: & France & Germany & UK & \multicolumn{1}{c}{ US } \\
War episodes & 0.6892 & 0.8752 & 0.1185 & -0.0382 \\
Productivity and investment shocks & -0.6391 & -0.6607 & -0.0196 & -0.0350 \\
Foreign demand shocks & 0.0602 & 0.0074 & 0.0061 & 0.0013 \\
Public spending shocks & -0.1991 & -0.0334 & 0.2768 & -1.5256 \\
Tax shocks & -0.5378 & 0.0049 & -0.0363 & -0.2480 \\
Money growth shocks & 0.0324 & -0.0245 & 0.0054 & 0.0022 \\
\hline All fluctuations & 0.0153 & 0.0103 & 0.0074 & 0.0586 \\
\hline \hline
\end{tabular}

for hours worked generate welfare losses. Quantitatively speaking, Germany suffers the largest welfare losses, representing $0.88 \%$ of permanent consumption. For France, the welfare losses are of the same order of magnitude, around $0.69 \%$ of permanent consumption.

For the UK and the US, the negative effects of war episodes are partly compensated by large jumps in public spending that supports the economy and brings welfare gains to the households since $(i)$ public consumption is a direct argument of the utility function and (ii) private consumption is crowded-in when public consumption increases, which attenuates the fall in private consumption. For the UK, these effects attenuate the welfare losses from war episodes, that reach $0.12 \%$ of permanent consumption, lower than those found for France and Germany. For the US, the "positive" effects on utility are large enough to generate small welfare gains, around $0.04 \%$ of permanent consumption. ${ }^{30}$

As robustness check, we also compute the total welfare losses from fluctuations. Based on the whole sample, the latter are much smaller, because the negative welfare effects of some shocks are almost fully compensated by the positive effects of other shocks. Overall, the resulting welfare losses from fluctuations are very small, in the order of magnitude typically reported by Lucas (1987) and the subsequent literature, ranging from $0.01 \%$ to $0.06 \%$ of permanent consumption.

\section{Conclusion}

War episodes induce large shifts in macroeconomic variables provoked by a series of potential related causes: destruction, military draft, changes in national borders, large wealth transfers from a defeated country to a victorious one, interventions of governments that raise public spending, inflate the public and military sector, alter the structure of the labor market and impose restrictions on financial and good markets.

This paper proposed an estimated open economy model that would be suited to capture the dynamics of countries such as France, Germany, the UK and the US both during normal times

\footnotetext{
${ }^{30}$ This result should be interpreted with caution. Clearly, US households would have preferred not to be involved in world war episodes, as the costs of those world war episodes are immensely larger than just their macroeconomic costs.
} 
and during war episodes. Of course, all the above aspects could not be fully taken into account but some of them (capital destruction, draft, partial default on public debt) were, and were shown to be statistically significant. In addition, we shown that the macroeconomic effects of war episodes were not fully accounted for by the shock on the war indicator variable, and needed to be completed with other shocks. A massive increase in public spending (UK, US), negative productivity and investment shocks (France, Germany and the UK), a negative foreign demand shock (France and the UK), and variations in the labor and capital income tax rates, were also important to fit the data. Our main conclusions thus complement Braun and McGrattan (1993) and McGrattan and Ohanian (2010) about the key role of public spending shocks on the US and UK economy during world wars episodes. For Continental Europe, however, war episodes affected the economy through the channels of capital destruction, military draft, partial default on public

debt, and spillovers. In these countries the public spending spillover was muted, investment, productivity and trade spillovers were negative and significant.

Finally, our estimation results were used investigate the size and state-dependence of public spending output multipliers and about the welfare losses from war episodes. Some countries (Germany and the US) had statistically similar patterns of spending output multipliers during normal times and during war episodes, while some others (France and the UK) featured larger multipliers during war episodes. The welfare analysis showed that Germany and France were the countries of our sample that suffered most in terms of the welfare effects of macroeconomic dynamics, while the welfare (economic) costs were smaller for the US and the UK.

\section{References}

Ambler, S. and A. Paquet, Stochastic Depreciation and the Business Cycle, International Economic Review, 1994, 35 (1), 101-116.

An, S. and F. Schorfheide, Bayesian Analysis of DSGE Models, Econometric Reviews, 2007, 26 $(2-4), 113-172$.

Anderton, C. H. and J. R. Carter, The Impact of War on Trade: An Interrupted Times-Series Study, Journal of Peace Research, 2001, 38 (4), 445-457.

Auerbach, A. J. and Y. Gorodnichenko, Fiscal Multipliers in Recession and Expansion, in Fiscal Policy after the Financial Crisis NBER Chapters, National Bureau of Economic Research, Inc, 2012, pp. 63-98.

Auray, S., A. Eyquem, and F. Jouneau-Sion, Wars and Capital Destruction, Journal of Economic Dynamics and Control, 2014, 41 (C), 224-240.

_, _, and P. Gomme, A Tale of Tax Policies in Open Economies, International Economic Review, 2016, 57 (4), 1299-1333. 
Backus, D. K., P. J. Kehoe, and F. E. Kydland, International Real Business Cycles: Theory vs. Evidence, Federal Reserve Bank of Minneapolis Quarterly Review, 1993, 17, 14-29.

Barro, R. J. and J. F. Ursúa, Stock-market Crashes and Depressions, Research in Economics, 2017, 71 (3), 384-398. Special issue on Macroeconomics.

Ben Zeev, N. and E. Pappa, Chronicle of a War Foretold: The Macroeconomic Effects of Anticipated Defense Spending Shocks, Economic Journal, 2015, 127 (603), 1568-1597.

Bouakez, H. and N. Rebei, Why Does Private Consumption Rise after a Government Spending Shock?, Canadian Journal of Economics, 2007, 40 (3), 954-979.

Braun, A. R. and E. R. McGrattan, The Macroeconomics of War and Peace, in NBER Macroeconomics Annual 1993, Volume 8 NBER Chapters, National Bureau of Economic Research, Inc, 1993, pp. 197-258.

Canova, F., F. Ferroni, and C. Matthes, Detecting and Analyzing the Effects of Time-Varying Parameters in DSGE Models, International Economic Review, 2019. Forthcoming.

Chari, V. V., Patrick J. Kehoe, and Ellen R. McGrattan, Business Cycle Accounting, Econometrica, 2007, 75 (3), 781-836.

Devereux, M. B. and G. W. Smith, Transfer Problem Dynamics: Macroeconomics of the FrancoPrussian War Indemnity, Journal of Monetary Economics, 2007, 54 (8), 2375-2398.

Fishback, P., US monetary and fiscal policy in the 1930s, Oxford Review of Economic Policy, 2010, 26 (3), 385-413.

Flandreau, M. and F. Zumer, The Making of Global Finance 1880-1913, OECD Development Centre Studies, 2004. 144 pages.

Frey, B. S. and D. Waldenström, Markets Work in War: World War II Reflected in the Zurich and Stockholm Bond Markets, Financial History Review, 2004, 11 (01), 51-67.

Friedman, M. and A. J. Schwartz, A Monetary History of the United States, 1867-1960 NBER Books, National Bureau of Economic Research, Inc, July 1963.

Furlanetto, F. and M. Seneca, New Perspectives on Capital Depreciation Shocks as Sources of Business Cycle Fluctuations, Macroeconomic Dynamics, 2014, 18 (6), 1209-1233.

Ghironi, F. and M. J. Melitz, International Trade and Macroeconomic Dynamics with Heterogeneous Firms, The Quarterly Journal of Economics, 2005, 120 (3), 865-915.

Glick, R. and A. M. Taylor, Collateral Damage: Trade Disruption and the Economic Impact of War, The Review of Economics and Statistics, 2010, 92 (1), 102-127. 
Justiniano, A., G. Primiceri, and A. Tambalotti, Investment Shocks and the Relative Price of Investment, Review of Economic Dynamics, 2011, 14 (1), 101-121.

Leeper, E. M., Equilibria under 'Active' and 'Passive' Monetary and Fiscal Policies, Journal of Monetary Economics, 1991, 27 (1), 129-147.

_ , N. Traum, and T. B. Walker, Clearing Up the Fiscal Multiplier Morass, American Economic Review, 2017, 107 (8), 2409-2454.

Lucas, R. E., Models of business cycles, Oxford: Blackwell, 1987.

Martin, P., T. Mayer, and M. Thoenig, Make Trade not War?, Review of Economic Studies, 2008, 75 (3), 865-900.

McGrattan, E. R. and L. E. Ohanian, Does Neoclassical Theory Account for the Effect of Big Fiscal Shocks? Evidence from WWII, International Economic Review, 2010, 51 (2), 509-532.

Mitchell, B. R., International historical statistics: the Americas, 1750-1993. 1998. London: Macmillan Reference / New York: Stockton Press.

Monnet, C. and W. E. Weber, Money and interest rates, Quarterly Review, 2001, (Fall), 2-13.

Ohanian, L. E., The Macroeconomic Effects of War Finance in the United States: World War II and the Korean War, American Economic Review, 1997, 87 (1), 23-40.

Owyang, M. T., V. A. Ramey, and S. Zubairy, Are Government Spending Multipliers Greater during Periods of Slack? Evidence from Twentieth-Century Historical Data, American Economic Review, 2013, 103 (3), 129-34.

Piketty, T. and G. Zucman, Capital is Back: Wealth-Income Ratios in Rich Countries, 1700-2010, Quarterly Journal of Economics, 2014, 129 (3), 1255-1310.

Ramey, V. A., Can Government Purchases Stimulate the Economy?, Journal of Economic Literature, 2011, $49(3), 673-85$.

_, Identifying Government Spending Shocks : It's All in the Timing, Quarterly Journal of Economics, 2011, 126 (1), 1-50.

_ , Ten Years After the Financial Crisis: What Have We Learned from the Renaissance in Fiscal Research?, The Journal of Economic Perspectives, 2019, 33 (2), 89-114.

- and M. Shapiro, Costly Capital Reallocation and the Effects of Government Spending, Carnegie-Rochester Conference Series on Public Policy, 1997, 48 (1), 145-194.

Siu, H. E., The Fiscal Role of Conscription in the U.S. World War II Effort, Journal of Monetary Economics, 2008, 55 (6), 1094-1112. 
Smets, F. and R. Wouters, An Estimated Dynamic Stochastic General Equilibrium Model of the Euro Area, Journal of the European Economic Association, 2003, 1 (5), 1123-1175.

_ and _ , Comparing Shocks and Frictions in US and Euro Area Business Cycles: A Bayesian DSGE Approach, Journal of Applied Econometrics, 2005, 20 (2), 161-183.

Young, A. and J. C. Musgrave, Estimation of Capital Stock in the United States, in The Measurement of Capital NBER Chapters, National Bureau of Economic Research, Inc, March 1980, pp. 23-82. 


\section{A Datasets}

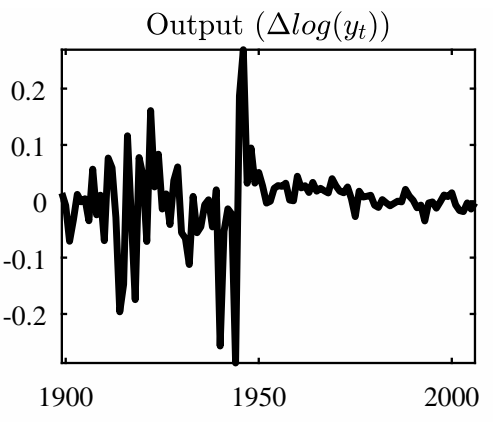

Figure 6: France
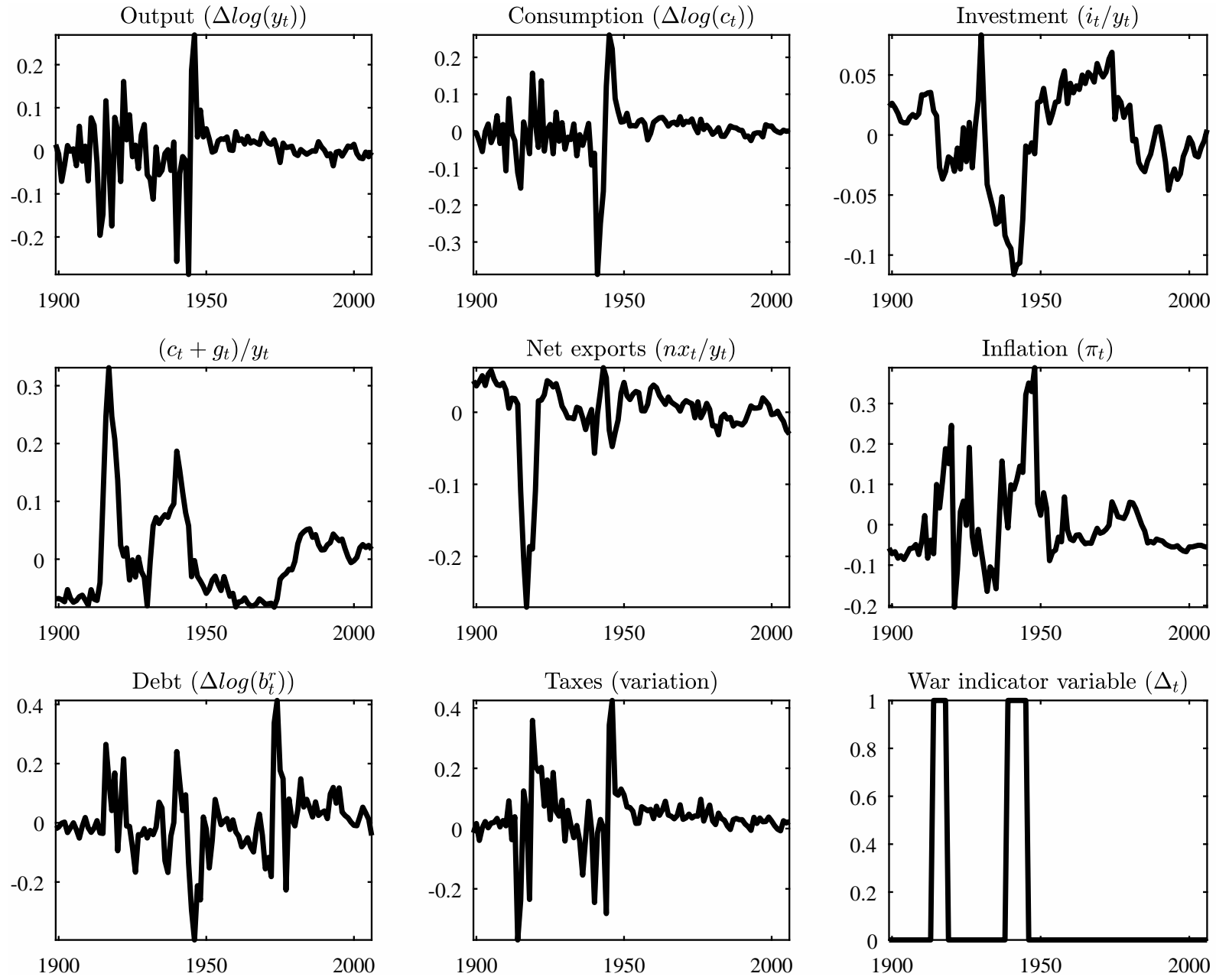
Figure 7: Germany
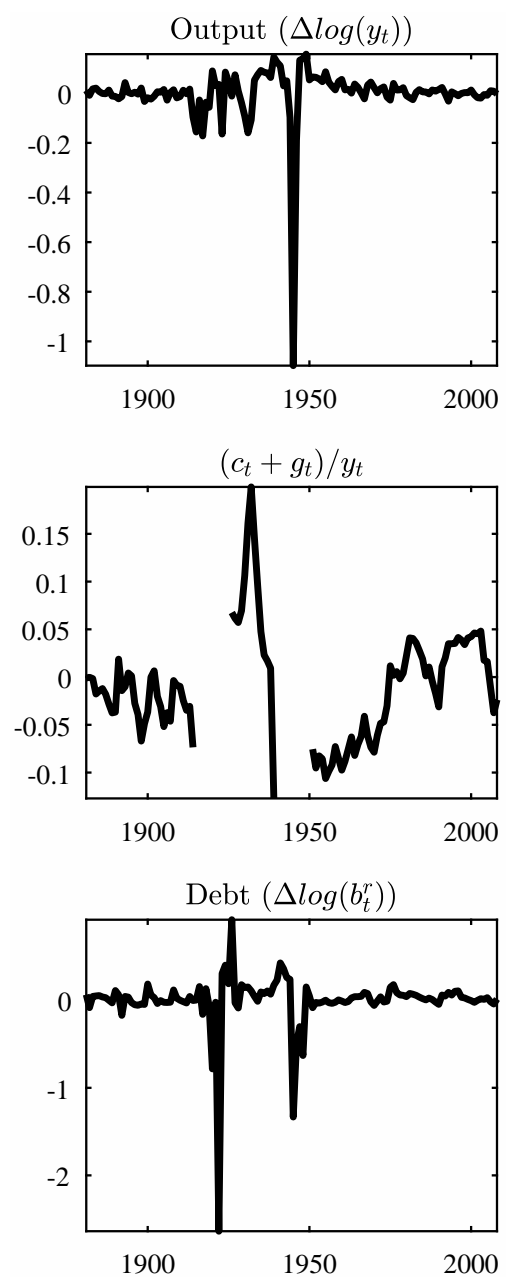
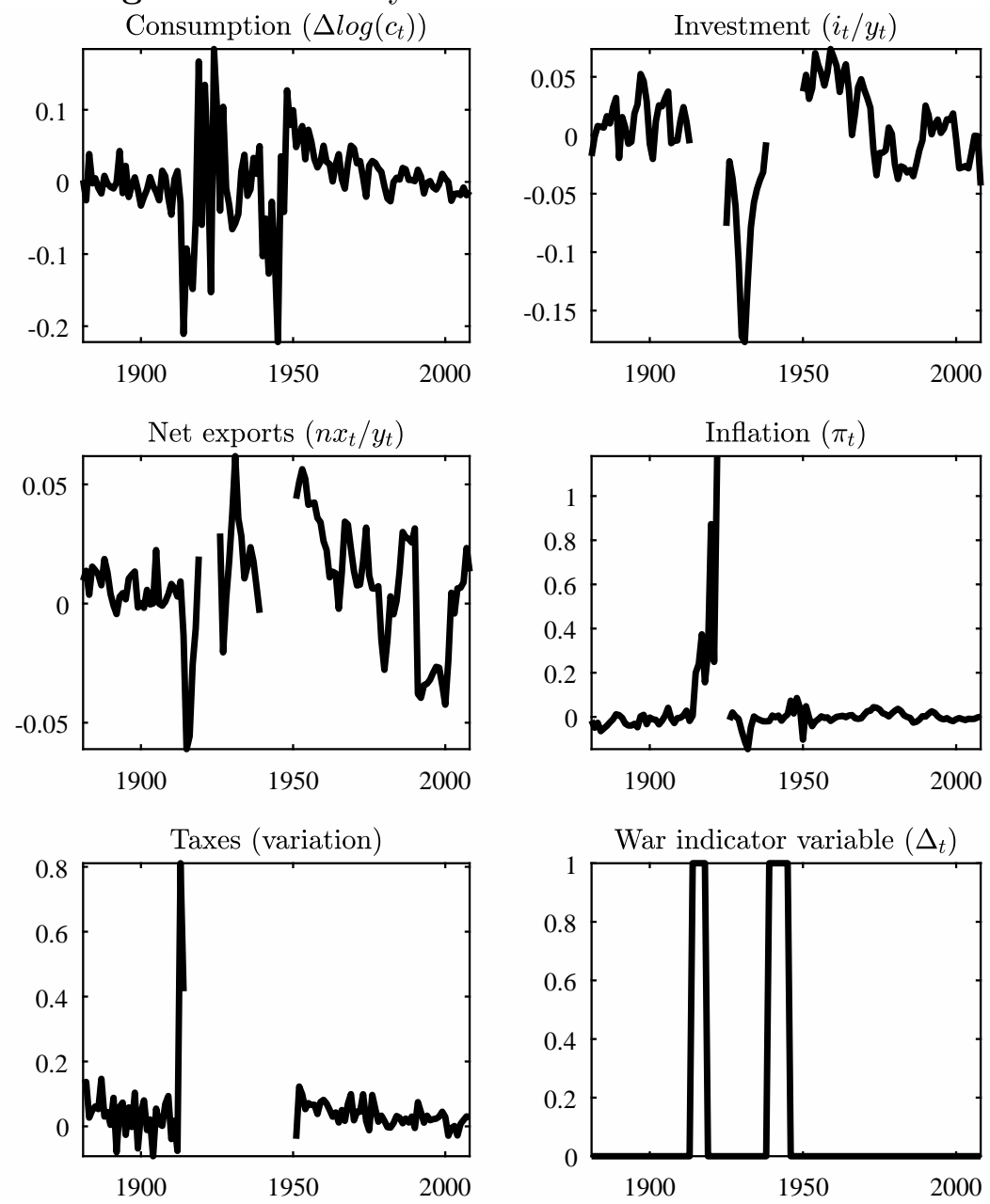


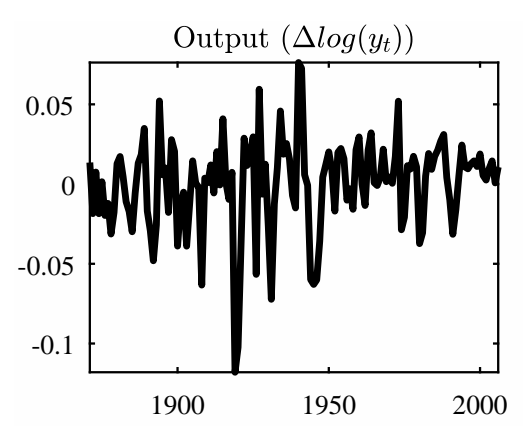

Figure 8: United Kingdom
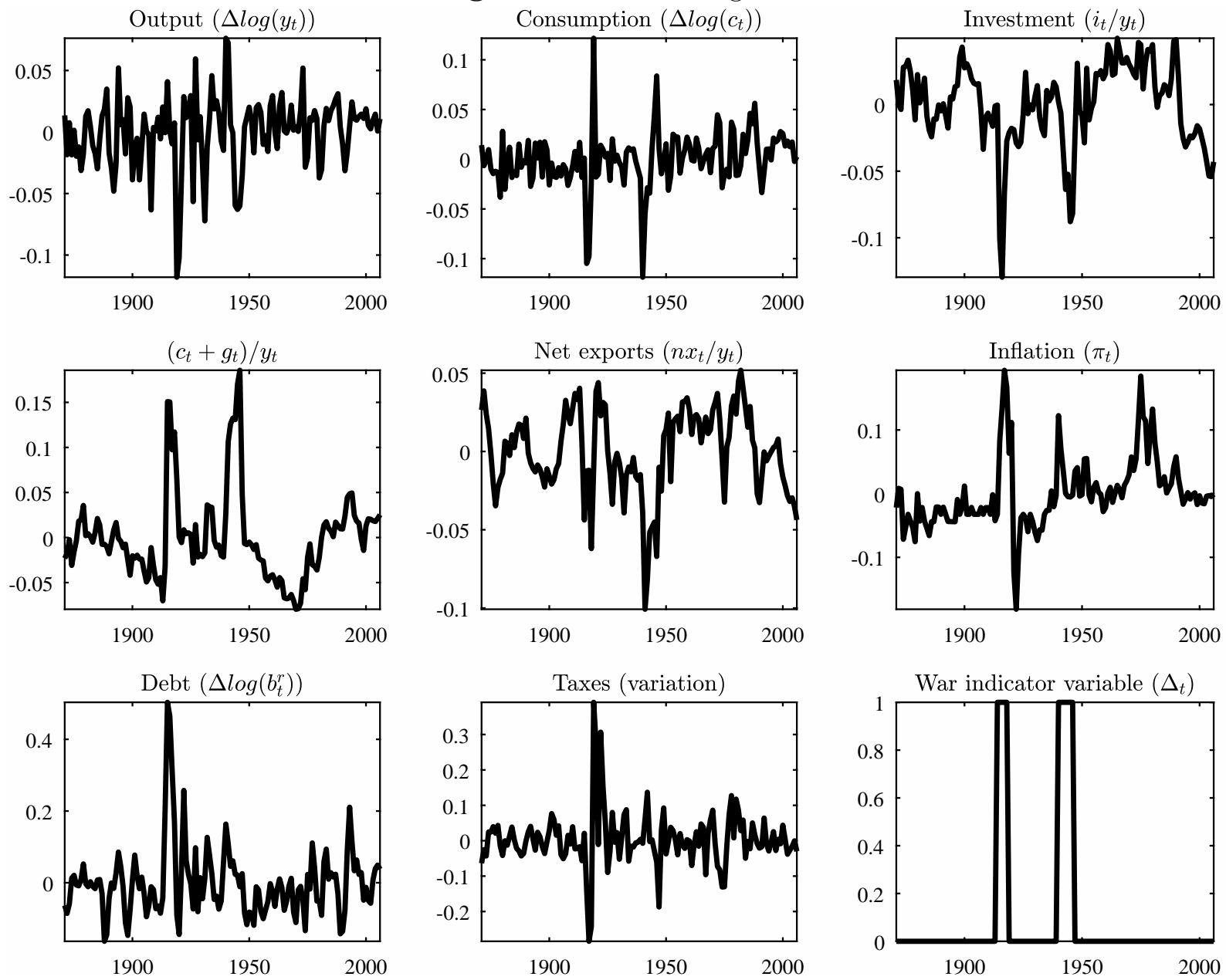
Figure 9: United States
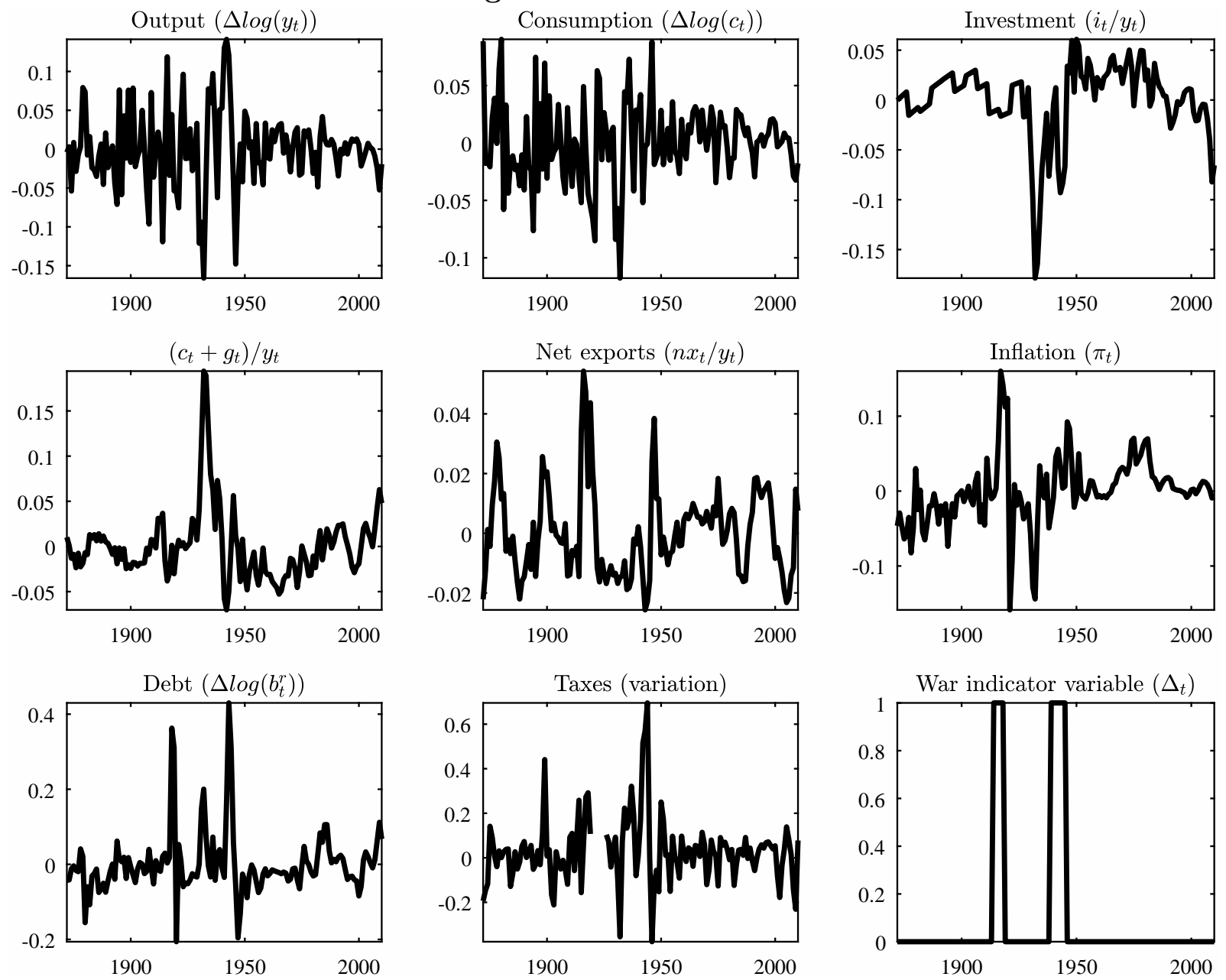


\section{B Model}

\section{B.1 Households}

We consider a unit continuum of households indexed in $j$ that maximize their lifetime welfare

$$
\mathcal{W}_{t}=E_{t}\left\{\sum_{s=t}^{\infty} \beta^{s-t}\left(\frac{\widetilde{c}_{s}(j)^{1-\sigma_{c}}}{1-\sigma_{c}}+\chi_{m} \frac{\left(m_{s}(j) / p_{s}\right)^{1-\sigma_{m}}}{1-\sigma_{m}}-\chi_{n} \frac{n_{s}(j)^{1+\psi}}{1+\psi}\right)\right\}
$$

In the welfare index, total consumption $\widetilde{c}_{s}(j)$ is a bundle of individual consumption of the private good $c_{t}(j)$ and the total consumption of public good $g_{t}$

$$
\widetilde{c}_{t}(j)=\left(\varphi c_{t}(j)^{\frac{\nu_{t}-1}{\nu_{t}}}+(1-\varphi) g_{t}^{\frac{\nu_{t}-1}{\nu_{t}}}\right)^{\frac{\nu_{t}-1}{\nu_{t}}}, \nu_{t}>0
$$

When $\nu_{t}>1$, private and public goods are substitutes while $\nu_{t}<1$ implies complementarity. We introduce the possibility that this parameter takes different values whether countries experience a war episode or not, that is

$$
\nu_{t}=\left(1-\Delta_{t}\right) \nu_{n o r m}+\Delta_{t} \nu_{w a r}
$$

where $\Delta_{t}=\{0,1\}$ is an indicator variable that equals one during war episodes and zero in normal times. Regarding other variables of the welfare index, $m_{t}(j) / p_{t}$ is the level of real money balances, and $n_{t}(j)$ is the total amount of labor supply, expressed in hours. Parameters $\sigma_{c}$ and $\sigma_{m}$ are the degrees of risk-aversion with respect to total consumption and real money balances, and $\psi$ is the inverse of the Frisch elasticity of labor supply.

The budget constraint of agent $j$ is

$$
\begin{aligned}
e_{t} f_{t}(j)+b_{t}(j) & +m_{t}(j)+p_{t}\left(c_{t}(j)+i_{t}(j)+a c_{t}^{f}(j)\right)=e_{t} r^{*} f_{t-1}(j)+r_{t-1}\left(1-\Delta_{t} p^{b}\right) b_{t-1}(j) \\
& +m_{t-1}(j)+\left(\left(1-\tau_{t}^{k}\right) r_{t}^{k} z_{t}(j)-p_{t} a c_{t}^{z}(j)+p_{t} \tau_{t}^{k} \delta_{t}\right) k_{t-1}(j) \\
& +\left(1-\tau_{t}^{n}\right) w_{t}(j) n_{t}(j)+\Pi_{t}(j)+\operatorname{tax}_{t}(j)
\end{aligned}
$$

In this equation, $e_{t}$ is the nominal exchange rate, $f_{t}(j)$ denotes the nominal value of foreign bonds returning a constant risk-free rate $r^{*}$ between period $t$ and $t+1$ and $b_{t}(j)$ denotes the nominal value of government bonds returning a nominal rate $r_{t}$ between period $t$ and $t+1$. Government bonds can be subject to partial default that lowers the face value of the stock of public debt by $p^{b}$ percents in the event of a war episode. Further, $p_{t}$ is the consumption price level, $i_{t}(j)$ is the investment in physical capital, $\tau_{t}^{n}$ is the labor income tax rate, $w_{t}(j)$ is the nominal wage rate paid to type- $j$ labor, $\tau_{t}^{k}$ the tax rate on capital income, that comes with a tax deduction on depreciated capital, $r_{t}^{k}$ is the gross nominal return on the capital stock, $z_{t}(j)$ is the utilization rate of private capital, $\delta_{t}$ the time-varying depreciation rate of capital. Variable $\operatorname{tax}_{t}$ 
is a lump-sum transfer that is rebated to the households. Capital depreciation is an additional channel through which war episodes can affect the dynamics of the economy as we assume

$$
\delta_{t}=\delta\left(1+\Delta_{t} p^{\delta}\right)
$$

Finally, $a c_{t}^{f}(j)=\left(\phi_{f} / 2\right)\left(e_{t} f_{t}(j) / p_{t}-e f(j) / p\right)^{2}$ is an adjustment cost on real net foreign assets, $a c_{t}^{z}(j)=\left(\phi_{z} / 2\right)\left(z_{t}(j)-1\right)^{2}$ is a utilization rate adjustment cost and $\Pi_{t}(j)$ denotes the profits from monopolistic firms paid to household $j$. An additional constraint to this optimization problem is the law of capital accumulation

$$
k_{t}(j)=\left(1-\delta_{t}\right) k_{t-1}(j)+\zeta_{t}\left(1-\frac{\phi_{i}}{2}\left(\frac{i_{t}(j)}{i_{t-1}(j)}-1\right)^{2}\right) i_{t}(j)
$$

The latter is subject to investment adjustment costs and to investment shocks $\zeta_{t}$. Formally the law of motion of investment shocks is:

$$
\zeta_{t}=\left(1-\rho_{\zeta}\right)+\rho_{\zeta} \zeta_{t-1}+\phi_{\zeta} \Delta_{t}+\varepsilon_{t}^{\zeta}
$$

Households maximize the welfare function subject to the budget constraints with respect to consumption, government and foreign bonds, as well as the quantity of money. First-order conditions imply

$$
\begin{aligned}
\beta E_{t}\left\{\frac{u_{c, t+1}(j)}{u_{c, t}(j)} \frac{r_{t}\left(1-\Delta_{t+1} p^{b}\right)}{\pi_{t+1}}\right\} & =1 \\
\beta E_{t}\left\{\frac{u_{c, t+1}(j)}{u_{c, t}(j)} \frac{e_{t+1} r^{*}}{e_{t} \pi_{t+1}\left(1+\phi_{f}\left(f_{t}^{r}(j)-f^{r}\right)\right)}\right\} & =1 \\
u_{m, t}(j)-u_{c, t}(j) E_{t}\left\{\frac{r_{t}\left(1-\Delta_{t+1} p^{b}\right)-1}{r_{t}\left(1-\Delta_{t+1} p^{b}\right)}\right\} & =0
\end{aligned}
$$

where $\pi_{t}=p_{t} / p_{t-1}$ is the CPI inflation rate, $u_{c, t}(j)$ is the marginal utility of consumption, $u_{m, t}(j)$ the marginal utility of real money balances, and $f_{t}^{r}(j)=e_{t} f_{t}(j) / p_{t}$ the real value of net foreign assets. The different types of labor offered by households are imperfectly substitutable, making them monopolistic wage-setters. Labor demands are

$$
n_{t}(j, \omega)=\left(\frac{w_{t}(j)}{w_{t}}\right)^{-\theta^{w}} n_{t}(\omega)
$$

where $\theta^{w}$ is the elasticity of substitution between types of labor. Those demands are taken into account by households along with the constraints when optimizing. Further, we assume sticky wages whereby wage-setters face an individual probability $1-\eta^{w}$ to be allowed to re-optimize and a probability $\eta^{w}$ to keep their previous-period nominal wage unchanged. The corresponding 
optimal nominal wage $\mathbf{w}_{t}(j)$ is thus

$$
\sum_{i=0}^{\infty}\left(\beta \eta^{w}\right)^{i} E_{t}\left\{n_{t+i}(j)\left(\frac{\theta^{w}}{\theta^{w}-1} \frac{u_{n, t+i}(j)}{u_{c, t+i}(j)}+\left(1-\tau_{t}^{n}\right) \frac{\mathrm{w}_{t}(j)}{p_{t+i}}\right)\right\}=0
$$

where $u_{n, t}(j)$ is the marginal disutility of hours worked. The dynamics of nominal wages are

$$
w_{t}^{1-\theta^{w}}=\eta^{w}\left(w_{t-1}\right)^{1-\theta^{w}}+\left(1-\eta^{w}\right) \mathbf{w}_{t}(j)^{1-\theta^{w}}
$$

From now on we assume perfect risk-sharing among households and drop the $j$ indices. Defining $q_{t} p_{t} \lambda_{t}$ as the Lagrange multiplier associated with the capital accumulation constraint, first-order conditions with respect to the capital stock, investment, and utilization are respectively:

$$
\begin{aligned}
\beta E_{t}\left\{\frac{u_{c, t+1}}{u_{c, t}}\left(q_{t+1}\left(1-\delta_{t+1}\right)+\left(1-\tau_{t+1}^{k}\right) \frac{r_{t+1}^{k}}{p_{t+1}}+\tau_{t+1}^{k} \delta_{t+1}\right)\right\} & =q_{t} \\
q_{t} \zeta_{t}\left(1-\frac{\phi_{i}}{2} \gamma_{t}^{2}-\phi_{i} \gamma_{t}\left(1+\gamma_{t}\right)\right)+\beta E_{t}\left\{\frac{u_{c, t+1}}{u_{c, t}} q_{t+1} \zeta_{t+1} \phi_{i} \gamma_{t+1}\left(1+\gamma_{t+1}\right)^{2}\right\} & =1 \\
\left(1-\tau_{t}^{k}\right) r_{t}^{k}-\phi_{z}\left(z_{t}-1\right) & =0
\end{aligned}
$$

where $\gamma_{t}=\left(i_{t} / i_{t-1}\right)-1$ is the growth rate of private investment. Consumption and capital goods are made of domestic $(d)$ and foreign $(f)$ goods. Adjustment costs are also paid in units of that composite good. The latter is defined as:

$$
x_{t}=\left((1-\alpha)^{\frac{1}{\mu}} x_{d, t}^{\frac{\mu-1}{\mu}}+\alpha^{\frac{1}{\mu}} x_{f, t}^{\frac{\mu-1}{\mu}}\right)^{\frac{\mu}{\mu-1}}, x=\left\{c, i, a c^{f}, a c^{z}, a c^{i}\right\}
$$

where $1-\alpha$ is the degree of home bias and $\mu$ the elasticity of substitution between domestic and foreign goods. The corresponding price index is

$$
p_{t}=\left((1-\alpha) p_{d, t}^{1-\mu}+\alpha\left(e_{t} p_{f, t}\right)^{1-\mu}\right)^{\frac{1}{1-\mu}}
$$

where $p_{d, t}$ and $p_{f, t}$ respectively denote the prices of domestic and foreign goods, expressed in units of local currency, and where $e_{t}$ is the nominal exchange rate. Optimal expenditure on each good implies

$$
\begin{aligned}
& x_{d, t}=(1-\alpha)\left(\frac{p_{d, t}}{p_{t}}\right)^{-\mu} x_{t}=(1-\alpha)\left(1-\alpha+\alpha s_{t}^{1-\mu}\right)^{\frac{\mu}{1-\mu}} x_{t} \\
& x_{f, t}=\alpha\left(\frac{e_{t} p_{f, t}}{p_{t}}\right)^{-\mu} x_{t}=\alpha\left((1-\alpha) s_{t}^{\mu-1}+\alpha\right)^{\frac{\mu}{1-\mu}} x_{t}
\end{aligned}
$$

for $x=\left\{c, i, a c^{f}, a c^{z}, a c^{i}\right\}$ where $s_{t}=e_{t} p_{f, t} / p_{d, t}$ stands for terms of trade. 


\section{B.2 Firms}

There is a continuum of final good producers indexed in $\omega$, with the following production function

$$
y_{t}(\omega)=a_{t} k_{t}^{s}(\omega)^{\iota}\left(\left(1-\Delta_{t} p^{\ell}\right) \ell_{t}(\omega)\right)^{1-\iota}
$$

where $k_{t}^{s}$ is a measure of capital services used in production and $\left(1-\Delta_{t} p^{\ell}\right) \ell_{t}$ is the amount of labor that firms use to produce. Total labor $\ell_{t}$ is affected by a military draft that lowers the amount of labor used by private firms during war episodes. Finally, $a_{t}$ is a productivity measure following an autoregressive process. Again, we introduce the possibility that war episodes have indirect effects on productivity through channels that are not explicitly specified in the model:

$$
a_{t}=\left(1-\rho_{a}\right)+\rho_{a} a_{t-1}+\phi_{a} \Delta_{t}+\varepsilon_{t}^{a}
$$

Cost minimization implies

$$
k_{t}^{s}(\omega)=\frac{\iota}{1-\iota} \frac{w_{t}}{r_{t}^{k}} \ell_{t}(\omega)
$$

which can be used to derive an expression of the nominal marginal cost

$$
m c_{t}(\omega)=m c_{t}=\frac{\left(r_{t}^{k}\right)^{\iota}\left(w_{t}\right)^{1-\iota}\left((1-\iota)\left(1-\Delta_{t} p^{\ell}\right)+\iota\right)}{a_{t} \iota^{\iota}(1-\iota)^{(1-\iota)}\left(1-\Delta_{t} p^{\ell}\right)^{1-\iota}}
$$

The adjustment of production prices is also subject to Calvo contracts. Re-setters face the following problem

$$
\max _{\mathbf{p}_{d, t}(\omega)} \sum_{i=0}^{\infty}\left(\beta \eta^{p}\right)^{i} E_{t}\left\{\frac{u_{c, t+i}}{u_{c, t}} \frac{p_{t}}{p_{t+i}}\left(\mathbf{p}_{d, t}(\omega) y_{t+i}(\omega)-m c_{t+i} y_{t+i}(\omega)\right)\right\}
$$

taking into account the demand addressed to firm $\omega$

$$
y_{d, t}(\omega)=\left(\frac{p_{d, t}(\omega)}{p_{d, t}}\right)^{-\theta^{p}} y_{d, t}
$$

The optimal pricing condition is thus

$$
\sum_{i=0}^{\infty}\left(\beta \eta^{p}\right)^{i} E_{t}\left\{\frac{u_{c, t+i}}{p_{t+i}} y_{t+i}(\omega)\left(\mathrm{p}_{d, t}(\omega)-\frac{\theta^{p}}{\theta^{p}-1} m c_{t+i}\right)\right\}=0
$$

while the dynamics of prices are given by

$$
p_{d, t}^{1-\theta^{p}}=\eta^{p}\left(p_{d, t-1}\right)^{1-\theta^{p}}+\left(1-\eta^{p}\right) \mathrm{p}_{d, t}(\omega)^{1-\theta^{p}}
$$




\section{B.3 Monetary policy, government and aggregation}

The government is in charge of both monetary policy, public spending and fiscal policy. Its budget constraint is

$$
\begin{aligned}
b_{t}+m_{t}+\tau_{t}^{n} w_{t} n_{t} & +\tau_{t}^{k}\left(r_{t}^{k} z_{t}-p_{t} \delta_{t}\right) k_{t-1}+\operatorname{tax}_{t} \\
& =r_{t-1}\left(1-\Delta_{t} p^{b}\right) b_{t-1}+m_{t-1}+\Delta_{t} p^{\ell} w_{t} \ell_{t}+p_{d, t}\left(g_{t}+i_{t}^{g}\right)
\end{aligned}
$$

The left-hand side shows government revenues and the right-hand side features government expenditure. In particular, the government has to pay drafted people. We assume that fiscal solvency is achieved in the medium run by tax rules and a government spending rule. These rules imply that policy instruments react to the deviations of real public debt to its steady state value. In addition, we consider war-specific spillovers on taxes and spending. Finally, policy instruments are also affected by autoregressive exogenous shocks:

$$
\begin{aligned}
g_{t} & =g+d_{\tau_{n}}\left(b r_{t-1}-b r\right)+\phi_{g} \Delta_{t}+s_{t}^{g} \\
\tau_{t}^{n} & =\tau^{n}+d_{\tau^{n}}\left(b r_{t-1}-b r\right)+\phi_{\tau^{n}} \Delta_{t}+s_{t}^{\tau^{n}} \\
\tau_{t}^{k} & =\tau^{k}+d_{\tau^{k}}\left(b r_{t-1}-b r\right)+\phi_{\tau^{k}} \Delta_{t}+s_{t}^{\tau^{k}}
\end{aligned}
$$

where

$$
\begin{aligned}
s_{t}^{g} & =\rho_{g} s_{t-1}^{g}+\varepsilon_{t}^{g} \\
s_{t}^{\tau_{n}} & =\rho_{\tau_{n}} s_{t-1}^{\tau_{n}}+\varepsilon_{t}^{\tau_{n}} \\
s_{t}^{\tau_{k}} & =\rho_{\tau_{k}} s_{t-1}^{\tau_{k}}+\varepsilon_{t}^{\tau_{k}}
\end{aligned}
$$

Finally, we consider that money supply grows at a rate $\mu_{t}^{m}=m_{t} / m_{t-1}$ that follows an $\operatorname{AR}(1)$ process augmented with a potential war-specific component:

$$
\mu_{t}^{m}=\left(1-\rho_{m}\right)+\rho_{m} \mu_{t-1}^{m}+\phi_{\mu} \Delta_{t}+\varepsilon_{t}^{m}
$$

Further, as in Auray et al. (2014), the government adjusts the amount of public investment to secure a given constant level of public unproductive capital $k^{g}$ :

$$
i_{t}^{g}=\delta_{t} k^{g}
$$

An equilibrium of the model is as a path of endogenous variables that, conditional on the dynamics of exogenous variables, $(i)$ satisfies households and firms first-order conditions, and (ii) clears markets. Equilibrium in the labor market implies

$$
\ell_{t}=\int_{0}^{1} \ell_{t}(\omega) d \omega=\int_{0}^{1} \int_{0}^{1} n_{t}(j, \omega) d j d \omega=\Upsilon_{t}^{w} n_{t}
$$


where $\Upsilon_{t}^{w}=\int_{0}^{1}\left(w_{t}(j) / w_{t}\right)^{-\theta^{w}} d j$ is the dispersion of wages. Equilibrium in the market for capital services gives

$$
k_{t}^{s}=\int_{0}^{1} k_{t}^{s}(\omega) d \omega=z_{t} k_{t-1}
$$

and equilibrium in goods market implies

$$
y_{t}=(1-\alpha)\left(\frac{p_{d, t}}{p_{t}}\right)^{-\mu} y_{t}^{d}+\alpha\left(\frac{p_{d, t}}{p_{t}^{*}}\right)^{-\mu} y_{t}^{*}+g_{t}+i_{t}+i_{t}^{g}
$$

where $y_{t}^{d}=c_{t}+i_{t}+\phi_{f}\left(f_{t}^{r}-f^{r}\right)^{2} / 2+\left(\phi_{z}\left(z_{t}-1\right)^{2} / 2\right) k_{t-1}$ and $y_{t}^{*}$ is the foreign counterpart of $y_{t}^{d}$. It is subject to autoregressive shocks, and augmented with a war-specific component:

$$
y_{t}^{*}=\left(1-\rho_{y^{*}}\right) y^{*}+\rho_{y^{*}} y_{t-1}^{*}+\phi_{y^{*}} \Delta_{t}+\varepsilon_{t}^{y^{*}}
$$

Finally, the aggregate production function is

$$
\Upsilon_{t}^{p} y_{t}=a_{t}\left(z_{t} k_{t-1}\right)^{\iota}\left(\Upsilon_{t}^{w}\left(1-\Delta_{t} p^{\ell}\right) n_{t}\right)^{1-\iota}
$$

where $\Upsilon_{t}^{p}=\int_{0}^{1}\left(p_{d, t}(\omega) / p_{d, t}\right)^{-\theta^{p}} d \omega$ is the dispersion of producer prices. This open economy model is closed by the net foreign asset equation, obtained by consolidating households, firms and government budget constraints

$$
f_{t}^{r}=\left(\frac{e_{t}}{e_{t-1}}\right) \frac{r^{*} f_{t-1}^{r}}{\pi_{t}}+n x_{t}
$$

where $n x_{t}$ stands for net exports, defined as

$$
n x_{t}=\frac{p_{d, t}}{p_{t}}\left(y_{t}-g_{t}-i_{t}^{g}\right)-c_{t}-i_{t}-\frac{\phi_{f}}{2}\left(f_{t}^{r}-f^{r}\right)^{2}-\frac{\phi_{z}}{2}\left(z_{t}-1\right)^{2} k_{t-1}
$$

\section{B.4 The steady state}

We analyze the linearized dynamics of the model around the closed economy steady-state without inflation, where we also assume $s=1$. The steady-state of the economy is one where the war indicator variable is zero, i.e. $\Delta=0$. Further, by definition, $\gamma=0$, and the dynamics of $q$ gives $q=1$. The condition on the utilization rate thus gives

$$
r^{k}=\frac{\phi_{z}(z-1)}{1-\tau^{k}}
$$

which plugged in the investment equation pins down $z$

$$
z=\sqrt{1+\frac{2\left(\beta^{-1}+\delta\left(1-\tau^{k}\right)-1\right)}{\phi_{z}}}
$$


as well as $r^{k}$. Next use the real marginal cost to get the real wage $w$

$$
w=\left(\frac{(\theta-1)}{\theta} \iota^{\iota}(1-\iota)^{(1-\iota)}\left(r^{k}\right)^{-\iota}\right)^{\frac{1}{1-\iota}}
$$

Further, we impose $a=n=1$ and use

$$
k=\frac{\iota}{1-\iota} \frac{w}{r^{k} z}
$$

and the aggregate production function

$$
y=(z k)^{\iota}
$$

to get consumption

$$
c=\left(1-\kappa-\kappa^{i}\right) y-\delta k-\frac{\phi_{z}}{2}(z-1)^{2} k
$$

where $\kappa=g / y$ and $\kappa^{i}=i^{g} / y$ are the (imposed) steady-state share of public consumption and investment expenditure in GDP. Finally, the steady-state wage-setting equation gives the value of $\chi_{n}$ that normalizes $n$ to one. 


\section{B.5 Set of estimated equations}

$\underline{\text { Households }}$

$$
\begin{aligned}
u_{t} & =\left(1-\sigma_{c}\right)^{-1} \widetilde{c}_{t}^{1-\sigma_{c}}+\chi_{m} \frac{\left(m_{t}^{r}\right)^{1-\sigma_{m}}}{1-\sigma_{m}}-\chi_{n} \frac{n_{t}^{1+\psi}}{1+\psi} \\
\widetilde{c}_{t} & =\left(\varphi c_{t}^{\frac{\nu_{t}-1}{\nu_{t}}}+(1-\varphi) g_{t}^{\frac{\nu_{t}-1}{\nu_{t}}}\right)^{\frac{\nu_{t}-1}{\nu_{t}}} \\
u_{c, t} & =\varphi c_{t}^{\frac{\nu_{t}-1}{\nu_{t}}}\left(\left(\varphi c_{t}^{\frac{\nu_{t}-1}{\nu_{t}}}+(1-\varphi) g_{t}^{\frac{\nu_{t}-1}{\nu_{t}}}\right)^{\frac{\nu_{t}-1}{\nu_{t}}}\right)^{1-\sigma_{c}} /\left(c_{t}\left(\varphi c_{t}^{\frac{\nu_{t}-1}{\nu_{t}}}+(1-\varphi) g_{t}^{\frac{\nu_{t}-1}{\nu_{t}}}\right)\right) \\
u_{m, t} & =\chi_{m}\left(m_{t}^{r}\right)^{-\sigma_{m}} \\
u_{n, t} & =-\chi_{n} n_{t}^{\psi} \\
1 & =\beta E_{t}\left\{\frac{u_{c, t+1}}{u_{c, t}} \frac{r_{t}\left(1-\Delta_{t+1} p^{b}\right)}{\pi_{t+1}}\right\} \\
1 & =\beta E_{t}\left\{\frac{u_{c, t+1}}{u_{c, t}} \frac{d_{t+1}^{e} r^{*}}{\pi_{t+1}\left(1+\phi_{f} f_{t}^{r}\right)}\right\} \\
u_{m, t} & =u_{c, t} E_{t}\left\{\frac{r_{t}\left(1-\Delta_{t+1} p^{b}\right)-1}{r_{t}\left(1-\Delta_{t+1} p^{b}\right)}\right\} \\
q_{t} & =\beta E_{t}\left\{\frac{u_{c, t+1}}{u_{c, t}}\left(q_{t+1}\left(1-\delta_{t+1}\right)+\left(1-\tau_{t+1}^{k}\right) r_{t+1}^{r k}+\tau_{t+1}^{k} \delta_{t+1}\right)\right\} \\
1 & =q_{t} \zeta_{t}\left(1-\frac{\phi_{i}}{2} \gamma_{t}^{2}-\phi_{i} \gamma_{t}\left(1+\gamma_{t}\right)\right)+\beta E_{t}\left\{\frac{u_{c, t+1}}{u_{c, t}} q_{t+1} \zeta_{t+1} \phi_{i} \gamma_{t+1}\left(1+\gamma_{t+1}\right)^{2}\right\} \\
\gamma_{t} & =i_{t} / i_{t-1}-1 \\
k_{t} & =\left(1-\delta_{t}\right) k_{t-1}+\zeta_{t}\left(1-\frac{\phi_{i}}{2} \gamma_{t}^{2}\right) i_{t}
\end{aligned}
$$

where $d_{t}^{e}=e_{t} / e_{t-1}$ and $r_{t}^{r k}=r_{t}^{k} / p_{t}$.

$\underline{\text { Firms }}$

$$
\begin{aligned}
r_{t}^{r k} & =\phi_{z}\left(z_{t}-1\right) /\left(1-\tau_{t}^{k}\right) \\
k_{t} & =\iota w_{t}^{r} n_{t} /\left((1-\iota) z_{t} r_{t}^{r k}\right) \\
m c_{t}^{r} & =\frac{\left(r_{t}^{r k}\right)^{\iota}\left(w_{t}^{r}\right)^{1-\iota}\left((1-\iota)\left(1-\Delta_{t} p^{\ell}\right)+\iota\right)}{a_{t} \iota^{\iota}(1-\iota)^{(1-\iota)}\left(1-\Delta_{t} p^{\ell}\right)^{1-\iota}} \\
\Upsilon_{t}^{p} y_{t} & =a_{t}\left(z_{t} k_{t-1}\right)^{\iota}\left(\Upsilon_{t}^{w}\left(1-\Delta_{t} p^{\ell}\right) n_{t}\right)^{1-\iota}
\end{aligned}
$$

where $w_{t}^{r}=w_{t} / p_{t}$ and $m c_{t}^{r}=m c_{t} / p_{t}$ 
$\underline{\text { Wage and produce price inflation }}$

$$
\begin{aligned}
\left(\pi_{t}^{w}\right)^{\theta^{w}-1} & =\left(1-\left(1-\eta^{w}\right)\left(w_{t}^{1} / w_{t}^{2}\right)^{1-\theta^{w}}\right) / \eta^{w} \\
w_{t}^{1} & =\beta \eta^{w} E_{t}\left\{w_{t+1}^{1}\left(\pi_{t+1}^{w}\right)^{1+\theta^{w}} / \pi_{t+1}\right\}+\left(\theta^{w} /\left(\theta^{w}-1\right)\right)\left(-u_{n, t} / u_{c, t}\right) /\left(\left(1-\tau_{t}^{n}\right) w_{t}^{r}\right) \\
w_{t}^{2} & =\beta \eta^{w} E_{t}\left\{w_{t+1}^{2}\left(\pi_{t+1}^{w}\right)^{\theta^{w}} / \pi_{t+1}\right\}+n_{t} \\
\Upsilon_{t}^{w} & =\eta^{w} \Upsilon_{t-1}^{w}\left(\pi_{t}^{w}\right)^{\theta^{w}}+\left(1-\eta^{w}\right)\left(w_{t}^{1} / w_{t}^{2}\right)^{-\theta^{w}} \\
\left(\pi_{t}^{d}\right)^{\theta^{p}-1} & =\left(1-\left(1-\eta^{p}\right)\left(p_{t}^{1} / p_{t}^{2}\right)^{1-\theta^{p}}\right) / \eta^{p} \\
p_{t}^{1} & =\beta \eta^{p} E_{t}\left\{p_{t+1}^{1}\left(\pi_{t+1}^{d}\right)^{1+\theta^{p}} / \pi_{t+1}\right\}+\left(\theta^{p} /\left(\theta^{p}-1\right)\right) u_{c, t} y_{t} m c_{t}^{r}\left(1-\alpha+\alpha s_{t}^{1-\mu}\right)^{1 /(\mu-1)} \\
p_{t}^{2} & =\beta \eta^{p} E_{t}\left\{p_{t+1}^{2}\left(\pi_{t+1}^{d}\right)^{\theta^{p}} / \pi_{t+1}\right\}+u_{c, t} y_{t} \\
\Upsilon_{t}^{p} & =\eta^{p} \Upsilon_{t-1}^{p}\left(\pi_{t}^{p}\right)^{\theta^{p}}+\left(1-\eta^{p}\right)\left(p_{t}^{1} / p_{t}^{2}\right)^{-\theta^{p}}
\end{aligned}
$$

Consumer price inflation and terms of trade

$$
\begin{aligned}
\pi_{t} & =\pi_{t}^{d}\left(\left(1-\alpha+\alpha s_{t}^{1-\mu}\right) /\left(1-\alpha+\alpha s_{t-1}^{1-\mu}\right)\right)^{1 /(1-\mu)} \\
s_{t} / s_{t-1} & =d_{t+1}^{e} \pi^{*} / \pi_{t}^{d}
\end{aligned}
$$

where $\pi^{*}=1$.

Goods market clearing, net foreign assets, net exports

$$
\begin{aligned}
y_{t} & =(1-\alpha)\left(1-\alpha+\alpha s_{t}^{1-\mu}\right)^{\mu /(1-\mu)}\left(c_{t}+i_{t}+\phi_{f}\left(f_{t}^{r}\right)^{2} / 2+\left(\phi_{z}\left(z_{t}-1\right)^{2} / 2\right) k_{t-1}\right) \\
& +\alpha\left(\alpha+(1-\alpha) s_{t}^{1-\mu}\right)^{\mu /(1-\mu)} y_{t}^{*}+g_{t}+i_{t}+i_{t}^{g} \\
f_{t}^{r} & =\beta^{-1} d_{t}^{e} f_{t-1}^{r} / \pi_{t}+n x y_{t} \times y_{t} \\
n x y_{t} & =\left[\left(1-\alpha+\alpha s_{t}^{1-\mu}\right)^{1 /(\mu-1)}\left(y_{t}-g_{t}-i_{t}^{g}\right)-c_{t}-i_{t}-\frac{\phi_{f}}{2}\left(f_{t}^{r}\right)^{2}-\frac{\phi_{z}}{2}\left(z_{t}-1\right)^{2} k_{t-1}\right] / y_{t}
\end{aligned}
$$

$\underline{\text { Government }}$

$$
\begin{aligned}
i_{t}^{g} & =\delta_{t} k^{g}=\delta_{t}\left(\kappa^{i} y / \delta\right) \\
m_{t}^{r} / m_{t-1}^{r} & =\mu_{t}^{m} / \pi_{t} \\
b_{t}^{r} & +\left(m_{t}^{r}+\left(\tau_{t}^{n}-\Delta_{t} p^{\ell}\right) w_{t}^{r} n_{t}+\tau_{t}^{k}\left(r_{t}^{r k} z_{t}-\delta_{t}\right) k_{t-1}\right)\left(1-\alpha+\alpha s_{t}^{1-\mu}\right)^{1 /(1-\mu)} \\
& =r_{t-1}\left(1-\Delta_{t} p^{b}\right) b_{t-1}^{r} / \pi_{t}^{d}-\phi_{b}\left(b_{t}^{r}-b^{r}\right)+\pi_{t} m_{t-1}^{r} / \pi_{t}^{d}+g_{t}+i_{t}^{g} \\
g_{t} & =g+d_{\tau_{n}}\left(b r_{t-1}-b r\right)+\phi_{g} \Delta_{t}+s_{t}^{g} \\
\tau_{t}^{n} & =\tau^{n}+d_{\tau^{n}}\left(b r_{t-1}-b r\right)+\phi_{\tau^{n}} \Delta_{t}+s_{t}^{\tau^{n}} \\
\tau_{t}^{k} & =\tau^{k}+d_{\tau^{k}}\left(b r_{t-1}-b r\right)+\phi_{\tau^{k}} \Delta_{t}+s_{t}^{\tau^{k}}
\end{aligned}
$$


$\underline{\text { Switching parameters and shocks }}$

$$
\begin{aligned}
\nu_{t} & =\left(1-\Delta_{t}\right) \nu_{n o r m}+\Delta_{t} \nu_{w a r} \\
\delta_{t} & =\delta\left(1+\Delta_{t} p^{\delta}\right) \\
a_{t} & =\left(1-\rho_{a}\right)+\rho_{a} a_{t-1}+\phi_{a} \Delta_{t}+\varepsilon_{t}^{a} \\
s_{t}^{g} & =\rho_{g} s_{t-1}^{g}+\varepsilon_{t}^{g} \\
\zeta_{t} & =\left(1-\rho_{\zeta}\right)+\rho_{\zeta} \zeta_{t-1}+\phi_{\zeta} \Delta_{t}+\varepsilon_{t}^{\zeta} \\
y_{t}^{*} & =\left(1-\rho_{y^{*}}\right) y^{*}+\rho_{y^{*}} y_{t-1}^{*}+\phi_{y^{*}} \Delta_{t}+\varepsilon_{t}^{y^{*}} \\
s_{t}^{\tau_{n}} & =\rho_{\tau_{n}} s_{t-1}^{\tau_{n}}+\varepsilon_{t}^{\tau_{n}} \\
s_{t}^{\tau_{k}} & =\rho_{\tau_{k}} s_{t-1}^{\tau_{k}}+\varepsilon_{t}^{\tau_{k}} \\
\mu_{t}^{m} & =\left(1-\rho_{m}\right)+\rho_{m} \mu_{t-1}^{m}+\phi_{\mu} \Delta_{t}+\varepsilon_{t}^{m} \\
y_{t}^{e r r} & =\rho_{e r r} y_{t-1}^{e r r}+\varepsilon_{t}^{e r r}
\end{aligned}
$$

$\underline{\text { Additional variables }}$

$$
\begin{aligned}
T_{t} & =\left(\left(\tau_{t}^{n}-\Delta_{t} p^{\ell}\right) w_{t}^{r} n_{t}+\tau_{t}^{k}\left(r_{t}^{r k} z_{t}-\delta_{t}\right) k_{t-1}\right)\left(1-\alpha+\alpha s_{t}^{1-\mu}\right)^{1 /(1-\mu)} \\
c g y_{t} & =\left(c_{t}+g_{t}\right) / y_{t} \\
d y_{t} & =b_{t}^{r} / y_{t} \\
m y_{t} & =m_{t}^{r} / y_{t} \\
i y_{t} & =\left(i_{t}+i_{t}^{g}\right) / y_{t}
\end{aligned}
$$

$\underline{\text { Measurement equations }}$

$$
\begin{aligned}
d y_{t}^{o b s} & =\log y_{t}-\log y_{t-1}+y_{t}^{e r r} \\
d c_{t}^{o b s} & =\log c_{t}-\log c_{t-1} \\
\pi_{t}^{o b s} & =\log \pi_{t-1} / \pi_{t}^{d, o b s}=\log \pi_{t-1}^{d} \\
d b_{t}^{o b s} & =\log b_{t}^{r}-\log b_{t-1}^{r} \\
d t_{t}^{o b s} & =\log T_{t}-\log T_{t-1} \\
c g y_{t}^{o b s} & =c g y_{t}-c g y \\
n x y_{t}^{o b s} & =n x y_{t}-n x y \\
i y_{t}^{o b s} & =i y_{t}-i y \\
\Delta_{t}^{o b s} & =\Delta_{t}
\end{aligned}
$$




\section{Estimation results}

Table 5: Country-specific estimated parameters for France

\begin{tabular}{|c|c|c|c|c|c|c|c|c|c|}
\hline \multirow[b]{2}{*}{ Structural parameters } & \multicolumn{3}{|c|}{ Priors } & \multicolumn{3}{|c|}{ Post. Baseline } & \multicolumn{3}{|c|}{ Post. Restricted } \\
\hline & Dist. & Mean & Sd. & Mean & Inf. & Sup. & Mean & Inf. & Sup. \\
\hline Calvo prices $\left(\eta^{p}\right)$ & $B$ & 0.25 & 0.10 & 0.20 & 0.15 & 0.25 & 0.23 & 0.15 & 0.31 \\
\hline Calvo wages $\left(\eta^{w}\right)$ & $B$ & 0.25 & 0.10 & 0.27 & 0.14 & 0.39 & 0.32 & 0.18 & 0.45 \\
\hline Edgeworth comp. $\left(\nu_{\text {norm }}\right)$ & $N$ & 0.50 & 0.25 & 0.50 & 0.47 & 0.53 & 0.38 & 0.27 & 0.50 \\
\hline Edgeworth comp. $\left(\nu_{w a r}\right)$ & $N$ & 0.50 & 0.25 & 0.35 & 0.30 & 0.40 & - & - & - \\
\hline War draft $\left(p^{\ell}\right)$ & $B$ & 0.15 & 0.05 & 0.08 & 0.02 & 0.14 & - & - & - \\
\hline War default $\left(p^{b}\right)$ & $B$ & 0.15 & 0.05 & 0.08 & 0.03 & 0.13 & - & - & - \\
\hline War capital depreciation $\left(p^{\delta}\right)$ & $B$ & 0.15 & 0.05 & 0.09 & 0.02 & 0.15 & - & - & - \\
\hline Investment adj. cost $\left(\phi_{i}\right)$ & $N$ & 5.00 & 0.50 & 4.04 & 3.21 & 4.89 & 4.50 & 3.76 & 5.25 \\
\hline Trade elasticity $(\mu)$ & $N$ & 1.50 & 0.25 & 1.48 & 1.31 & 1.65 & 1.53 & 1.36 & 1.68 \\
\hline Labor tax rule $\left(d_{\tau^{n}}\right)$ & $I G$ & 0.25 & 0.25 & 0.09 & 0.07 & 0.12 & 0.11 & 0.07 & 0.14 \\
\hline Capital tax rule $\left(d_{\tau} n\right)$ & $I G$ & 0.25 & 0.25 & 0.13 & 0.08 & 0.18 & 0.14 & 0.08 & 0.22 \\
\hline Spending rule $\left(d_{g}\right)$ & $I G$ & 0.25 & 0.25 & 0.15 & 0.09 & 0.21 & 0.11 & 0.07 & 0.15 \\
\hline \multicolumn{10}{|l|}{ War spillovers } \\
\hline Productivity $\left(\phi_{a}\right)$ & $N$ & 0.00 & 2.00 & -0.05 & -0.08 & -0.02 & - & - & - \\
\hline Spending $\left(\phi_{g}\right)$ & $N$ & 0.00 & 2.00 & 0.01 & -0.09 & 0.11 & - & - & - \\
\hline Investment $\left(\phi_{\varsigma}\right)$ & $N$ & 0.00 & 2.00 & -0.62 & -1.08 & -0.17 & - & - & - \\
\hline Trade $\left(\phi_{y} *\right)$ & $N$ & 0.00 & 2.00 & -0.70 & -0.94 & -0.45 & - & - & - \\
\hline Labor tax $\left(\phi_{\tau} n\right)$ & $N$ & 0.00 & 2.00 & -0.18 & -0.25 & -0.10 & - & - & - \\
\hline Capital tax $\left(\phi_{\tau} n\right)$ & $N$ & 0.00 & 2.00 & 0.38 & 0.18 & 0.59 & - & - & - \\
\hline Money growth $\left(\phi_{\mu}\right)$ & $N$ & 0.00 & 2.00 & 0.03 & -0.03 & 0.10 & - & - & - \\
\hline \multicolumn{10}{|l|}{ Persistence } \\
\hline Productivity $\left(\rho_{a}\right)$ & $B$ & 0.70 & 0.20 & 0.98 & 0.97 & 1.00 & 0.99 & 0.97 & 1.00 \\
\hline Public spending $\left(\rho_{g}\right)$ & $B$ & 0.70 & 0.20 & 0.99 & 0.98 & 1.00 & 1.00 & 0.99 & 1.00 \\
\hline Investment $\left(\rho_{\zeta}\right)$ & $B$ & 0.70 & 0.20 & 0.39 & 0.26 & 0.52 & 0.40 & 0.20 & 0.59 \\
\hline Foreign demand $\left(\rho_{y^{*}}\right)$ & $B$ & 0.70 & 0.20 & 0.65 & 0.58 & 0.71 & 0.66 & 0.59 & 0.73 \\
\hline Meas. error $\left(\rho_{\text {err }}^{y}\right)$ & $B$ & 0.70 & 0.20 & 0.13 & 0.03 & 0.22 & 0.21 & 0.04 & 0.37 \\
\hline Labor tax $\left(\rho_{\tau} n\right)$ & $B$ & 0.70 & 0.20 & 1.00 & 1.00 & 1.00 & 1.00 & 1.00 & 1.00 \\
\hline Capital tax $\left(\rho_{\tau k}\right)$ & $B$ & 0.70 & 0.20 & 0.88 & 0.82 & 0.94 & 0.87 & 0.82 & 0.93 \\
\hline Money growth $\left(\rho_{m}\right)$ & $B$ & 0.70 & 0.20 & 0.14 & 0.03 & 0.24 & 0.19 & 0.04 & 0.33 \\
\hline \multicolumn{10}{|l|}{ Standard deviations of shocks } \\
\hline Productivity & $I G$ & 0.10 & $\operatorname{Inf}$ & 0.06 & 0.05 & 0.07 & 0.08 & 0.06 & 0.10 \\
\hline Public spending & $I G$ & 0.10 & Inf & 0.10 & 0.09 & 0.12 & 0.06 & 0.01 & 0.11 \\
\hline Investment & $I G$ & 0.10 & Inf & 0.78 & 0.59 & 0.96 & 0.81 & 0.63 & 1.00 \\
\hline Foreign demand & $I G$ & 0.10 & Inf & 0.38 & 0.33 & 0.44 & 0.31 & 0.18 & 0.45 \\
\hline Meas. error & $I G$ & 0.10 & Inf & 0.10 & 0.09 & 0.11 & 0.09 & 0.07 & 0.11 \\
\hline Labor tax & $I G$ & 0.10 & Inf & 0.06 & 0.05 & 0.06 & 0.05 & 0.04 & 0.06 \\
\hline Capital tax & $I G$ & 0.10 & $\operatorname{Inf}$ & 0.14 & 0.12 & 0.16 & 0.13 & 0.11 & 0.15 \\
\hline Money growth & $I G$ & 0.10 & Inf & 0.13 & 0.11 & 0.16 & 0.13 & 0.11 & 0.16 \\
\hline War & $I G$ & 0.10 & $\operatorname{Inf}$ & 0.33 & 0.29 & 0.37 & 0.33 & 0.29 & 0.37 \\
\hline \multirow{2}{*}{\multicolumn{10}{|c|}{ Marginal data density }} \\
\hline & & & & & 1113.42 & & & 1102.40 & \\
\hline
\end{tabular}

Notes: Results based on 250000 replications of the MH algorithm. Standard deviations are expressed in percents. $N, B$ and $I G$ respectively denote Normal, Beta and Inverse Gamma distributions. Marginal data density is the harmonic mean. 
Table 6: Country-specific estimated parameters for Germany

\begin{tabular}{|c|c|c|c|c|c|c|c|c|c|}
\hline \multirow[b]{2}{*}{ Structural parameters } & \multicolumn{3}{|c|}{ Priors } & \multicolumn{3}{|c|}{ Post. Baseline } & \multicolumn{3}{|c|}{ Post. Restricted } \\
\hline & Dist. & Mean & Sd. & Mean & Inf. & Sup. & Mean & Inf. & Sup. \\
\hline Calvo prices $\left(\eta^{p}\right)$ & $B$ & 0.25 & 0.10 & 0.22 & 0.16 & 0.27 & 0.27 & 0.20 & 0.33 \\
\hline Calvo wages $\left(\eta^{w}\right)$ & $B$ & 0.25 & 0.10 & 0.40 & 0.33 & 0.47 & 0.39 & 0.31 & 0.46 \\
\hline Edgeworth comp. $\left(\nu_{\text {norm }}\right)$ & $N$ & 0.50 & 0.25 & 0.56 & 0.52 & 0.60 & 0.63 & 0.57 & 0.68 \\
\hline Edgeworth comp. $\left(\nu_{w a r}\right)$ & $N$ & 0.50 & 0.25 & 0.48 & 0.40 & 0.55 & - & - & - \\
\hline War draft $\left(p^{\ell}\right)$ & $B$ & 0.15 & 0.05 & 0.08 & 0.02 & 0.15 & - & - & - \\
\hline War default $\left(p^{b}\right)$ & $B$ & 0.15 & 0.05 & 0.10 & 0.02 & 0.16 & - & - & - \\
\hline War capital depreciation $\left(p^{\delta}\right)$ & $B$ & 0.15 & 0.05 & 0.10 & 0.02 & 0.17 & - & - & - \\
\hline Investment adj. cost $\left(\phi_{i}\right)$ & $N$ & 5.00 & 0.50 & 4.68 & 3.85 & 5.52 & 4.60 & 3.77 & 5.40 \\
\hline Trade elasticity $(\mu)$ & $N$ & 1.50 & 0.25 & 1.24 & 1.08 & 1.40 & 1.28 & 1.11 & 1.44 \\
\hline Labor tax rule $\left(d_{\tau} n\right)$ & $I G$ & 0.25 & 0.25 & 0.32 & 0.18 & 0.44 & 0.35 & 0.22 & 0.49 \\
\hline Capital tax rule $\left(d_{\tau n}\right)$ & $I G$ & 0.25 & 0.25 & 0.15 & 0.08 & 0.22 & 0.15 & 0.08 & 0.21 \\
\hline Spending rule $\left(d_{g}\right)$ & $I G$ & 0.25 & 0.25 & 0.10 & 0.07 & 0.13 & 0.09 & 0.06 & 0.11 \\
\hline \multicolumn{10}{|l|}{ War spillovers } \\
\hline Productivity $\left(\phi_{a}\right)$ & $N$ & 0.00 & 2.00 & -0.06 & -0.09 & -0.03 & - & - & - \\
\hline Spending $\left(\phi_{g}\right)$ & $N$ & 0.00 & 2.00 & 0.03 & -0.10 & 0.17 & - & - & - \\
\hline Investment $\left(\phi_{\varsigma}\right)$ & $N$ & 0.00 & 2.00 & -0.46 & -0.91 & -0.02 & - & - & - \\
\hline Trade $\left(\phi_{y^{*}}\right)$ & $N$ & 0.00 & 2.00 & -0.08 & -0.29 & 0.12 & - & - & - \\
\hline Labor tax $\left(\phi_{\tau} n\right)$ & $N$ & 0.00 & 2.00 & 0.44 & 0.24 & 0.63 & - & - & - \\
\hline Capital tax $\left(\phi_{\tau} n\right)$ & $N$ & 0.00 & 2.00 & -1.75 & -2.49 & -1.00 & - & - & - \\
\hline Money growth $\left(\phi_{\mu}\right)$ & $N$ & 0.00 & 2.00 & -0.01 & -0.07 & 0.05 & - & - & - \\
\hline \multicolumn{10}{|l|}{ Persistence } \\
\hline Productivity $\left(\rho_{a}\right)$ & $B$ & 0.70 & 0.20 & 0.99 & 0.97 & 1.00 & 0.99 & 0.99 & 1.00 \\
\hline Public spending $\left(\rho_{g}\right)$ & $B$ & 0.70 & 0.20 & 0.97 & 0.95 & 0.99 & 0.96 & 0.94 & 0.98 \\
\hline Investment $\left(\rho_{\zeta}\right)$ & $B$ & 0.70 & 0.20 & 0.59 & 0.45 & 0.73 & 0.55 & 0.42 & 0.68 \\
\hline Foreign demand $\left(\rho_{y^{*}}\right)$ & $B$ & 0.70 & 0.20 & 0.63 & 0.49 & 0.77 & 0.68 & 0.57 & 0.79 \\
\hline Meas. error $\left(\rho^{y}\right)$ & $B$ & 0.70 & 0.20 & 0.24 & 0.10 & 0.39 & 0.24 & 0.10 & 0.38 \\
\hline Labor tax $\left(\rho_{\tau} n\right)$ & $B$ & 0.70 & 0.20 & 0.85 & 0.75 & 0.95 & 0.82 & 0.74 & 0.91 \\
\hline Capital tax $\left(\rho_{\tau k}\right)$ & $B$ & 0.70 & 0.20 & 0.53 & 0.34 & 0.71 & 0.55 & 0.39 & 0.73 \\
\hline Money growth ${ }^{\tau}\left(\rho_{m}\right)$ & $B$ & 0.70 & 0.20 & 0.38 & 0.05 & 0.68 & 0.67 & 0.51 & 0.83 \\
\hline \multicolumn{10}{|l|}{ Standard deviations of shocks } \\
\hline Productivity & $I G$ & 0.10 & $\operatorname{Inf}$ & 0.04 & 0.03 & 0.05 & 0.05 & 0.04 & 0.06 \\
\hline Public spending & $I G$ & 0.10 & $\operatorname{Inf}$ & 0.10 & 0.09 & 0.12 & 0.10 & 0.08 & 0.11 \\
\hline Investment & $I G$ & 0.10 & $\operatorname{Inf}$ & 0.54 & 0.41 & 0.66 & 0.53 & 0.40 & 0.64 \\
\hline Foreign demand & $I G$ & 0.10 & $\operatorname{Inf}$ & 0.23 & 0.19 & 0.26 & 0.23 & 0.20 & 0.27 \\
\hline Meas. error & $I G$ & 0.10 & $\operatorname{Inf}$ & 0.05 & 0.04 & 0.06 & 0.06 & 0.05 & 0.07 \\
\hline Labor tax & $I G$ & 0.10 & Inf & 0.16 & 0.13 & 0.19 & 0.18 & 0.16 & 0.21 \\
\hline Capital tax & $I G$ & 0.10 & Inf & 0.28 & 0.24 & 0.33 & 0.29 & 0.25 & 0.33 \\
\hline Money growth & $I G$ & 0.10 & Inf & 0.11 & 0.05 & 0.17 & 0.06 & 0.03 & 0.08 \\
\hline War & $I G$ & 0.10 & Inf & 0.31 & 0.27 & 0.34 & 0.31 & 0.27 & 0.34 \\
\hline \multicolumn{10}{|l|}{ Marginal data density } \\
\hline & & & & & 1186.84 & & & $177.4 \mathrm{~s}$ & \\
\hline
\end{tabular}

Notes: Results based on 250000 replications of the MH algorithm. Standard deviations are expressed in percents. $N, B$ and $I G$ respectively denote Normal, Beta and Inverse Gamma distributions. Marginal data density is the harmonic mean. 
Table 7: Country-specific estimated parameters for the United Kingdom

\begin{tabular}{|c|c|c|c|c|c|c|c|c|c|}
\hline \multirow[b]{3}{*}{ Structural parameters } & \multicolumn{3}{|c|}{ Priors } & \multicolumn{3}{|c|}{ Post. Baseline } & \multicolumn{3}{|c|}{ Post. Restricted } \\
\hline & Dist. & Mean & Sd. & Mean & Inf & Sup & Mean & Inf & Sup \\
\hline & & & & & & & & & \\
\hline Calvo prices $\left(\eta^{p}\right)$ & $B$ & 0.25 & 0.10 & 0.25 & 0.20 & 0.31 & 0.33 & 0.31 & 0.34 \\
\hline Calvo wages $\left(\eta^{w}\right)$ & $B$ & 0.25 & 0.10 & 0.14 & 0.05 & 0.22 & 0.38 & 0.36 & 0.40 \\
\hline Edgeworth comp. $\left(\nu_{\text {norm }}\right)$ & $N$ & 0.50 & 0.25 & 0.60 & 0.59 & 0.62 & 0.63 & 0.61 & 0.64 \\
\hline Edgeworth comp. ( $\left.\nu_{\text {war }}\right)$ & $N$ & 0.50 & 0.25 & 0.46 & 0.42 & 0.51 & - & - & - \\
\hline War draft $\left(p^{\ell}\right)$ & $B$ & 0.15 & 0.05 & 0.11 & 0.03 & 0.18 & - & - & - \\
\hline War default $\left(p^{b}\right)$ & $B$ & 0.15 & 0.05 & 0.06 & 0.02 & 0.10 & - & - & - \\
\hline War capital depreciation $\left(p^{\delta}\right)$ & $B$ & 0.15 & 0.05 & 0.09 & 0.02 & 0.15 & - & - & - \\
\hline Investment adj. cost $\left(\phi_{i}\right)$ & $N$ & 5.00 & 0.50 & 3.74 & 2.92 & 4.53 & 4.85 & 4.68 & 5.04 \\
\hline Trade elasticity $(\mu)$ & $N$ & 1.50 & 0.25 & 1.17 & 1.08 & 1.26 & 1.22 & 1.17 & 1.30 \\
\hline Labor tax rule $\left(d_{\tau} n\right)$ & $I G$ & 0.25 & 0.25 & 0.07 & 0.06 & 0.09 & 0.08 & 0.06 & 0.09 \\
\hline Capital tax rule $\left(d_{\tau n}\right)$ & $I G$ & 0.25 & 0.25 & 0.11 & 0.08 & 0.15 & 0.12 & 0.09 & 0.17 \\
\hline Spending rule $\left(d_{g}\right)$ & $I G$ & 0.25 & 0.25 & 0.11 & 0.07 & 0.15 & 0.11 & 0.08 & 0.15 \\
\hline \multicolumn{10}{|l|}{ War spillovers } \\
\hline Productivity $\left(\phi_{a}\right)$ & $N$ & 0.00 & 2.00 & -0.02 & -0.04 & -0.01 & - & - & - \\
\hline Spending $\left(\phi_{g}\right)$ & $N$ & 0.00 & 2.00 & 0.34 & 0.22 & 0.47 & - & - & - \\
\hline Investment $\left(\phi_{\varsigma}\right)$ & $N$ & 0.00 & 2.00 & -0.34 & -0.64 & -0.05 & - & - & - \\
\hline Trade $\left(\phi_{y^{*}}\right)$ & $N$ & 0.00 & 2.00 & -0.38 & -0.52 & -0.24 & - & - & - \\
\hline Labor tax $\left(\phi_{\tau} n\right)$ & $N$ & 0.00 & 2.00 & -0.14 & -0.20 & -0.09 & - & - & - \\
\hline Capital tax $\left(\phi_{\tau} n\right)$ & $N$ & 0.00 & 2.00 & 0.22 & 0.08 & 0.36 & - & - & - \\
\hline Money growth $\left(\phi_{\mu}\right)$ & $N$ & 0.00 & 2.00 & 0.02 & -0.00 & 0.05 & - & - & - \\
\hline \multicolumn{10}{|l|}{ Persistence } \\
\hline Productivity $\left(\rho_{a}\right)$ & $B$ & 0.70 & 0.20 & 0.95 & 0.92 & 0.99 & 0.94 & 0.91 & 0.96 \\
\hline Public spending $\left(\rho_{g}\right)$ & $B$ & 0.70 & 0.20 & 0.97 & 0.95 & 0.99 & 0.93 & 0.90 & 0.95 \\
\hline Investment $\left(\rho_{\zeta}\right)$ & $B$ & 0.70 & 0.20 & 0.51 & 0.40 & 0.62 & 0.68 & 0.61 & 0.72 \\
\hline Foreign demand $\left(\rho_{y} *\right)$ & $B$ & 0.70 & 0.20 & 0.60 & 0.53 & 0.68 & 0.65 & 0.61 & 0.69 \\
\hline Meas. error $\left(\rho_{e r r}^{y}\right)^{9}$ & $B$ & 0.70 & 0.20 & 0.15 & 0.05 & 0.25 & 0.29 & 0.26 & 0.35 \\
\hline Labor tax $\left(\rho_{\tau} n\right)$ & $B$ & 0.70 & 0.20 & 1.00 & 0.99 & 1.00 & 1.00 & 0.99 & 1.00 \\
\hline Capital tax $\left(\rho_{\tau k}\right)$ & $B$ & 0.70 & 0.20 & 0.97 & 0.94 & 1.00 & 0.96 & 0.94 & 0.99 \\
\hline Money growth $\left(\rho_{m}\right)$ & $B$ & 0.70 & 0.20 & 0.25 & 0.06 & 0.43 & 0.46 & 0.43 & 0.49 \\
\hline \multicolumn{10}{|l|}{ Standard deviations of shocks } \\
\hline Productivity & $I G$ & 0.10 & Inf & 0.03 & 0.03 & 0.04 & 0.04 & 0.04 & 0.05 \\
\hline Public spending & $I G$ & 0.10 & Inf & 0.12 & 0.11 & 0.14 & 0.14 & 0.12 & 0.15 \\
\hline Investment & $I G$ & 0.10 & Inf & 0.52 & 0.40 & 0.63 & 0.58 & 0.51 & 0.65 \\
\hline Foreign demand & $I G$ & 0.10 & $\operatorname{Inf}$ & 0.23 & 0.21 & 0.26 & 0.25 & 0.23 & 0.28 \\
\hline Meas. error & $I G$ & 0.10 & Inf & 0.08 & 0.07 & 0.09 & 0.09 & 0.08 & 0.10 \\
\hline Labor tax & $I G$ & 0.10 & Inf & 0.05 & 0.04 & 0.05 & 0.05 & 0.04 & 0.05 \\
\hline Capital tax & $I G$ & 0.10 & Inf & 0.10 & 0.09 & 0.11 & 0.10 & 0.09 & 0.12 \\
\hline Money growth & $I G$ & 0.10 & $\operatorname{Inf}$ & 0.05 & 0.04 & 0.07 & 0.04 & 0.03 & 0.04 \\
\hline War & $I G$ & 0.10 & $\operatorname{Inf}$ & 0.30 & 0.27 & 0.32 & 0.30 & 0.27 & 0.33 \\
\hline \multicolumn{10}{|l|}{ Marginal data density } \\
\hline & & & & & 1883.54 & & & 848.58 & \\
\hline
\end{tabular}

Notes: Results based on 250000 replications of the $\mathrm{MH}$ algorithm. Standard deviations are expressed in percents. $N, B$ and $I G$ respectively denote Normal, Beta and Inverse Gamma distributions. Marginal data density is the harmonic mean. 
Table 8: Country-specific estimated parameters for the United States

\begin{tabular}{|c|c|c|c|c|c|c|c|c|c|}
\hline \multirow[b]{2}{*}{ Structural parameters } & \multicolumn{3}{|c|}{ Priors } & \multicolumn{3}{|c|}{ Post. Baseline } & \multicolumn{3}{|c|}{ Post. Restricted } \\
\hline & Dist. & Mean & Sd. & Mean & Inf & Sup & Mean & Inf & Sup \\
\hline Calvo prices $\left(\eta^{p}\right)$ & $B$ & 0.25 & 0.10 & 0.40 & 0.36 & 0.44 & 0.35 & 0.34 & 0.36 \\
\hline Calvo wages $\left(\eta^{w}\right)$ & $B$ & 0.25 & 0.10 & 0.20 & 0.11 & 0.30 & 0.26 & 0.26 & 0.27 \\
\hline Edgeworth comp. $\left(\nu_{\text {norm }}\right)$ & $N$ & 0.50 & 0.25 & 0.55 & 0.53 & 0.57 & 0.55 & 0.54 & 0.56 \\
\hline Edgeworth comp. $\left(\nu_{\text {war }}\right)$ & $N$ & 0.50 & 0.25 & 0.51 & 0.47 & 0.55 & - & - & - \\
\hline War draft $\left(p^{\ell}\right)$ & $B$ & 0.15 & 0.05 & 0.06 & 0.02 & 0.11 & - & - & - \\
\hline War default $\left(p^{b}\right)$ & $B$ & 0.15 & 0.05 & 0.12 & 0.06 & 0.18 & - & - & - \\
\hline War capital depreciation $\left(p^{\delta}\right)$ & $B$ & 0.15 & 0.05 & 0.09 & 0.02 & 0.16 & - & - & - \\
\hline Investment adj. cost $\left(\phi_{i}\right)$ & $N$ & 5.00 & 0.50 & 4.27 & 3.49 & 5.05 & 5.48 & 5.43 & 5.54 \\
\hline Trade elasticity $(\mu)$ & $N$ & 1.50 & 0.25 & 1.26 & 1.17 & 1.35 & 1.24 & 1.22 & 1.25 \\
\hline Labor tax rule $\left(d_{\tau} n\right)$ & $I G$ & 0.25 & 0.25 & 0.13 & 0.08 & 0.17 & 0.26 & 0.23 & 0.30 \\
\hline Capital tax rule $\left(d_{\tau} n\right)$ & $I G$ & 0.25 & 0.25 & 0.17 & 0.08 & 0.25 & 0.29 & 0.26 & 0.32 \\
\hline Spending rule $\left(d_{g}\right)$ & $I G$ & 0.25 & 0.25 & 0.10 & 0.07 & 0.13 & 0.10 & 0.09 & 0.12 \\
\hline \multicolumn{10}{|l|}{ War spillovers } \\
\hline Productivity $\left(\phi_{a}\right)$ & $N$ & 0.00 & 2.00 & 0.01 & -0.01 & 0.02 & - & - & - \\
\hline Spending $\left(\phi_{g}\right)$ & $N$ & 0.00 & 2.00 & 0.14 & 0.07 & 0.21 & - & - & - \\
\hline Investment $\left(\phi_{\varsigma}\right)$ & $N$ & 0.00 & 2.00 & 0.06 & -0.31 & 0.41 & - & - & - \\
\hline Trade $\left(\phi_{y^{*}}\right)$ & $N$ & 0.00 & 2.00 & 0.16 & 0.06 & 0.26 & - & - & - \\
\hline Labor $\operatorname{tax}\left(\phi_{\tau} n\right)$ & $N$ & 0.00 & 2.00 & 0.13 & 0.06 & 0.20 & - & - & - \\
\hline Capital tax $\left(\phi_{\tau} n\right)$ & $N$ & 0.00 & 2.00 & -0.34 & -0.54 & -0.14 & - & - & - \\
\hline Money growth $\left(\phi_{\mu}\right)$ & $N$ & 0.00 & 2.00 & -0.02 & -0.04 & 0.01 & - & - & - \\
\hline \multicolumn{10}{|l|}{ Persistence } \\
\hline Productivity $\left(\rho_{a}\right)$ & $B$ & 0.70 & 0.20 & 0.97 & 0.95 & 1.00 & 0.97 & 0.95 & 1.00 \\
\hline Public spending $\left(\rho_{g}\right)$ & $B$ & 0.70 & 0.20 & 1.00 & 1.00 & 1.00 & 1.00 & 1.00 & 1.00 \\
\hline Investment $\left(\rho_{\zeta}\right)$ & $B$ & 0.70 & 0.20 & 0.55 & 0.43 & 0.67 & 0.46 & 0.44 & 0.48 \\
\hline Foreign demand $\left(\rho_{y^{*}}\right)$ & $B$ & 0.70 & 0.20 & 0.86 & 0.81 & 0.92 & 0.75 & 0.72 & 0.79 \\
\hline Meas. error $\left(\rho_{e r r}^{y}\right)$ & $B$ & 0.70 & 0.20 & 0.15 & 0.04 & 0.24 & 0.50 & 0.49 & 0.52 \\
\hline Labor tax $\left(\rho_{\tau} n\right)^{r}$ & $B$ & 0.70 & 0.20 & 1.00 & 1.00 & 1.00 & 1.00 & 0.99 & 1.00 \\
\hline Capital tax $\left(\rho_{\tau k}\right)$ & $B$ & 0.70 & 0.20 & 0.81 & 0.75 & 0.88 & 0.85 & 0.84 & 0.86 \\
\hline Money growth ${ }^{\tau}\left(\rho_{m}\right)$ & $B$ & 0.70 & 0.20 & 0.41 & 0.23 & 0.59 & 0.65 & 0.64 & 0.67 \\
\hline \multicolumn{10}{|l|}{ Standard deviations of shocks } \\
\hline Productivity & $I G$ & 0.10 & $\operatorname{Inf}$ & 0.03 & 0.03 & 0.03 & 0.03 & 0.03 & 0.03 \\
\hline Public spending & $I G$ & 0.10 & $\operatorname{Inf}$ & 0.07 & 0.06 & 0.08 & 0.07 & 0.06 & 0.08 \\
\hline Investment & $I G$ & 0.10 & $\operatorname{Inf}$ & 0.70 & 0.56 & 0.83 & 0.93 & 0.85 & 1.01 \\
\hline Foreign demand & $I G$ & 0.10 & $\operatorname{Inf}$ & 0.19 & 0.15 & 0.22 & 0.17 & 0.15 & 0.18 \\
\hline Meas. error & $I G$ & 0.10 & $\operatorname{Inf}$ & 0.05 & 0.04 & 0.05 & 0.05 & 0.05 & 0.06 \\
\hline Labor tax & $I G$ & 0.10 & $\operatorname{Inf}$ & 0.08 & 0.07 & 0.08 & 0.08 & 0.07 & 0.10 \\
\hline Capital tax & $I G$ & 0.10 & $\operatorname{Inf}$ & 0.17 & 0.15 & 0.19 & 0.18 & 0.16 & 0.19 \\
\hline Money growth & $I G$ & 0.10 & $\operatorname{Inf}$ & 0.05 & 0.03 & 0.06 & 0.03 & 0.03 & 0.03 \\
\hline War & $I G$ & 0.10 & Inf & 0.29 & 0.26 & 0.32 & 0.28 & 0.26 & 0.30 \\
\hline \multirow{2}{*}{\multicolumn{10}{|c|}{ Marginal data density }} \\
\hline & & & & & 1870.81 & & & $8 \overline{816.41}$ & \\
\hline
\end{tabular}

Notes: Results based on 250000 replications of the $\mathrm{MH}$ algorithm. Standard deviations are expressed in percents. $N, B$ and $I G$ respectively denote Normal, Beta and Inverse Gamma distributions. Marginal data density is the harmonic mean. 


\section{Prior and posterior distributions}

Figure 10: Priors and Posteriors - France

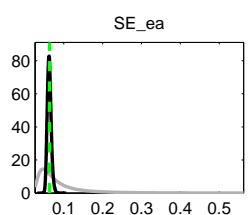

SE_ei

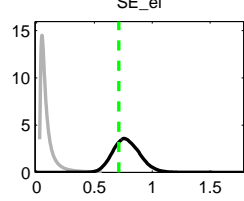

SE_etk

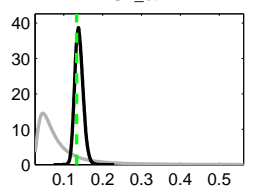

dtn
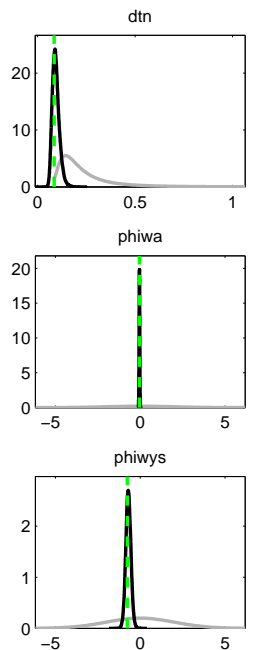
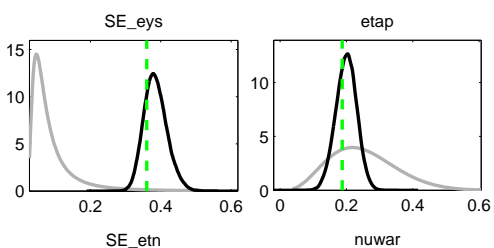

SE_err

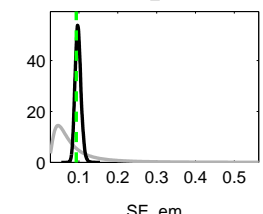

SE_em

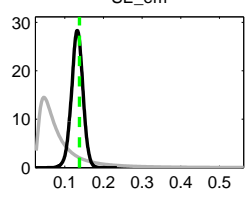

dtk
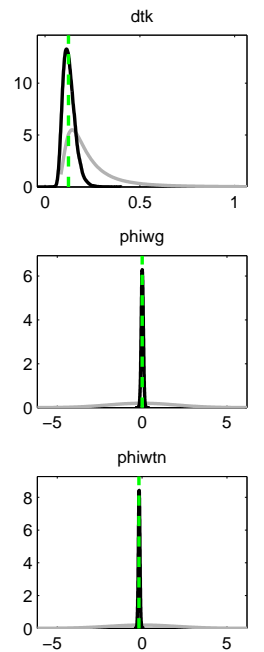

SE_ewar
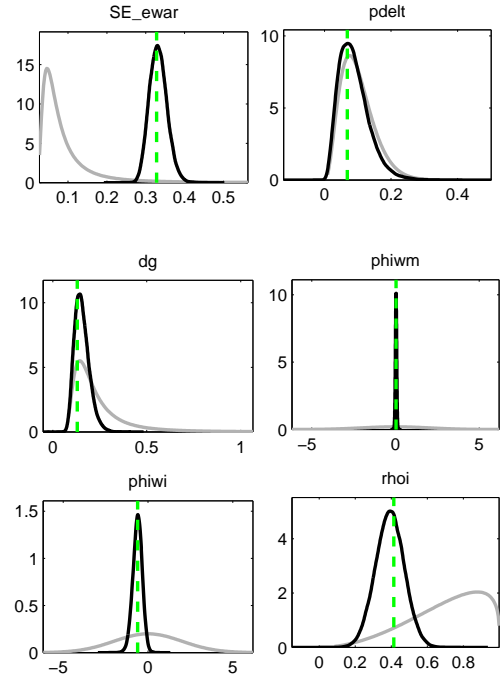
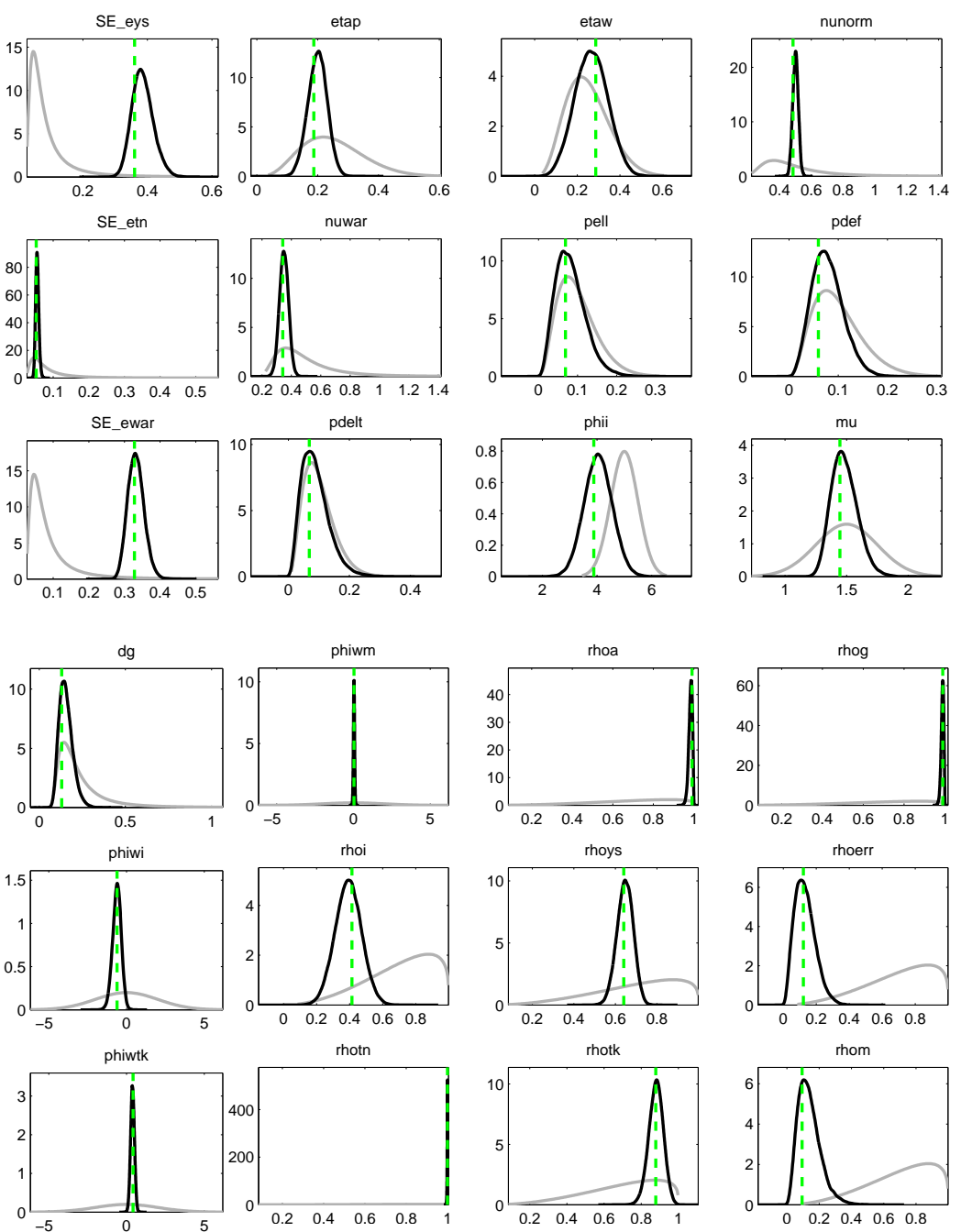

rhotk

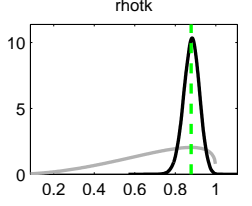

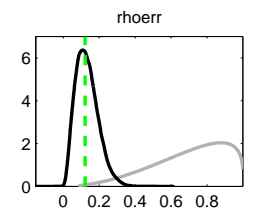

rhom

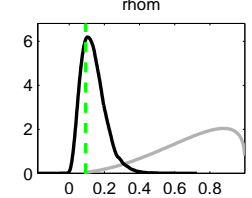


Figure 11: Priors and Posteriors - Germany
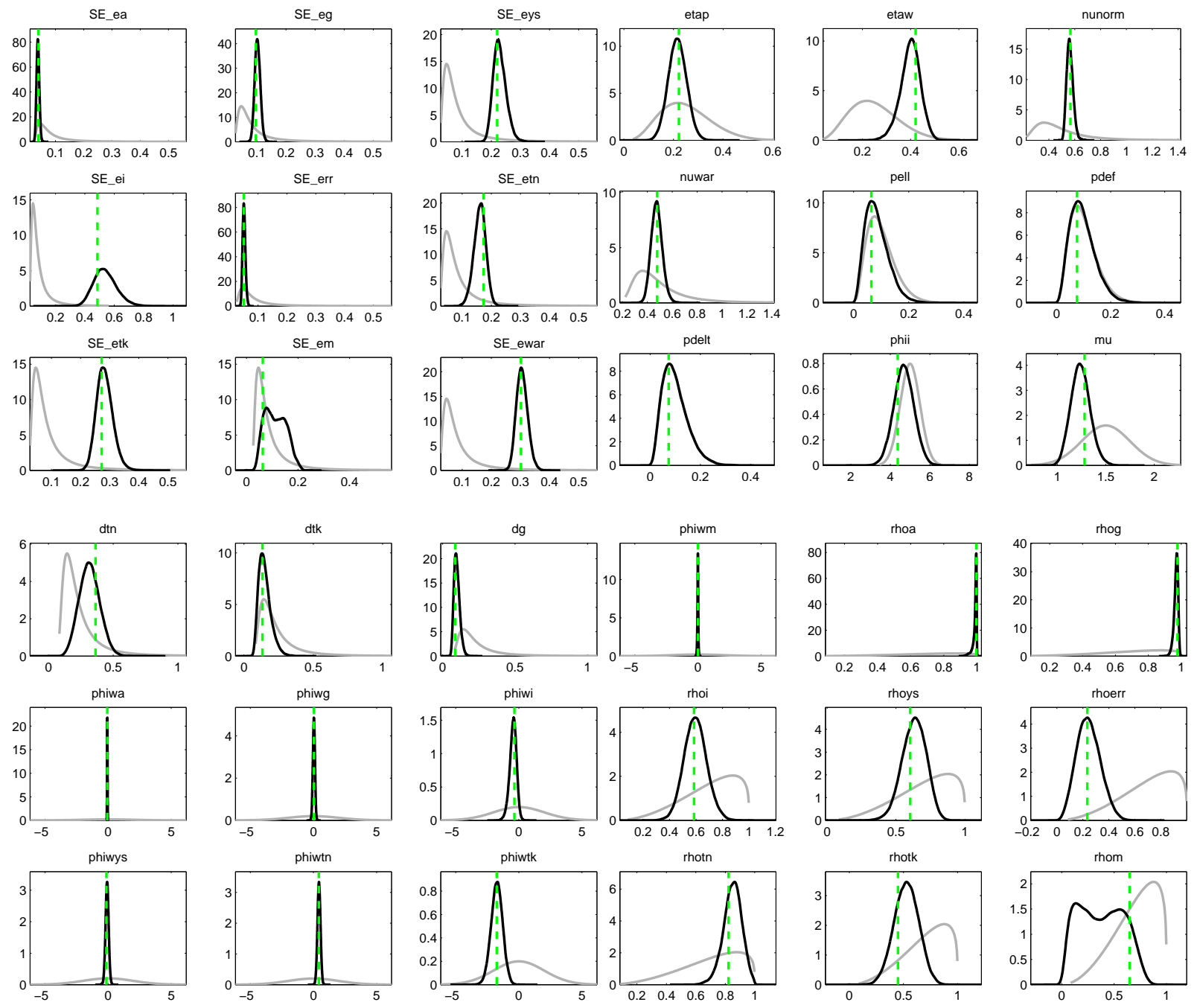
Figure 12: Priors and Posteriors - UK
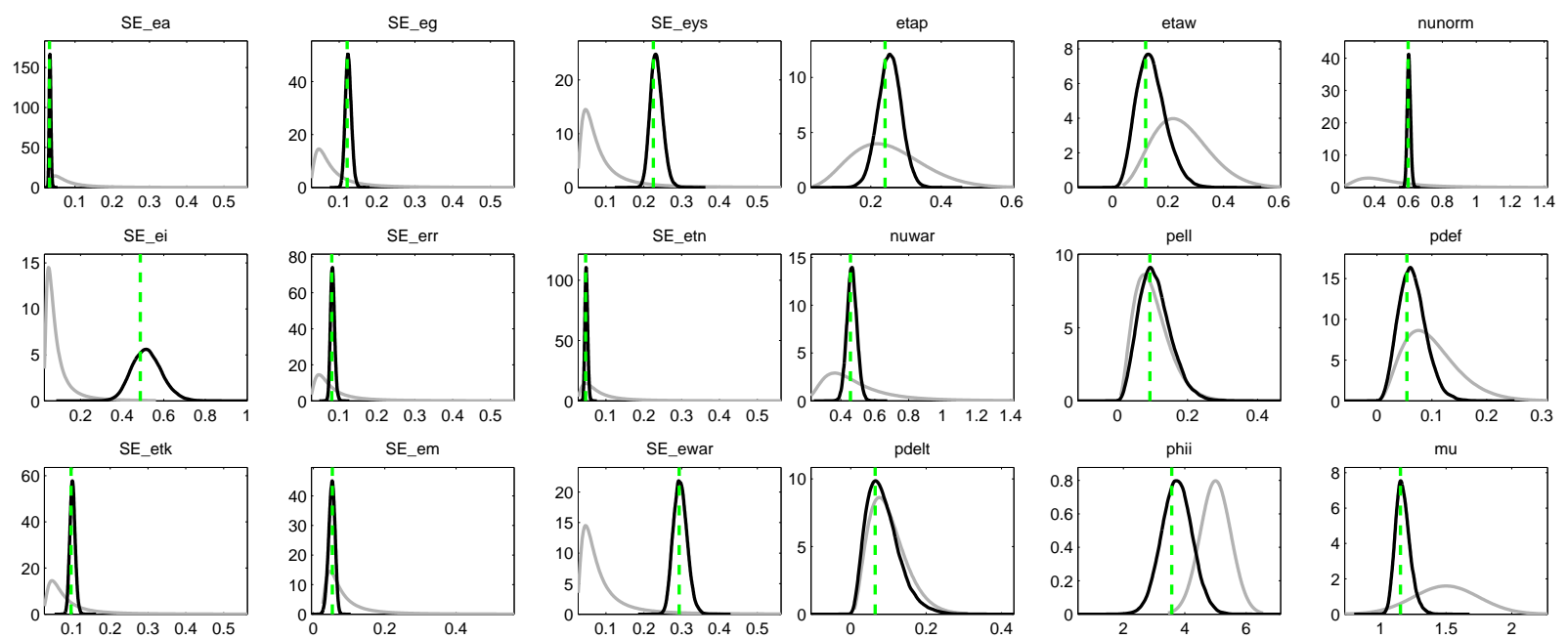

$\mathrm{dtn}$

dtk
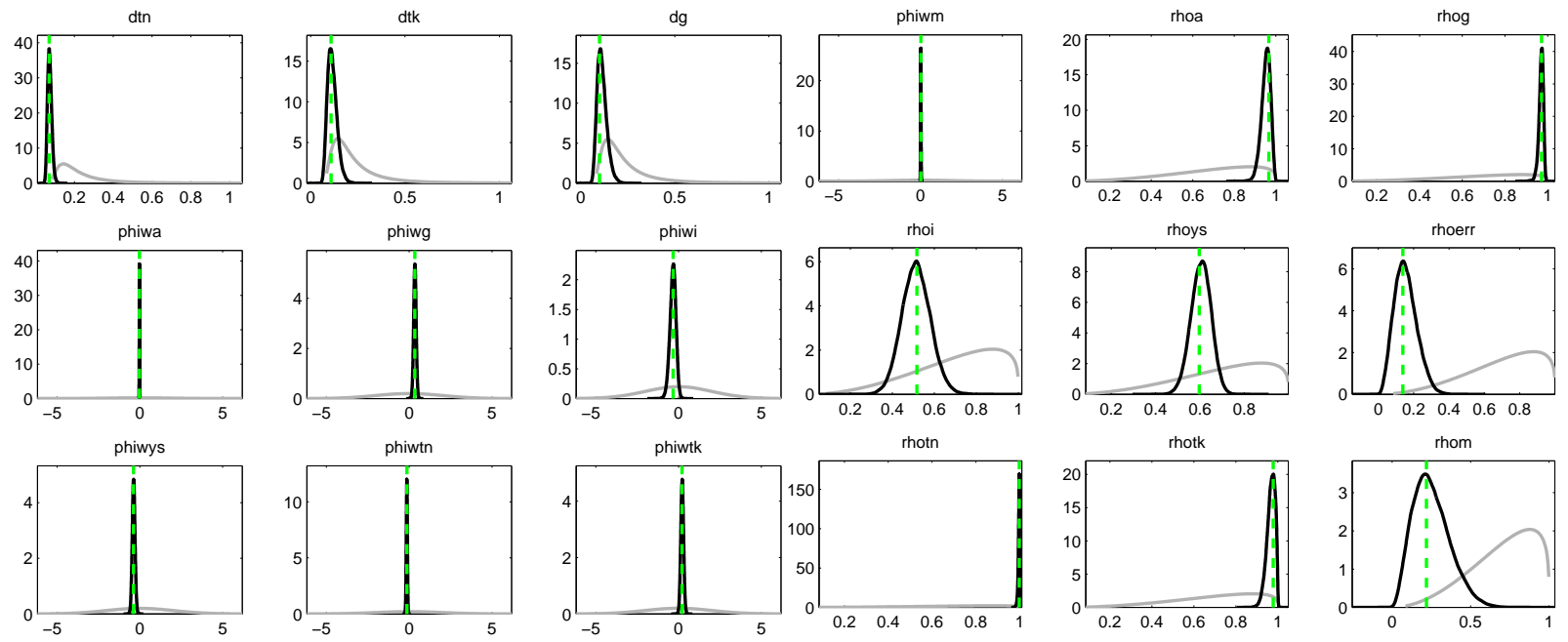
Figure 13: Priors and Posteriors - US
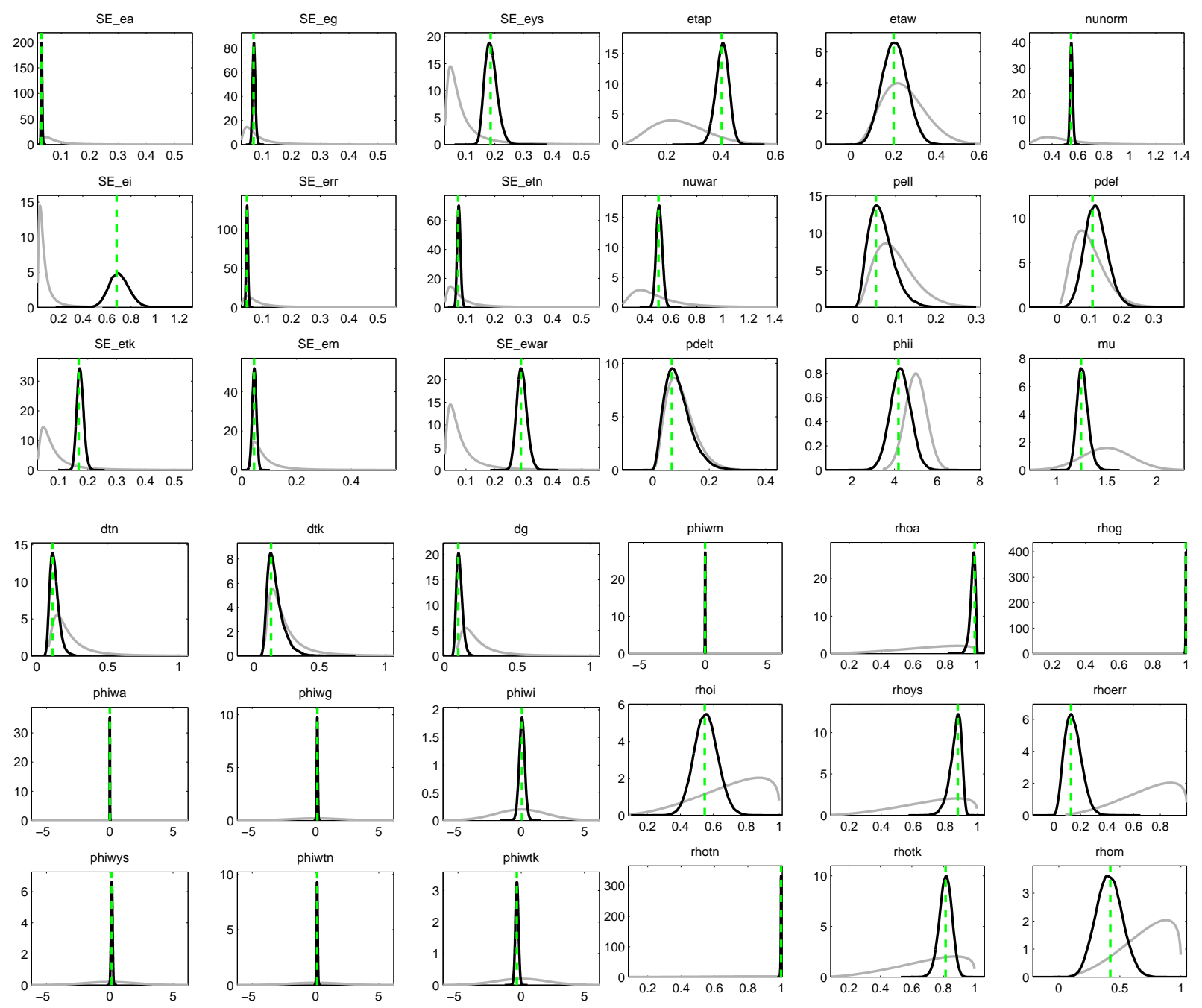


\section{E Smoothed innovations to the structural shocks}

Figure 14: Smoothed innovations to the structural shocks - France
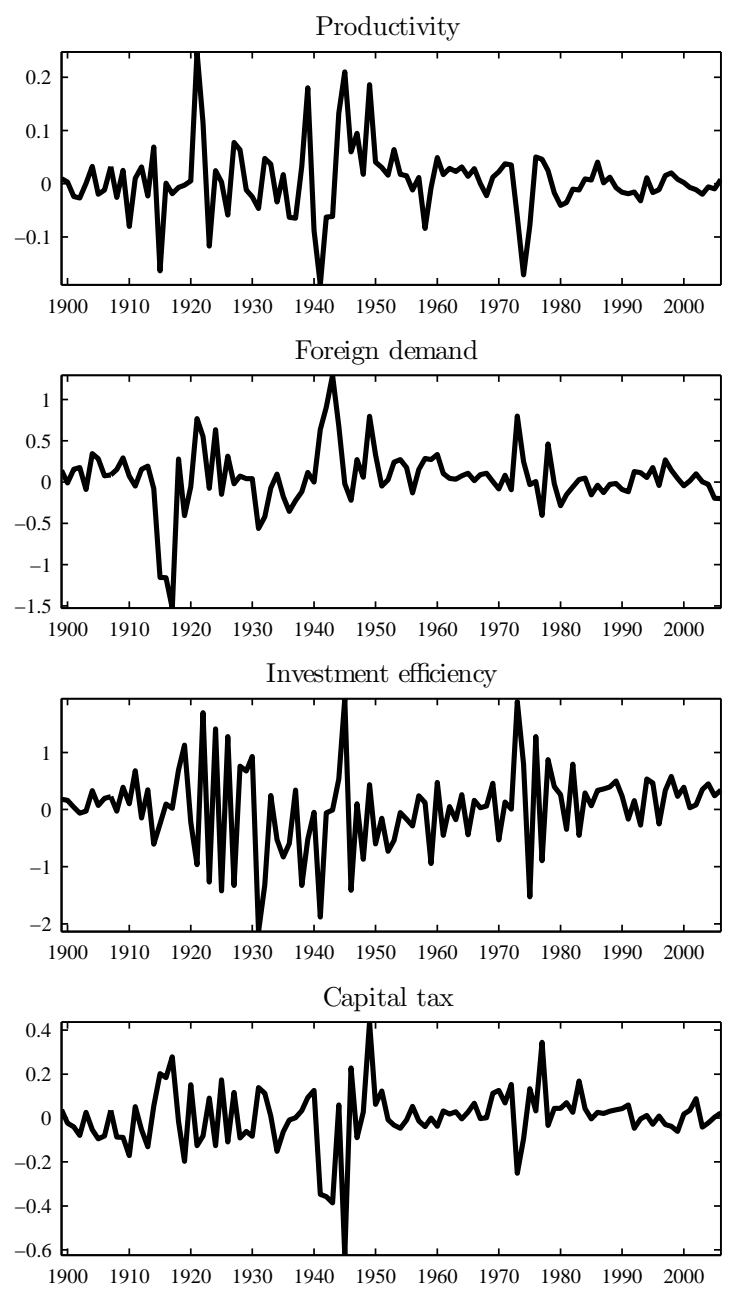
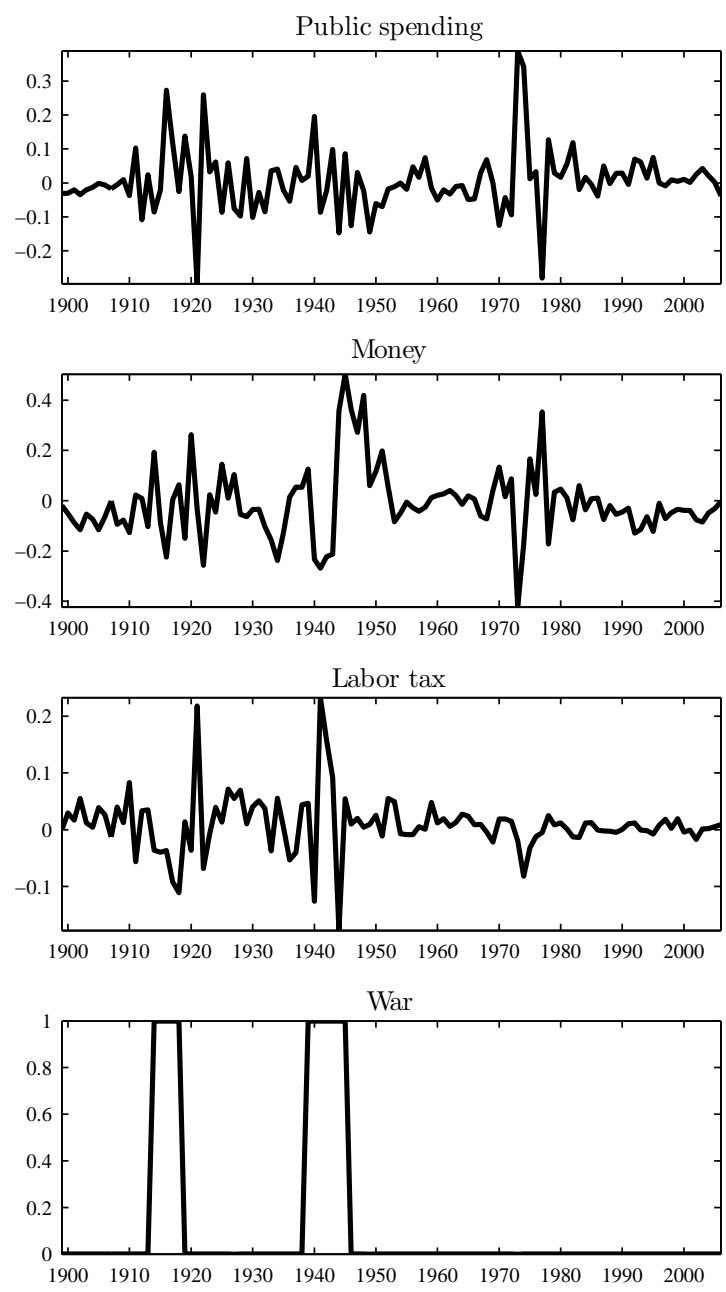
Figure 15: Smoothed innovations to the structural shocks - Germany
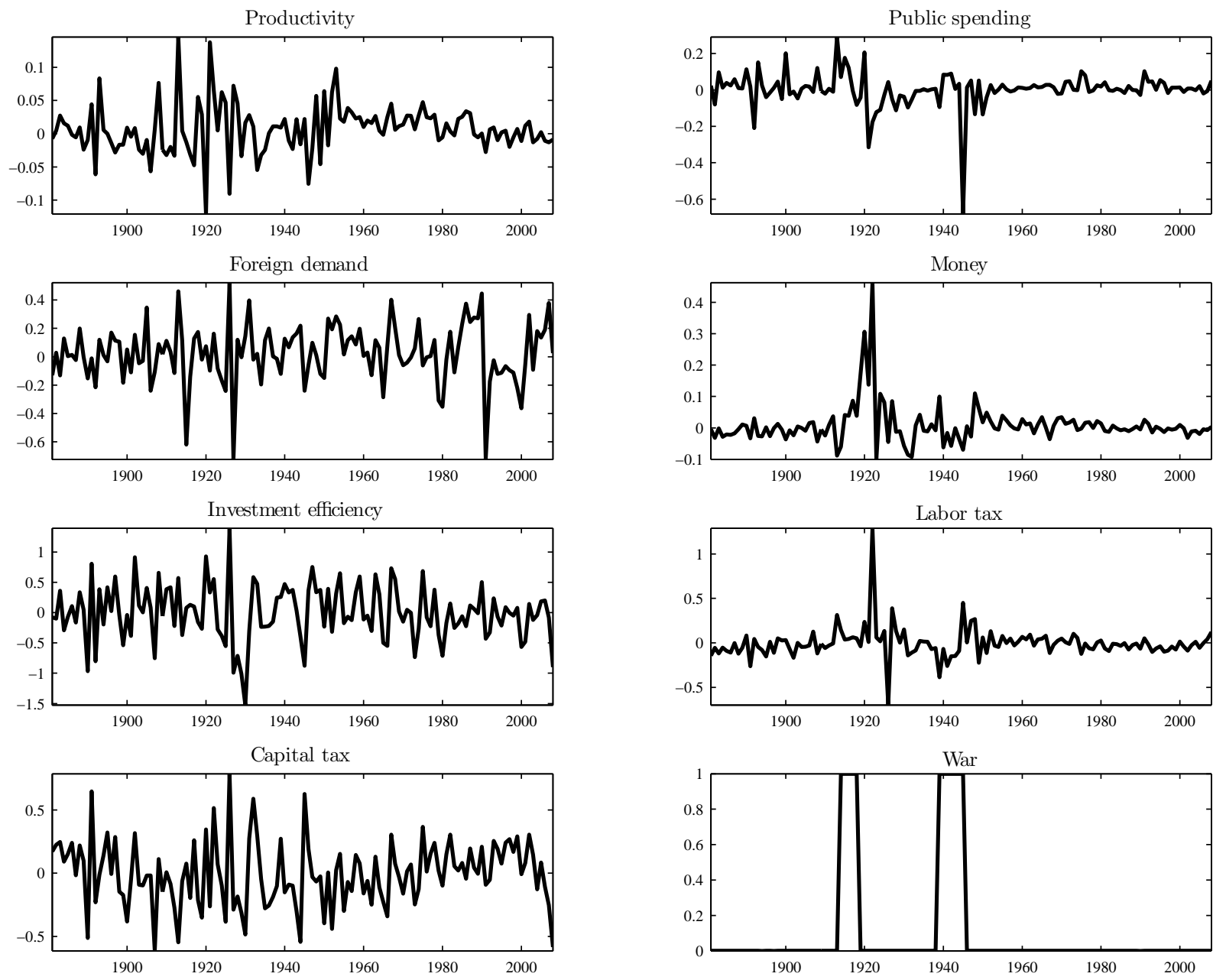
Figure 16: Smoothed innovations to the structural shocks - United Kingdom
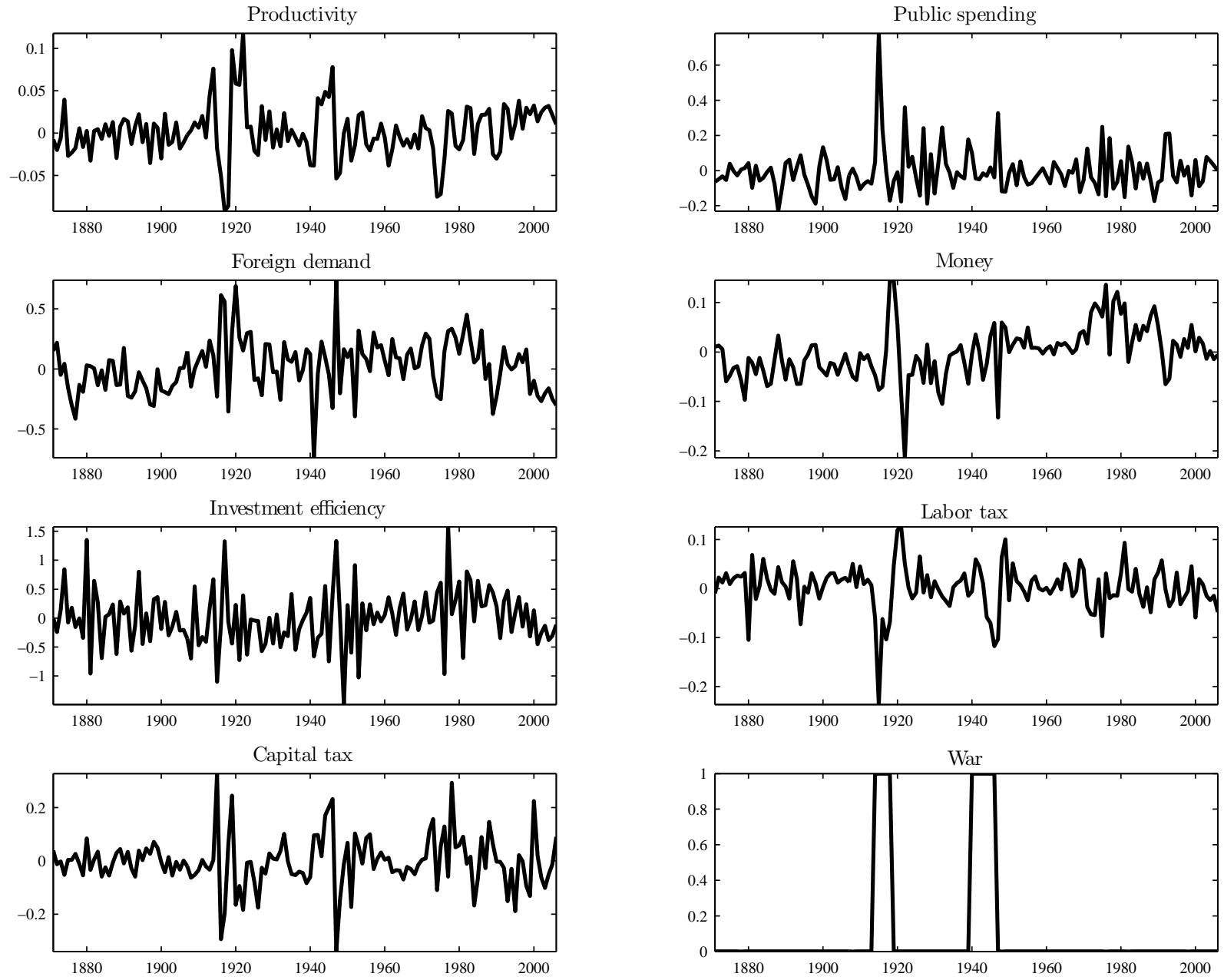
Figure 17: Smoothed innovations to the structural shocks - United States
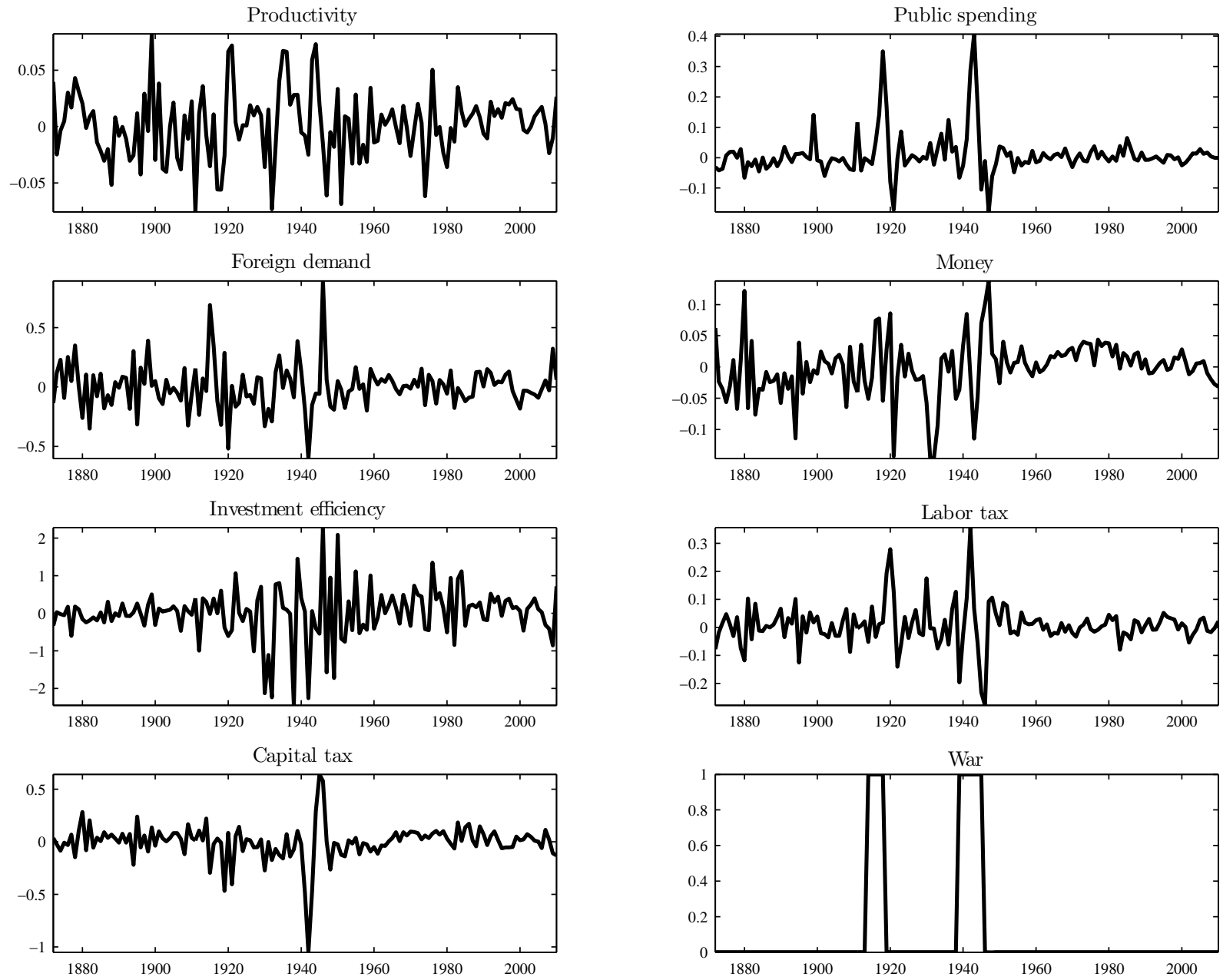


\section{F The macroeconomic effects of a shock on the war indicator variable in the US}

Based on 120 simulations, Figures 18 and 19 report the effects of a 5-years war episode, along with the associated confidence intervals for macro variables and for policy variables respectively.

Figure 18: Impulse Response Functions to a 5-year shock on $\Delta_{t}$ - Macro variables
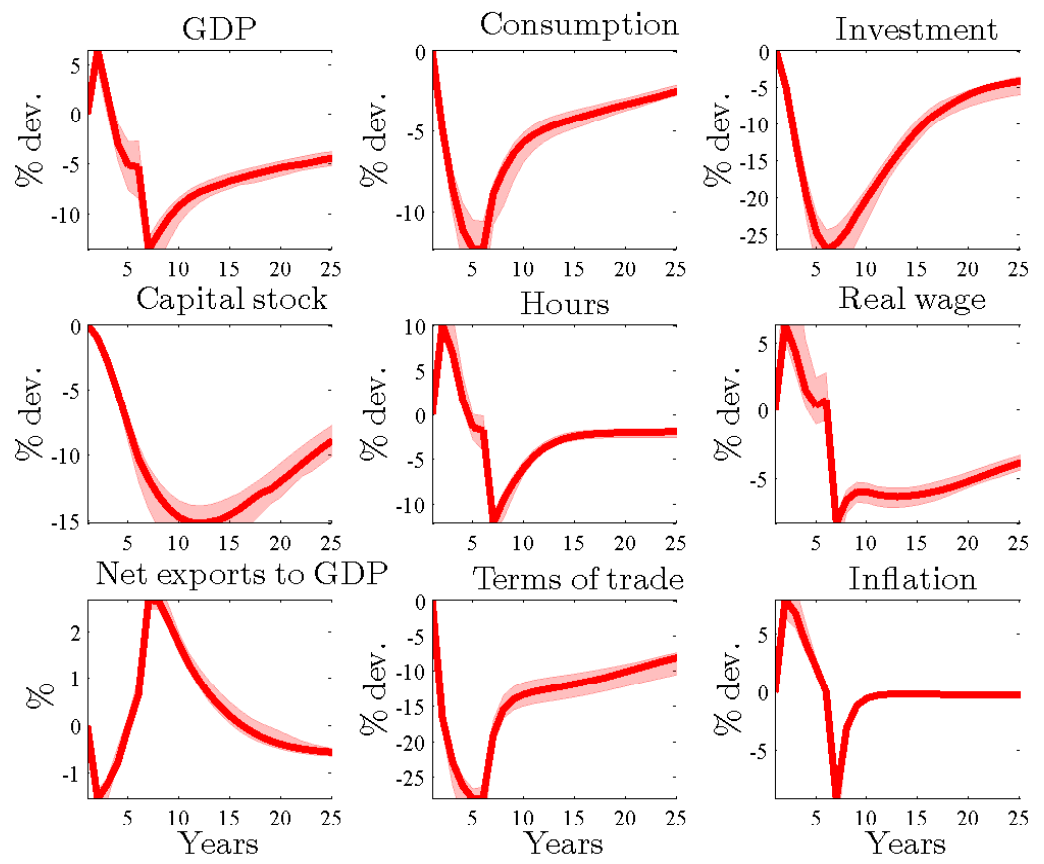

Shaded areas correspond to one standard deviation confidence intervals $\left(16^{\text {th }}\right.$ and $84^{\text {th }}$ percentiles) based on 120 simulations.

First, the capital stocks (both private and public) depreciate, which contributes negatively on impact to the dynamics of output but boosts public and private investment with positive impact on output in the subsequent periods. The effect on consumption is clearly negative as savings must increase to finance the rise in investment. Second, a war-related partial default occurs, which, all else equal, tends to lower the debt-to-GDP ratio and lowers tax rates through the fiscal rules, with positive expected effects on output dynamics. As shown in the next set of figures, it happens that these two effects play a relatively minor role from a quantitative perspective and are therefore not at the center of the stage. Third, a military draft lowers the bulk of hours worked used in the production process, which tends to put upward pressure on equilibrium wages, lowers output and consumption. This channel has quantitatively limited implications as well, although to a lesser extent than capital depreciation and partial default.

Spillover terms play a much bigger role. The shock on the war indicator variable is associated with a positive foreign demand shock that should lead to an improvement of the trade balance. However, this effect is more than compensated by the public spending spillover. Its importance is massive, as depicted by Figure 20 and 21. The rise of public spending is very large - public expenditure almost double and drives the positive dynamics of output, the crowding-out effect on investment, the negative (positive) 
Figure 19: Impulse Response Functions to a 5-year shock on $\Delta_{t}$ - Policy variables
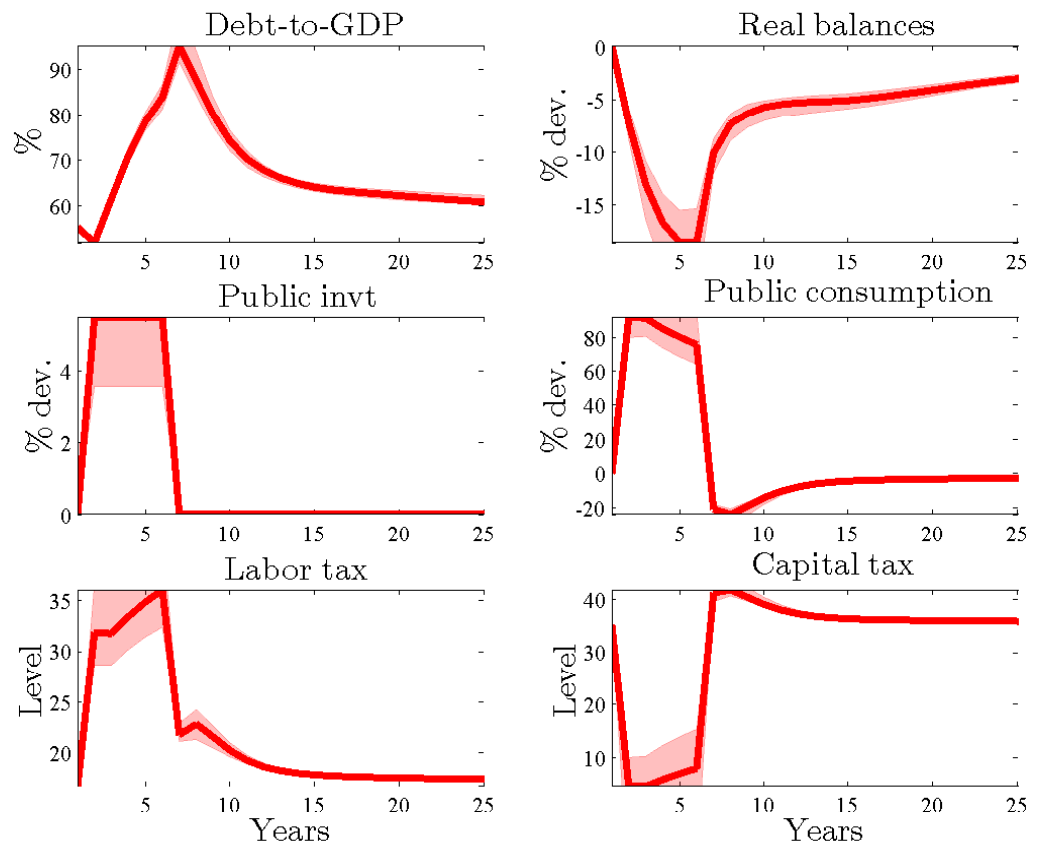

Shaded areas correspond to one standard deviation confidence intervals $\left(16^{\text {th }}\right.$ and $84^{\text {th }}$ percentiles) based on 120 simulations.

effect on consumption (hours worked), and the terms-of-trade appreciation. It generates a trade deficit in the first periods as well as a massive increase in the debt-to-GDP ratio. Finally, tax spillovers imply a large rise in the labor income tax and a fall in the capital income tax, as was expected given the signs of estimated spillover coefficients (see Table 8 in Appendix C). The labor tax tends to cut GDP and consumption while the capital tax should act as a subsidy to investment and should boost output. However, as already mentioned, the overall dynamics of the economy seem almost entirely driven by the rise in public spending.

How does our analysis compare with existing papers? Quite well actually, in the sense that most of them find that the dynamics of the US economy during WWII are well captured by a large rise in public spending (see McGrattan and Ohanian (2010)). In particular, the positive joint dynamics of hours worked, pre-tax wages, GDP and the negative dynamics of investment identified in the data by McGrattan and Ohanian (2010) are correctly reproduced, at least qualitatively. Similarly, our model predicts a rise in the labor income tax and a rise in public debt, as observed in US data. Most of the additional channels of our model (military draft, partial default, capital depreciation) contribute only marginally to the dynamics of the economy and are quantitatively almost negligible compared to the effects of the massive rise in public spending.

\section{G Historical decompositions for France, Germany and the UK}


Figure 20: IRFs to a 5 -year shock on $\Delta_{t}$ - Sensitivity - Macro variables
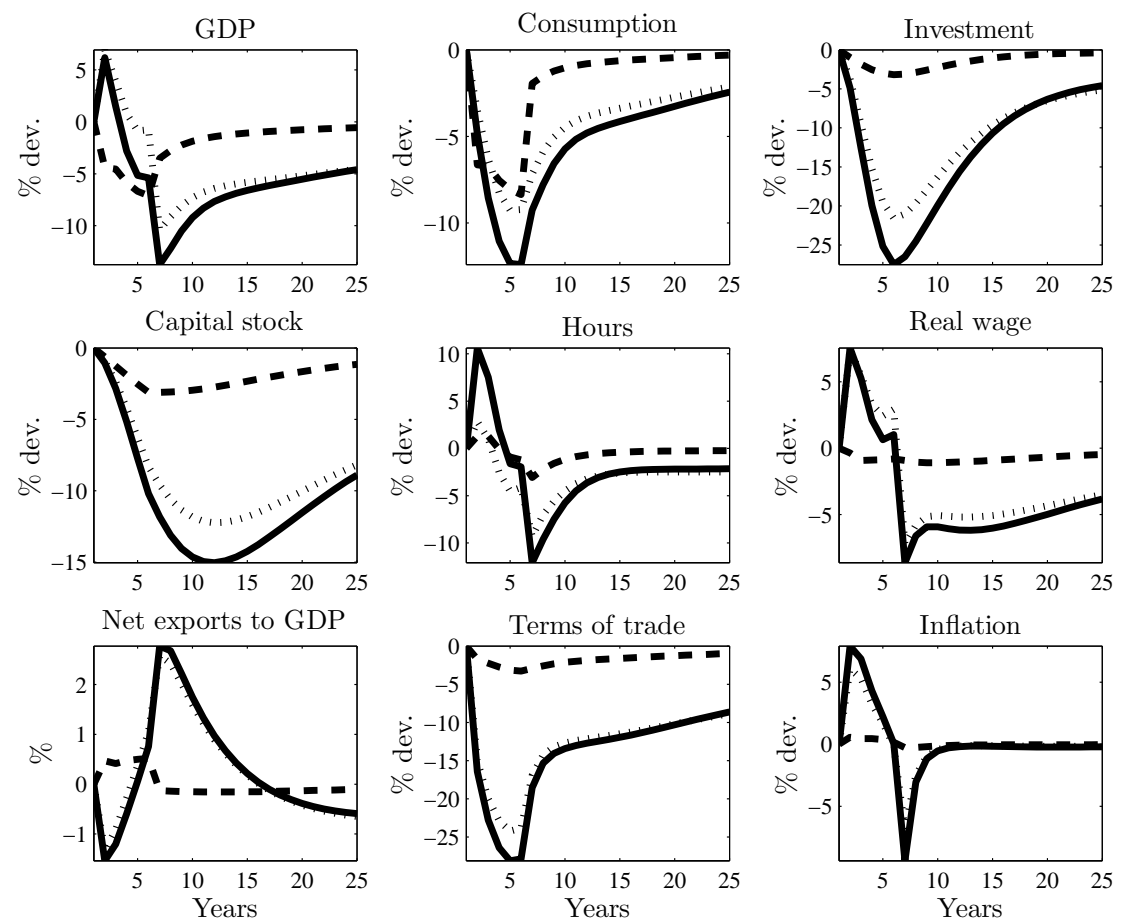

Black: baseline model, dashed: no spillovers, dotted: no draft

Figure 21: IRFs to a 5-year shock on $\Delta_{t}$ - Sensitivity - Policy variables
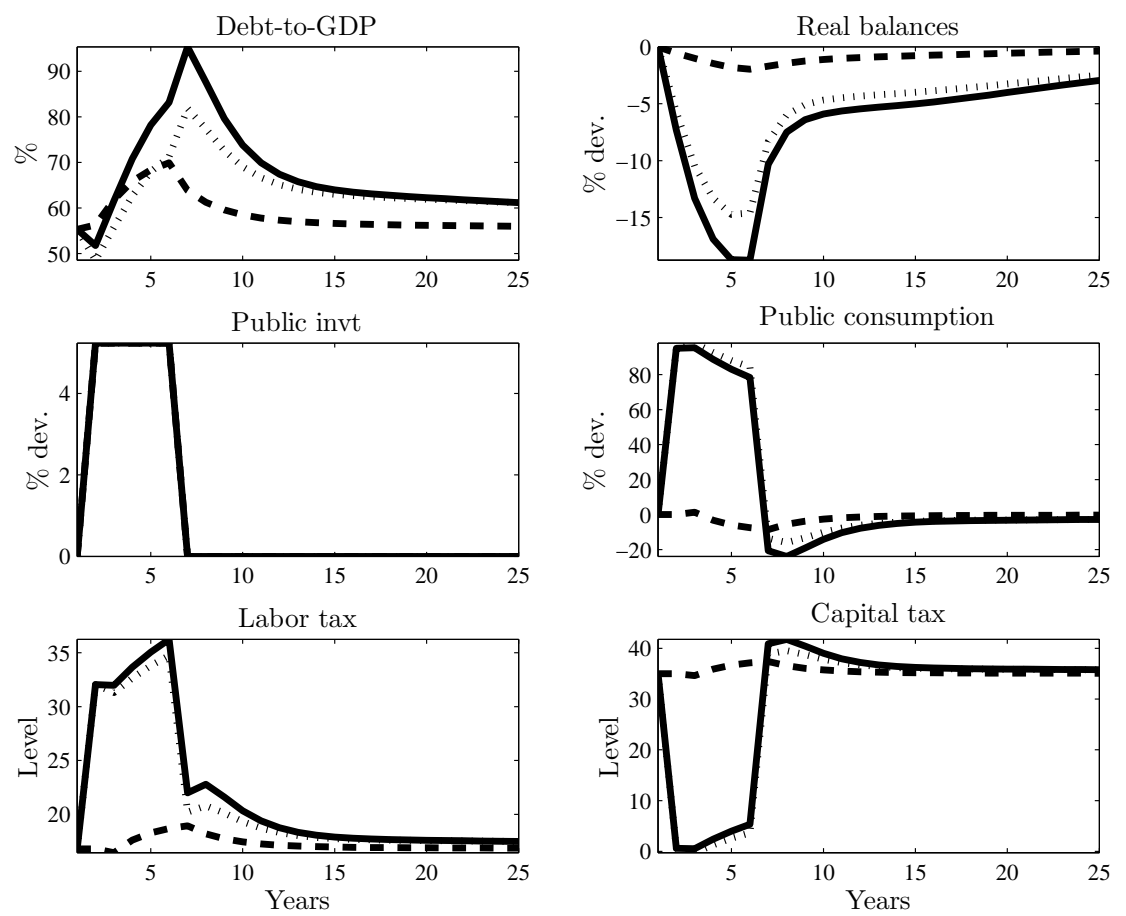

Black: baseline model, dashed: no spillovers, dotted: no draft 


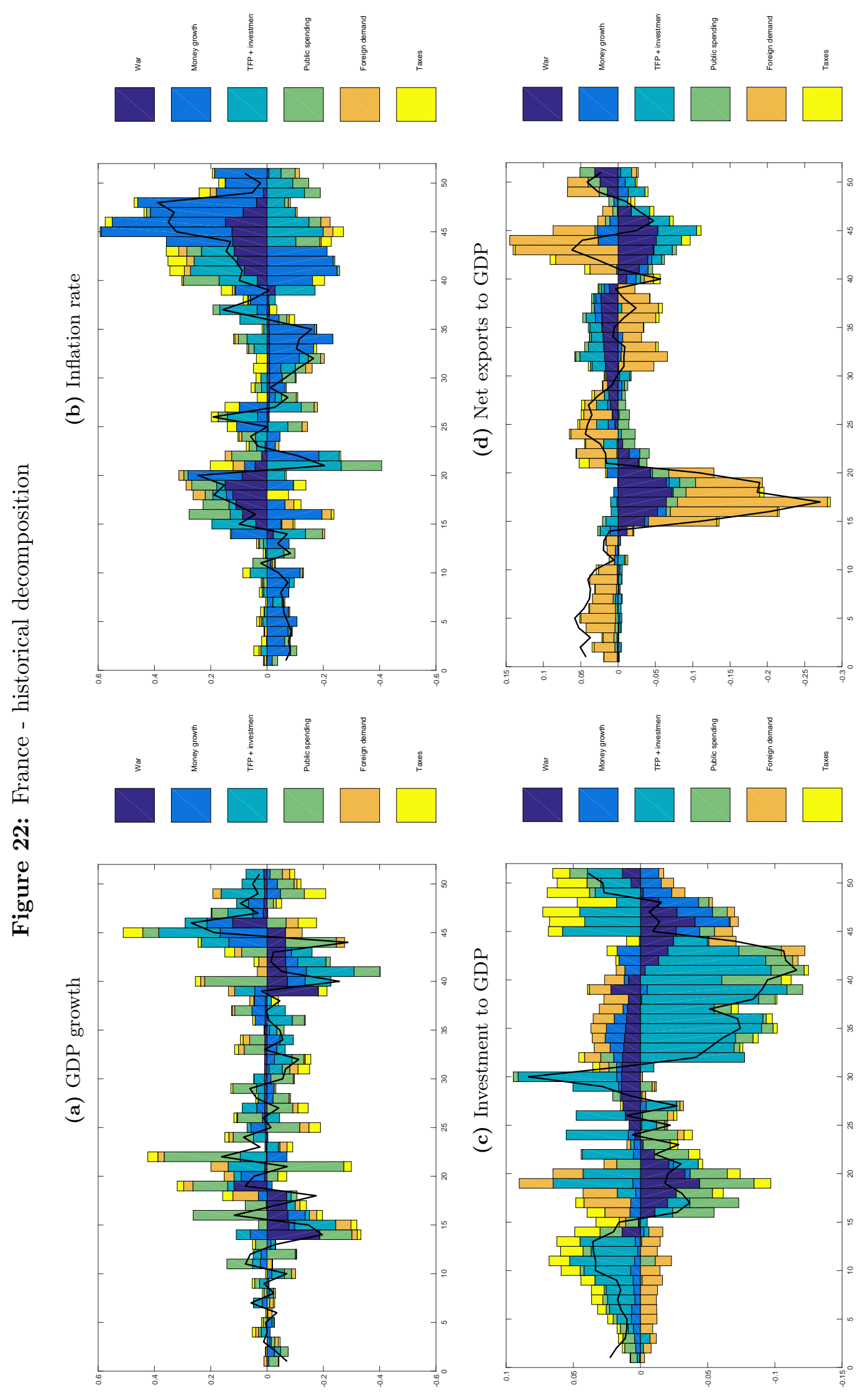




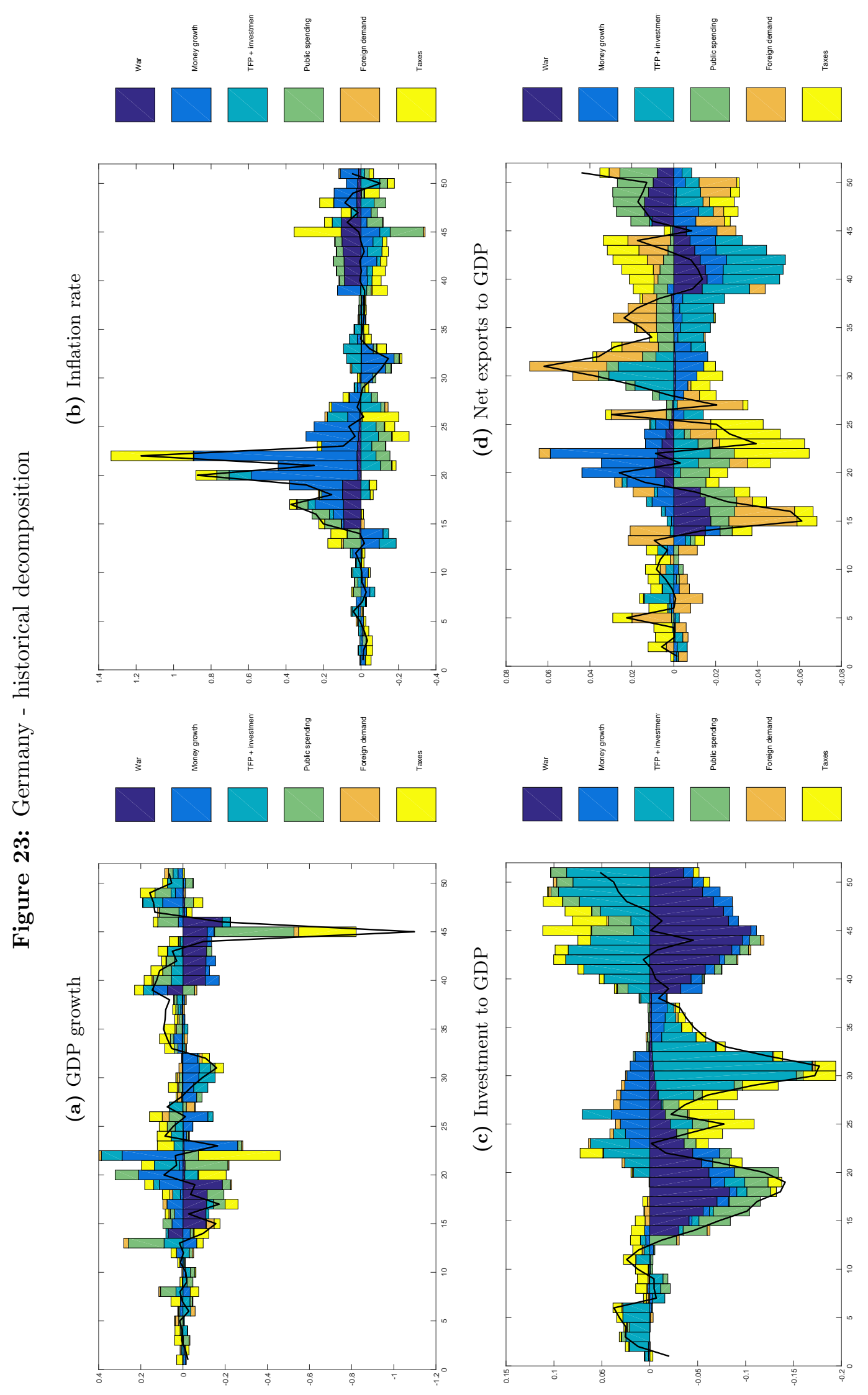




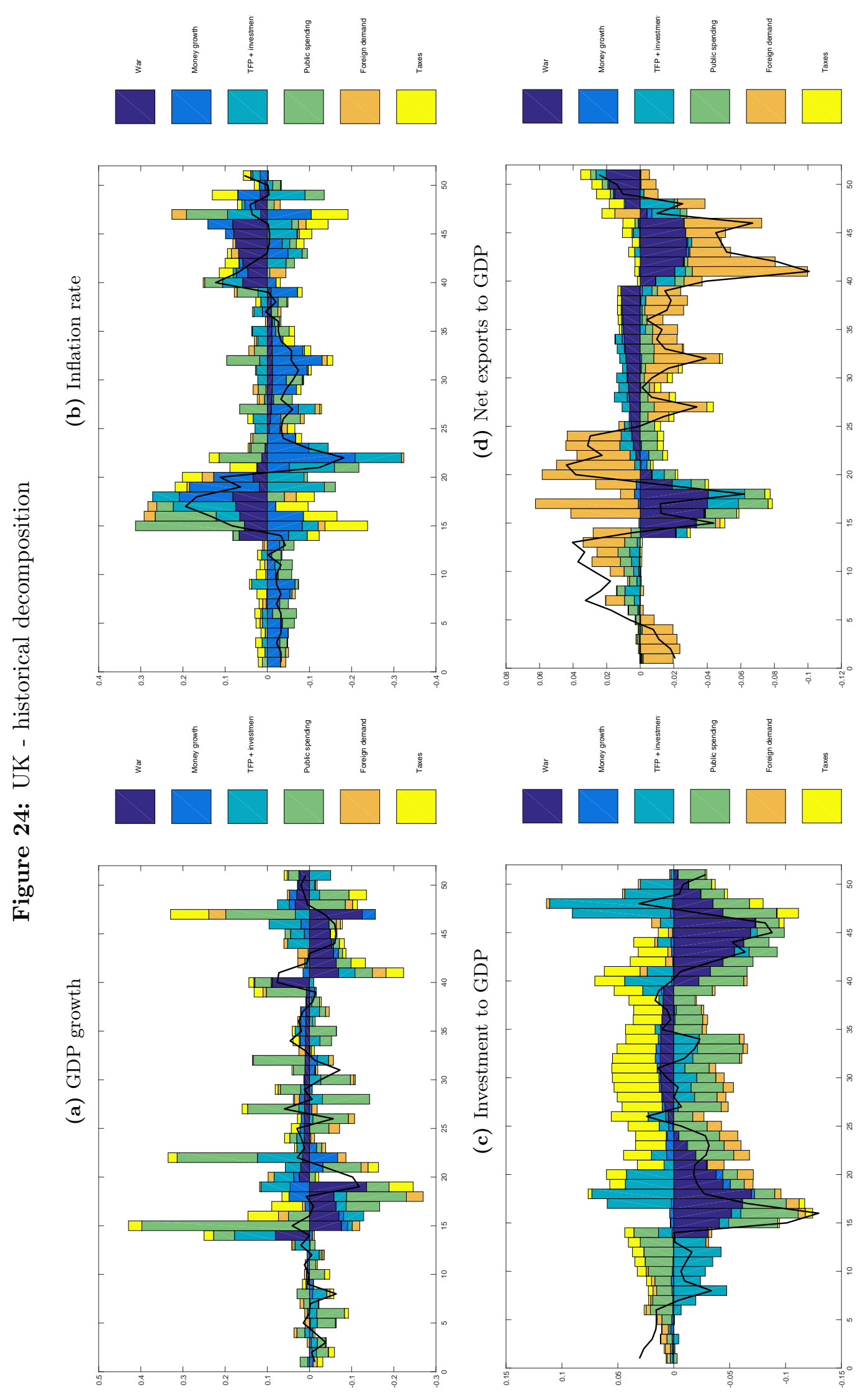




\section{$\mathrm{H}$ The hyperinflation in Germany and the Great Depression in the US}

What does our model predict for those two particular periods? More precisely, what are the shocks that account for the data around these dates according to our estimated model? Figure 25 below shows the model innovations to the structural shocks produced by our estimation of the model for Germany and the US during these historical episodes.

Figure 25: Smoothed innovations to the structural shocks

(a) Germany
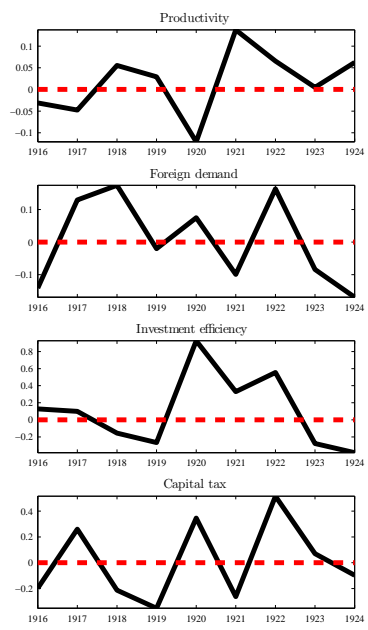
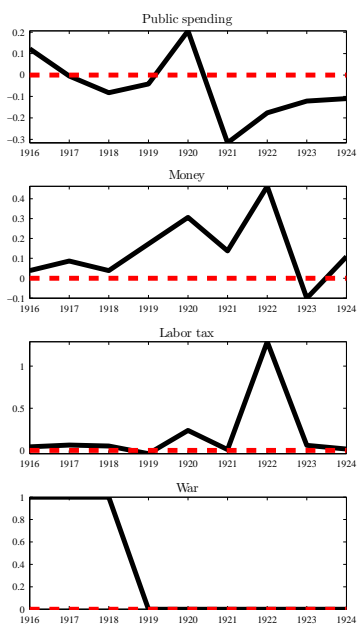

(b) US
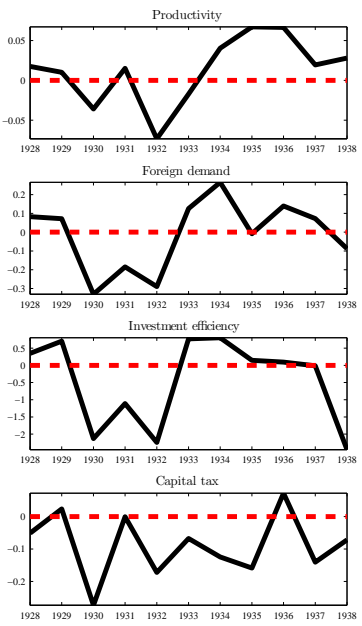
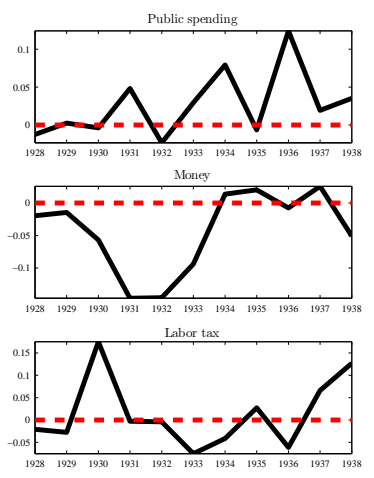

War

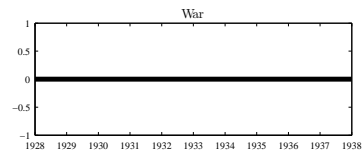

Starting with Germany, Figure 25a shows that the hyperinflation of the early 20's episode is captured by our model through a series of large positive shocks to the money growth rate, along with a peak in the labor income tax. The latter probably helps capturing the large fall in hours worked and the rise in unemployment observed in Germany at that time. In addition, a moderate increase in investment efficiency appears as the last "driver" of the economy over this period.

Now let us look at smoothed shocks during the Great Depression, reported in Figure 25b. The fall in GDP in the early years of the Great Depression is captured by our model through a negative shock on investment efficiency. This is consistent with the fact that the Great Depression was arguably generated by a crash of financial markets and resulted in a twisted channeling of savings to investment opportunities. In addition, the resulting trade collapse is captured by a negative shock on foreign demand. Deflationary pressures are captured by negative shocks to the money growth rate, starting in 1929 and returning to normal in 1934. The model also finds a large increase in the labor income tax. Here again, we believe that this is the way our model copes with the large rise in unemployment. Last but not least, our model predicts a small discretionary rise in public spending in 1934, and a much larger rise in 1936, certainly reflecting the New Deal. 